\title{
Asthma control in general practice : the effect of self- management and allergen avoidance
}

Citation for published version (APA):

de Vries, M. P. (2006). Asthma control in general practice : the effect of self-management and allergen avoidance. [Doctoral Thesis, Maastricht University]. Datawyse / Universitaire Pers Maastricht. https://doi.org/10.26481/dis.20060217mv

Document status and date:

Published: 01/01/2006

DOI:

10.26481/dis.20060217mv

Document Version:

Publisher's PDF, also known as Version of record

\section{Please check the document version of this publication:}

- A submitted manuscript is the version of the article upon submission and before peer-review. There can be important differences between the submitted version and the official published version of record.

People interested in the research are advised to contact the author for the final version of the publication, or visit the DOI to the publisher's website.

- The final author version and the galley proof are versions of the publication after peer review.

- The final published version features the final layout of the paper including the volume, issue and page numbers.

Link to publication

\footnotetext{
General rights rights.

- You may freely distribute the URL identifying the publication in the public portal. please follow below link for the End User Agreement:

www.umlib.nl/taverne-license

Take down policy

If you believe that this document breaches copyright please contact us at:

repository@maastrichtuniversity.nl

providing details and we will investigate your claim.
}

Copyright and moral rights for the publications made accessible in the public portal are retained by the authors and/or other copyright owners and it is a condition of accessing publications that users recognise and abide by the legal requirements associated with these

- Users may download and print one copy of any publication from the public portal for the purpose of private study or research.

- You may not further distribute the material or use it for any profit-making activity or commercial gain

If the publication is distributed under the terms of Article $25 \mathrm{fa}$ of the Dutch Copyright Act, indicated by the "Taverne" license above, 


\section{Asthma Control in General Practice}

The effect of self-management and allergen avoidance 
(c) Marjolein de Vries, Maastricht 2006

ISBN: $90-5278-510-4$

Cover illustration: Mw. N. de Vries-Blonk

Cover design: Datawyse

Layout: Tiny Wouters

Production: Datawyse | Universitaire Pers Maastricht

The studies in this thesis have been supported by the Dutch Council for Medical and Health Research (MW-NWO), grant no. 904-58-091; the Dutch Asthma Foundation, project no. 98.55, Astra Zeneca B.V. and Boehringer Ingelheim.

Publication of this thesis was kindly sponsored by the Dutch Asthma Foundation, Astra Zeneca B.V, Cara C'air B.V. 


\section{Asthma Control in General Practice}

The effect of self-management and allergen avoidance

\section{PROEFSCHRIFT}

ter verkrijging van de graad van doctor

aan de Universiteit Maastricht,

op gezag van de Rector Magnificus, Prof. mr. G.P.M.F. Mols,

volgens het besluit van het College van Decanen,

in het openbaar te verdedigen

op vrijdag 17 februari 2006 om 12.00 uur

door

Marjolein Pauline de Vries

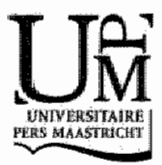


Promotor

Prof. Dr. C.P. van Schayck

\section{Co-promotores}

Dr. J.W.M. Muris

Dr. B.P.A. Thoonen, Universitair Medisch Centrum Nijmegen

\section{Beoordelingscommissie}

Prof. Dr. G.J. Dinant (voorzitter)

Prof. Dr. T. van der Molen, Universitailr Medisch Centrum Groningen Prof. Dr. H. de Vries

Dr. G. Wesseling 
Voor mijn moeder

Ter herinnering aan mijn vader 



\section{Contents}

Chapter 1 General introduction 9

Chapter 2 The prevalence of house dust mite allergy and the use of 23 HDM impermeable covers in a primary care population of patients with persistent asthma in the Netherlands

Chapter 3 Influence of mattress characteristics on house dust mite allergen concentration

Chapter 4 Factors associated with asthma control

Chapter 5 Asthma control in patients with different severity degrees of 59 asthma in primary care and the effect of a self-management plan on asthma control

Chapter 6 Could high exposure to house dust mite allergen be an obstacle for tapering off inhaled corticosteroids in a self-management plan?

Chapter $\bar{T} \quad$ Does house dust mite allergen avoidance allow tapering off 83 inhaled corticosteroids in allergic asthma patients using a self-management plan?

Chapter 8 General discussion

Summary

Samenvatting

Appendix A : Summary of the self-management plan

Appendix B : Asthma Control Questionnaire

Publications

Dankwoord 

Chapter 1

General introduction 
The main issue of this thesis, is whether we can achieve better asthma control in general practice by combining self-management and allergen avoidance. To gain more insight into this issue the following subjects will be addressed in this thesis: occurrence of house dust mite allergy and exposure to house dust mite allergen; factors associated with asthma control; asthma control related to severity; and house dust mite allergen avoidance as a component of a self-management plan.

\section{Asthma general}

Asthma is a chronic disease of the airways. Asthma is a common disease, affecting 5 till 10 percent of the population, especially in western countries ${ }^{1-3}$. As many as 300 million people of all ages all around the world suffer from asthmas.

In the Netherlands, the prevallence in primary care varies from 20 patients per 1000 per year between 15 and 24 years, till 5 per 1000 per year between 65 and 74 years; the incidence in primary care is respectively 2 per 1000 per year and 1 per 1000 per year 4,5 .

Over the last decades, the prevallence is rising. This is probably partlly due to better diagnostic tools and increased awareness ${ }^{6}$, but it seems likely that there is also a real increase ${ }^{7-9}$.

\section{Asthma pathophysiology, hyperresponsiveness and allergy}

The underlying pathophysiologic process of asthma is inflammation ${ }^{10,11 .}$ Inflammation leads to airway obstruction and this again leads to symptoms like dyspnoea, tightness, and coughing.

Asthma is associated with variable levels of airflow limitation. Considerable evidence has been obtained, showing that airway inflammation is a major factor in the pathogenesis of asthma reflecting itself in bronchial hyperresponsiveness. The inflammatory pattern of asthma is multicellular in nature, with mast cells, neutrophils, eosinophils, $T$ lymphocytes, and epithelial cells participating in the response. Furthermore, it is known that mediators, cytokines, and chemokines from these cells contribute to the inflammatory process ${ }^{11.12}$. Even in mild disease, the histopathologic features of bronchial asthma are consistent with chronic inflammation ${ }^{13}$.

Asthma has a variable course. Periods of severe complaints are usually alternated with symptom-free periods.

Airway hyperresponsiveness is a central feature of asthma. It indicates an increased sensitivity of the airways to constrictor agonists ${ }^{14}$. With increased hyperresponsiveness patients respond earlier with symptoms to allergens and nonm 
specific irritants. Airway hyperresponsiveness can be demonstrated in almost all patients with current symptomatic asthma15. It is measured by using inhalation challenges with airway constrictor agonists, such as histamine or metacholine. The severity of airway hyperresponsiveness is correlated with the severity of asthma. The degree of airway hyperresponsiveness correlates with variations in peak flow expiratory flow rates (peak flow variability) and with improvement in forced expiratory volume in one-second (FEV) after receiving an inhaled bronchodilator (reversibility) ${ }^{16}$.

Allergy plays an important role in asthma. The majority of asthma patients is sensitised to one or more allergens ${ }^{17.18}$. Exposure to indoor allergens is an independent risk factor for the development of asthma 19.20 . The relationship between exposure to allergens and the subsequent sensitisation has been demonstrated in several studies ${ }^{21,22}$. However, the relationship between allergen exposure and severity of symptoms in patients with established allergic asthma is complex ${ }^{23}$.

Tunnicliffe et al. found an association between the degree of domestic allergen exposure in sensitized individuals and asthma severity ${ }^{24}$. Airway hyperresponsiveness is sensitive to changes in allergen exposure 25 . A prolonged stay on a high altitude environment dramatically decreased the hyperresponsiveness in asthmatic patients sensitised to house dust mite allergen ${ }^{26}$. Repeated low-dose allergen exposure in asthma can lead to airway inflammation without worsening of the symptoms ${ }^{27}$.

As people spend most of their time indoors, house dust mite (HDM) allergen is one of the most common allergens;. Especially in areas with a humid climate, sensitisation to HDM allergen is very common ${ }^{19}$.

One of the most common species of the HDM is the Dermatophagoides pteronyssinus allergen 1 (Der p 1). Der $p 1$ is its most important allergen.

\section{Asthma control}

The goal of asthma management is achieving asthma control for all types and severity of asthma $28-30$

Asthma control can be characterised by minimisation of chronic asthma symptoms during day and night, prevention of asthma exacerbations, maintaining normal activity levels, optimising lung function, reducing the need for relieving $\beta_{2}$-agonist therapy, and minimising side effects of medication $28_{2} 29$. Optimal control, therefore, contributes to a reduction of the risk of life threatening exacerbations and longterm morbidity. Optimal control should be achieved at the lowest possible drug "oad. However, the definition of asthma control can differ between guidelines and
physicians 31,32 . 
Asthma control is not always measured in a standardised way. Different studies use different definitions and parameters to indicate asthma control ${ }^{33-39}$.

Since the publication of the Asthma Control Questionnaire $(A C Q)^{40}$ a validated instrument for measuring asthma control is available. The ACQ integrates different aspects of asthma control in one instrument. In Appendix B on page 133 an example of the ACQ is included. This questionnaire contains questions about asthma symptom severity (wheezing, shortness of breath, waking up at night, limitation of daily activities, and symptom severity in the morning), bronchodilators use, and lung function. The questionnaire is easy to use in daily practice. It is also possible to use the questionnaire without the rescue medication and/or the lung function item without altering the validity ${ }^{41,42}$. It has been used, so far, in several studies $^{43-46}$.

Other measuring instruments to assess asthma control have been developed as well 4749 .

With measuring asthma control it is possible to evaluate different treatments, and to determine whether the goals set in guidelines are achieved.

\section{Pharmacological treatment of asthma}

Because airway inflammation appears to be a critical etiologic feature of asthma, it has become the target of therapy 11 .

Inhaled corticosteroids (ICS) are the cornerstone in the treatment, since they treat the underlying inflammatory process. Regular use of ICS has shown to decrease the risk of death 50 . The degree of risk reduction is directly correlated to the amount of ICS used. Furthermore, ICS in asthma have shown to reduce symptoms and exacerbation rates and to improve lung function 51.52. Bronchial hyperresponsiveness $\left(\mathrm{PC}_{20}\right)$, total Immunoglobulin $\mathrm{E}$ ( $\left.\mathrm{IgE}\right)$, and smoking habits are independent predictors of immediate treatment response to ICS ${ }^{53}$.

Long-term effects of ICS remain uncertain. Side effects may occur if high doses are used during langer periods 54,55 .

Because of possible side effects, it is important to keep the dose as low as possible ${ }^{54}$. Reduction of ICS can be achieved in patients with mild asthma ${ }^{56 .}$

Next to ICS, short-acting beta agonists and, more recently, long-acting beta agonists are playing an important role as, respectively, rescue and maintenance treatment. Combination of long-acting beta agonists and $\| C S$ gives more symptom reduction and fewer exacerbations than monotherapy with high dose of ICS57. Moreover the combination of long-acting beta agonists and ICS seems to lead to better asthma contro/58. Another study showed, that adjustable maintenance dosing with an inhaler with the combination of a long-acting beta agonist and an ICS provided better asthma control compared with fixed dose inhaler therapy ${ }^{59}$. 


\section{Self-management}

Self-management plans are recommended in several guidelines $28-30$.

Self-management is defined as effective behaviour regarding asthma, based on sufficient knowledge about asthma and its provoking factors, adequate coping behaviour, compliance with inhaled medication, attention to changes in severity of the disease, adequate technique of inhaling medication, and the correct use of a peak flow meter.

Self-treatment is a component of self-management; it is the process of making alterations in treatment in response to changes in symptoms or lung function. A self-treatment plan is often a written action plan, based on symptoms and lung function (peak flow). It has shown to be of supporting value for patients to adjust the dose of medication to the perceived severity of asthma. The plan is individualised towards the needs and ability of individual patients.

Individualised written action plans based on PEF are equivalent to action plans based on symptoms ${ }^{c 0}$.

Education in asthma self-management which involves self-monitoring by either peak expiratory flow or symptoms, coupled with regular medical review, and a written action plan improves health outcomes for adults with asthma. Training programmes that enable people to adjust their medication using a written action plan appear to be more effective than other forms of asthma self-management 61 .

Self-management plans are appropriate to keep the dose of inhaled steroids at an optimum level62. Furthermore, self-management plans have proven to have positive effects on several asthma outcomes ${ }^{63-65}$. They might even lead to fewer costs 66.67 .

Especially individualised written action plans based on personal best peak expiratory flow (PEF), using some action points, and recommending both inhaled corticosteroids (ICS) and oral corticosteroids (OCS) for treatment of exacerbations consistently improve asthma health outcomes ${ }^{61}$. Selfmanagement plans are multifaceted. Often allergen avoidance is proposed as part of self-management plans. However, whether allergen avoidance interventions are efficient components of self-management plans is not yet clear.

The selfmanagement plan used in this thesis was investigated before, with positive effects on ICS use and successfully treated weeks6?. In that study the mean expenses for HDM avoidance measures were significantly higher among selfmanagement patients according to usual care patients 67 . This finding has led to the question whether HDM allergen avoidance measures were, at least pantly, responsible for the positive effects of the self-management plan. In Appendix A on page 129 a summary of the self-management plan is displayed. 


\section{Allergen avoidance in treatment of asthma}

Apart from pharmacological treatment, avoidance of specific and non-specific irritants also plays a role in asthma treatment.

Reducing exposure to allergens in sensitised patients might lead to fewer symptoms. In bed an ideal climate for HDM to grow and to multiply exists. Within most houses the highest concentrations of HDM allergen have been found in dust from mattresses followed by textile floor coverings 68,69 .

Since people spend approximately one-third of their time in bed, the bed is the most important exposure source to HDM allergen in adult asthma patients. Covers around mattresses, pillow, and bedding are the best way of reducing exposure to these allergens ${ }^{70-72}$. Over the years, a large number of studies have investigated the effect of HDM impermeable covers on several asthma related outcomes, like symptoms, lung function, and medication use. However the results of these studies are conflicting ${ }^{72.79}$.

Our group carried out a pilot-study with fifty-two allergic asthma patients, to investigate the effects of HDM impermeable bed covers on peak flow parameters and symptoms ${ }^{80}$. After a follow-up period of nine weeks, we found a significant increase in morning peak flow in the intervention group compared to the control group. 


\section{Aim of this thesis}

In this thesis, different aspects of asthma control in general practice in the Netherlands have been investigated. The effectiveness of self-management and allergen avoldance on asthma control has been assessed. Furthermore, the hypothesis was tested if allergen avoidance in combination with self-management would lead to the ability of tapering off more lCS than performing self-management alone.

Moreover, the prevalence of HDM allergy in a primary care population, factors associated with asthma control, and the association between exposure to HDM allergen and the use of ICS has been assessed.

In Chapter 2 the results of a study investigating the prevalence of HDM allergy in asthma patients in primary care in the Netherlands are described. Funthermore the current use of HDM impermeable covers in that population was determined.

In Chapter 3 the results of a study assessing the influence of mattress characteristics on HDM allergen concentration are presented.

In Chapter 4 the results of a cross-sectional study assessing factors associated with asthma control are presented. The association of several factors with asthma control was investigated in a multiple regression model. Asthma control was assessed by means of the Asthma Control Questionnaire.

Chapter 5 shows the results of a study investigating asthma control in patients with different severity of persistent asthma in primary care. Furthermore the effect of a self-management plan on asthma control was observed after one-year follow-up.

Chapter 6 describes the results of a study in which was assessed if high exposure to HDM allergen was an obstacle for tapering off ICS. During 3 months patients were carrying out the self-management plan.

The actual exposure to HDM allergen was assessed by means of a semiquantitative test.

In Chapter 7 the results of the randomised controlled trial are presented. The hypothesis whether allergen avoidance allows tapering off ICS was tested in a twoyear follow up trial. Patients with asthma and sensitised to HDM allergen were randomly allocated to the intervention group with HDM impermeable covers or to the control group with placebo, HDM permeable covers. All patients carried out a self-management plan that was instructed by either their GP or a research nurse. Symptoms, peak flow, and medication use were recorded in diaries. Furthermore annual asthma control was assessed with the Asthma Control Questionnaire. A generall discussion is presented in Chapter 8. 


\section{References}

1. Variations in the prevalence of respiratory symptoms, self-reported asthma attacks, and use of asthma medication in the European Community Respiratory Health Survey (ECRHS). Eur Respir \& 1996:9(4):687-95.

2. Worldwide variation in prevalence of symptoms of asthma, allergic rhinoconjunctivitis, and atopic eczema: ISAAC. The International Study of Asthma and Allergies in Childhood (ISAAC) Steering Committee. Lancet 1998;351(9111):1225 32.

3. Masoli $M$, Fabian $D$, Holt $S$, Beasley $R$. The global burden of asthma: executive summary of the GINA Dissemination Committee Report. Allergy 2004;59(5):469-78.

4. Lamberts $H$. In het huis van de huisants. Verslag van het Transitieproject. Lelystad: Meditekst, 1994.

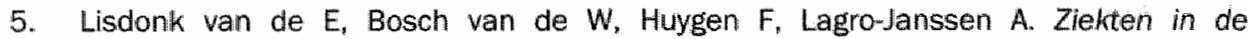
huisartspraktijk. 4e druk ed. Maarssen: Elsevier Gezondheidszorg, 2003.

6. Wieringa $\mathrm{MH}$, Vermeire PA, Brunekreef $\mathrm{B}$, Weyler $1 \mathrm{~J}$. Increased occurrence of asthma and allergy: critical appraisal of studies using allergic sensitization, bronchial hyperresponsiveness and lung function measurements. Clin Exp Allergy 2001:31(10):1553 63.

7. Tirimanna PR, wan Schayck $C P$, den Otter JJ, van Weel $C$, van Herwaarden $C L$, van den Boom $G_{x}$ et al. Prevalence of asthma and COPD in general practice in 1992: has it changed since 1977?" Br J Gen Pract 1996;46(406):277-81.

8. Upton MN, McConnachie $A_{*}$ McSharry $C$, Hart $C L$, Smith GD, Gillis $C R$, et al. Intergenerational 20 year trends in the prevalence of asthma and hay fever in adults: the Midspan family study surveys of parents and offspring. Br Med / 2000;321:88-92.

9. Downs SH, Marks GB, Sporik R, Belosouva EG, Car NG, Peat JK. Continued increase in the prevalence of asthma and atopy. Arch Dis Child 2001;84(1):20-23.

10. Kay AB. Asthma and inflammation. J Allergy Clin Immunol 1991;87(5):893-910.

11. Busse WW. Inflammation in asthma: the cornerstone of the disease and target of therapy. J Allergy Clin Immunol 1998;102(4 Pt 2):S17-22.

12. Boushey HA. Effects of inhalled corticosteroids on the consequences of asthma. $J$ Allergy Clin Immunol 1998;102(4 Pt 2):S5-16.

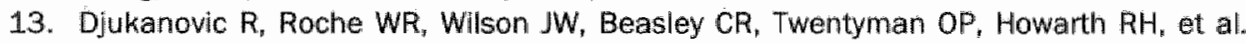
Mucosal inflammation in asthma. Am Rev Respir Dis 1990;142(2):434-57.

14. O'Byrne PM, inman MD. Airway hyperresponsiveness. Chest $2003 ; 123(3$ Suppl):411S65 .

15. Cockcroft DW, Killian DN, Mellon IJ, Hargreave FE. Bronchial reactivity to Inhaled histamine: a method and clinical survey. Clin Allergy 1977;7(3):235-43.

16. Ryan $\mathrm{G}$, Latimer $\mathrm{KM}$, Dolovich J, Hargreave FE. Bronchial responsiveness to histamine: relationship to diurnal variation of peak flow rate, improvement after bronchodilator, and airway calibre. Thorax 1982;37(6):423-9.

17. Colloff MJ, Ayres J, Carswell F, Howarth PH, Merrett TG, Mitchell EB, et all. The control of allergens of dust mites and domestic pets: a position paper. Clin Exp Allergy 1992;22 Suppl $2: 1-28$.

18. von Mutius $E$, Fritzsch $C$, Weiland S, Röll G, Magnussen H. Prevalence of asthma and allergic disorders among children in united Germany: a descriptive comparison. Br Med 11992;(305):1395-9.

19. Peat JK, Tovey E, Toelle BG, Haby MM, Gray E, Mahmic A, et al. House dust mite allergens. A major risk factor for childhood asthma in Australia. Am J. Respir Crit Care Med 1996;153(1):141-6. 
20. Sears $M_{*}$, Herbison $G$, Holdaway $M_{\text {, Hewitt }} C$. Flanery $E_{\text {, Silva }} P$. The relative risks of sensitivity to grass pollen, house dust mite and cat dander in the dewelopment of childhood asthma. Clin Exp Allergy 1989;19:419-24.

21. Lau $S$, Faikenhorst G, Weber A, Werthmann I, Lind P, Buettner-Goetz P, et al. High miteallergen exposure increases the risk of sensitization in atopic children and young adults. I Allergy Clin Immunol 1989;84(5 Pt 1):718-25.

22. Kuehr J, Frisscher $T$, Meinert $R$, Barth $R$, Forster $J$, Scharaub $S_{n}$ et al. Mite allergen exposure is a risk for the incidence of specific sensitization. I Allergy Clin Immunol $1994,94(1): 44-52$.

23. Platts-Mills TAE, Vervloet D, Thomas WR, Aalberse RC, Chapman MD. Indoor allergens and asthma: report of the third international workshop. I Allergy Clin Immunol $1997 ; 100(6): \$ 1-\$ 24$.

24. Tunnicliffe $W$, Fletcher $T$, Hammond $K_{n}$ Roberts $K$, Custovic $A_{n}$ Simpson $A_{n}$ et all. Sensitivity and exposuire to indoor allergens in adults with differing asthma severity. Eur Respir J 1999;13:654-9.

25. Ehnert B, Lau Schadendorf $S$, Weber A, Buettner $P$, Schou $C$, Wahn U. Reducing domestic exposure to dust mite allergen reduces bronchial hyperreactivity in sensitive children with asthma. J Allergy Clin Immunal 1992;90(1):135-8.

26. Peroni $D$, Boner $A$, Vallone $G$, Antolini I, Warner J. Effective allergen avoidance at high altitude reduces allergen induces bronchial hyperresponsiveness. Am J Respir Crit Care Med 1994:149:1442-6.

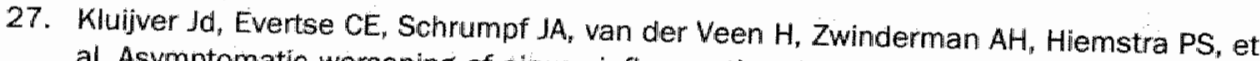
al. Asymptomatic worsening of airway inflammation during low-dose allergen exposure in asthma: protection by inthaled steroids. Am I Respir Crit Care Med 2002;166(3):
294-300.

28. BTS/SIGN Biritish Guideline on the Management of Asthma. Thorax 2003;58(supplement 1):1-83.

29. Global Initiative for Asthma. Global Strategy for asthma management and prevention: NHLBI/WHO Workshop Report. Bethesida: National Institutes of Health, National Heart, Lung and Blood institute ${ }_{\text {2 }}$ 002:Publication No. 02-3659.

30. Geijer RMM, Van Hensbergen W, Bottema BJAM, Van Schayck CP, Sachs APE, Smeele UM, et al. NHG-Standaard Astma bij Volwassenen: Behandeling (NHG Guideline on Astima in Adults: Treatment). Huisarts Wet 2001;44(4):153-64.

31. Partridge MR. What do the words "asthma control" and "exacerbation" really mean? Prim Care Respir f 2004:13(4):179-80. 32. O"Brien $K$, Bukstein $D$. What is "more effective asthma control"? / Allergy clin Immunol
$2001 ; 107(6): 1107-9$.

33. Harrison TW, Oborne J, Wilding P $\mathrm{J}$, Tattersfield AE. Randomised placebo controlled trial of beta agonist dose reduction in asthma. Thorax 1999;54(2):98-102.

34. Vermetten FA, Boemans $A$, Luiten $W D$, Mulder $P G$, Vermue NA. salmeterol with beclomethasone in adult patients $\mathrm{PG}$, Vermue NA. Comparison of already on low-dose inhaled steroids

35. Noonan M. Chervinsky P. Busse WW. Asthma 1999,36(1):97-106.

Fluticasone propionate reduces WW. Weisberg SC, Pinnas $\downarrow$, de Boisblanc BP, et al and quality of life. Am I Respir Crit Care

36. Raphael GD multiple doses of fluticasone $J$, Edwards L, Rickard K, Lincourt WR. A comparison of with persistent asthma. $J$ Allergy cin 
37. Virchow J. Prasse A, Naya I, Summerton L, Harris A. Zafirlukast improves asthma control in patients receiving high-dose inhaled conticosteiroids. Am I Respir Crit Care Med 2000;162:578-85.

38. Pauwels RA, Pedersen $S$, Busse WW, Tan WC, Chen $Z_{2}$, Ohlsson $S V$, et al, Early intervention with budesonide in mild persistent asthma: a randomised, double-blind trial. Lancet 2003;361(9363):1071-6.

39. Bukstein DA, Luskin AT, Bernstein A. "Realwworld" effectiveness of daily controller medicine in children with mild persistent asthma. Ann Allergy Asthma Immunol 2003;90(5):543-9.

40. Jumiper EF, O'Byrme PM, Guyatt GH . Ferrie PJ, King DR. Development and validation of a questionnaire to measure asthma control. Eur Respir J 1999;14(4):902-7.

41. Juniper EF, O'Byrne PM, Roberts. IN. Measuring asthma control in group studies: do we need airway calibre and rescue beta2-agonist use? Respir Med 2001;95(5):319-23.

42. Juniper EF, Svensson $K$, Mork A-C, Stahl E. Measurement properties and interpretation of three shortened versions of the asthma control questionnaire. Respir Med 2005;99(5):553-8.

43. Chaudhuri $R$, Livingston $E$, McMahon $A D$, Thomson $L$, Borland $W$, Thomson $N C_{\text {w }}$ Cigarette smoking impairs the therapeutic response to oral corticosteroids in chronic asthma. Am J Respir Crit Care Med 2003;168(11):1308-11.

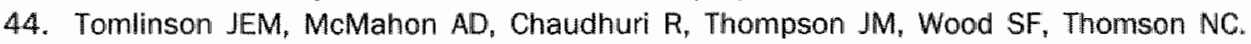
Efficacy of low and high dose inhaled corticosteroid in smokers versus nom-smokers with mild asthma. Thorax 2005;60(4):282-7.

45. Boushey HA, Sorkness CA, King TS, Sullivan SD, Fahy JV, Lazarus SC, et al. Daily versus As-Needed Corticosteroids for Mild Persistent Asthma. N Engl J Med 2005;352(15): 1519-28.

46. Molimard M, Martinat $Y$, Rogeaux $Y$, Moyse D, Pello J.Y, Giraud V. Improvement of asthma control with beclomethasone extrafine aerosol compared to fluticasone and budesonide. Respir Med 2005;99(6):770-8.

47. Nathan RA, Sorkness CA, Kosinski M, Schatz M, Li JT, Marcus $P$, et al. Development of the asthma control test: a survey for assessing asthma control. $J$ Allergy Clin Immunol $2004 ; 113(1): 59-65$.

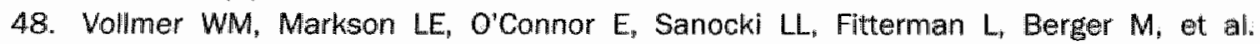
Association of asthma control with health care utilization and quality of life. Am J. Respir Crit Care Med 1999;160:1647-52.

49. Boulet LP, Boulet V, Milot J. How should we quantify asthma control? A proposal. Chest $2002 ; 122(6): 2217-23$.

50. Suissa S, Ernst P, Benayoun S, Baltzan M, Cai B. Low-dose inhaled corticosterolds and the prevention of death from asthma. N Engl J Med 2000;343(5):332 6 .

51. Lipworth $\mathrm{B}$. Modern drug treatment of chronic asthma Fortnightly review. $\mathrm{Br}$ Med J 1999; $318_{*}^{*} 380-4$.

52. Barnes PJ, Pedersen S, Busse WW. Efficacy and safety of inhaled corticosteroids. New developments. Am J Respir Crit Care Med 1998;157(3 Pt 2):\$1-53.

53. Kerstjens HA, Overbeek SE, Schouten JP, Brand PL, Postma DS. Airways hyperresponsiveness, bronchodilator response, allergy and smoking predict improvement in FEV1 during longterm inhaled corticasteroid treatment. Dutch CNSLD Study Group. Eur Respir J 1993;6(6):868-76.

54. Kelly HW, Nelson HS. Potential adverse effects of the inhaled corticosteroids. I Allergy Clin Immunol 2003;112(3):469-78.

55. Smeeth L, Boulis M, Hubbard R, Fletcher AE. A population based case-control study of cataract and inhaled corticosteroids. $\mathrm{Br} J \mathrm{Ophthalmol} 2003 ; 87(10): 1247-51$. 
56. Haahtela $T$, Järvinen $M_{s}$ Kava $T$, Kiviranta $K_{s}$ Koskinen $S_{\text {i }}$ Lehtonen $K_{8}$ et al. Effects of reducing or discontinuling inhaled budesonide in patients with mild asthma. $N$ Engl I Med 1994;331:700-5.

57. Pauwels R, Lofdahl C, Postma D, Tattersfield A, O'Byrne $P$, Barnes $P_{n}$ et al. Effect of inhaled formoterol and budesonide on exacerbations of asthma. $N$ Engl $/$ Med 1997:337(20):1405-11.

58. Bateman ED, Boushey HA, Bousquet $J$, Busse $W W$, Clark TJ, Pauwels RA, et al. Can Guideline-defined Asthma Control be Achieved? The Gaining Optimal Asthma ControL Study. Am I Respir Crit Care Med 2004;170:836-44.

59. Aalbers $R$, Backer $V$, Kava $T$, Omenaas $E R$, Sandstrom $T$, Jorup $C$, et al. Adjustable maintenance dosing with budesonide/formoterol compared with fixed-close salmeterol/fluticasone in moderate to severe asthma. Curr Med Res Opin 2004:20(2):225-40.

60. Powell $H$, Gibson $P G$. Options for self-management education for adults with asthma. Cochrane Database Syst Rev 2002(3):Art. No.:CD004107. DO: 10.1002/14651858. CDO04107.

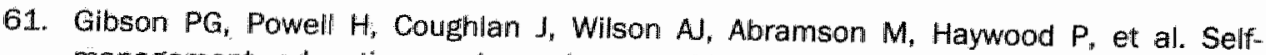
management educiation and regular practitioner review for adults with asthma. Cochrane Database Syst Rev 2002(3):Art. No: CD001117. DOI: 10.1002/14651858. CDO01117.

62. Thoonen BP, Schermer TR, van den Boom G, Molema J, Folgering $H$, Akkermans RP, et al. Self-management of asthma in general practice, asthma control and quality of life: a randomised controlled trial. Thorax 2003;58(1):30-6.

63. Beasly $R$, Cushley $M$, Holgate ST. A self management plan in the treatment of adult asthma. Thorax 1989;44:200-4.

64. D'Souza W, Crane J, Burgess C, Karu Te H, Fox C, Harper M, et al. Community-based asthma care: trial of a "credit card"asthma self-management plan. Eur Respir $f$

65. Guevara JP, Wolf FM, Grum CM, Clark NM. Effects of educational interventions for self management of asthma in children and adolescents: systematic review and meta-

66. Lahdensuo $A_{1}$ Haahtela $T$, Herrala J, Kava T, Kiviranta $K$, Kuusisto $P$, et al. Randomised comparison of cost effectiveness of guided self management and traditional treatment of astituma in Finland. Br Med J 1998;316(7138):1138-9.

67. Schemer TR, Thoonen BP, van den Boom G, Akkermans RP, Grol RP, Folgering HT, et al. Randomized controlled economic evaluation of asthma self-management in primary health care. Am J Respir Crit Care Med 2002;166(8):1062-72.

68. Tovey ER, Chapman MD ${ }_{n}$ Wells CW, Platts-Mills TA. The distribution of dust mite allergen in the houses of patients with asthma. Am Rev Respir Dis 1981;124(5):630-5.

69. van Strien RT, Verhoeff AP, Brunekreef B, van Wijnen $\mathrm{JH}$. Mite antigen in house dust: relationship with different housing characteristics in The Netherlands. Clin Exp Allergy

70. Hegarty JM, Jessop WJ, Warner JA, Warner JO. The effect of a bed covering system on

71. Owen S, Morganstern M, Hepworth J, Wood Alergy 1993;48:108. in bedding. Lancet 1990;335(8686):396-7.

72. van der Helide S, Kauffman HF, Dubois AE.

in houses of allergic asthmatic impermeable mattress covers. Eur Respir 1997:10ts of air-cleaners and allergen- 
73. Gotzsche $\mathrm{PC}_{\mathrm{in}}$ lohansen $\mathrm{HK}$, Burr M. Are encasings effective in asthma caused by house dust mite allergens? I Allergy Clin Immunol 2003;112(1):220; author reply 2201.

74. Walshaw MJ, Evans CC. Allergen Avoidance in House Dust Mite Sensitive Adult Asthma. Q J Med 1986"226(New Series 58):199-215.

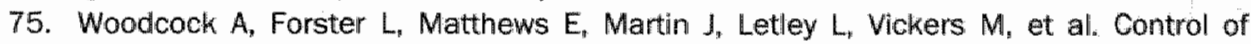
exposure to mite allergen and allergen-impermeable bed covers for adults with asthma. N Engl J Med 2003;349(3):225-36.

76. Rijssenbeek-Nouwens LHM, Oosting AJ, de Bruin-Weller MS, Bregman I, de Monchy JG, Postma DS. Clinical evaluation of the effect of anti-allergic mattress covers in patients with moderate to severe asthma and house dust mite allergy: a randomised double blind placebo controlled study. Thorax 2002;57:784-90.

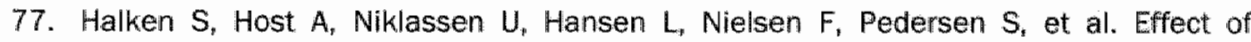
mattress and pillow encasings on children with asthma and house dust mite allergy. $J$ Allergy Clin Immunol 2003:111:169-76.

78. Cloosterman SGM, Hofland ID, Lukassen HGM, Wieringa MH, Folgering HTM vain der Heide $S$, et al. House dust mite avoidance measures improve peak flow and symptoms in patients with allergy but without asthma: $A$ possible delay in the manifestation of clinical asthma? I Allergy Clin Immunol 1997;100:313-9.

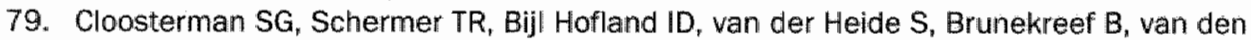
Elshout FJ, et al. Effects of house dust mite avoidance measures on Der $p 1$ concentrations and clinical condition of mild adult house dust mite-allergic asthmatic patients, using no inhaled steroids. Clin Exp Allergy 1999;29(10):1336-46.

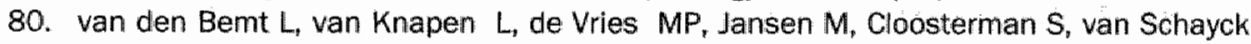
CP. Clinical effectiveness of a mite allergen-impermeable bed-covering system in asthmatic mite-sensitive patients. J Allergy Clim Immunol 2004;114(4):858-62. 


\section{Chapter

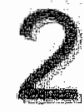

The prevalence of house dust mite allergy and the use of HDM impermeable covers in a primary care population of patients with persistent asthma in the Netherlands

MP de Vries, L van den Bemt, S Lince, JWM Muris, BPA Thoonen, CP van Schayck Primary Care Respiratory Journal, 2005;14:210-214 


\section{Abstract}

\section{Background}

House dust mite (HDM) allergen is one of the most common allergens to which asthma patients are sensitised. Prevalence of HDM allergy varies in the literature. Use of house dust mite impermeable covers reduces exposure to HDM allergen. The alm of this study was to assess the prevalence of HDM allergy in a primary care population of asthma patients, as well as the use of HDM impermeable covers by these patients.

\section{Methods}

A random sample of asthma patients between 16 and 60 years old was taken from general practices. Allergy was assessed with a radio-allergo-sorbent test (RAST). A questionnaire was used to identify demographic characteristics and the actual use of bed covers.

\section{Results}

534 patients were invited and 160 patients participated. 53 patients not willing to participate were randomly selected to test the external validity of our findings. The sample was representative for the primary care asthma population. $48.8 \%$ of the asthma population was sensitised to HDM allergen. $25.6 \%$ of the HDM allergic asthma patients were using HDM impermeable bed covers.

\section{Conclusion}

Almost half of the patients with asthma were sensitised to HDM allergen. Only a minority of the patients used HDM impermeable bed covers. 


\section{Introduction}

House dust mite (HDM) allergen is one of the most common allergens to which asthma patients are sensitised ${ }^{1,2}$. Exposure to HDM allergen can result in bronchoconstriction and an inflammatory reaction of the airways ${ }^{3}$.

Up to $85 \%$ of atopic asthmatic patients may have an HDM allergy, but these figures vary widely in literature from 45 till $85 \% 10.4,5$.

HDM allergen avoidance measures are available in daily care. People spend approximately one third of their lives in bed. Therefore, HDM in mattresses, bedding and pillows contribute considerably to total HDM exposure ${ }^{6.7}$. Use of HDM impermeable bed covers results in a considerable reduction in concentration of HDM allergen levels in bed8-11. Although the clinical efficacy of covers is still under debate ${ }^{12}$ and some studies do not find a clinical benefit from covers ${ }^{11,13}$, other studies show promising effects ${ }^{10.14-16}$. These differences in study outcomes may be partially explained by differences in study population, duration of follow up, baseline exposure to allergens, and medication use. In some studies assessing the efficacy of bed covers, patients were included who were not sensitised to HDM allergen.

HDM avoidance measures seem especially effective as an early prevention measure in allergic patients who do not yet have a clinical diagnosis of asthma ${ }^{17,18}$. Health policy and various guidelines support the use of HDM impermeable covers in different countries ${ }^{19-21}$.

In several countries, including the Netherlands, insurance companies are reimbursing the cost of bed covers when HDM allergy is diagnosed. As a consequence, this ought to encourage widespread use of bed covers by allergic asthmatic patients in the Netherlands. However, it is uncertain to what extent HDM allergic asthmatic patients are using these covers at the moment.

The aim of this study was to assess the prevalence of HDM allergy in a primary care population of adult asthmatic patients in the Netherlands. In addition, the use of HDM impermeable covers in this asthma population was determined.

\section{Methods}

Asthma patients aged between 16 and 60 who were using inhaled steroids were selected from 15 general practices in the Netherlands.

All subjects were invited to participate in a trial to test the effect of HDM impermeable covers. With the invitation letter they received a questionnaire about the use of HDM impermeable covers. If they were willing to participate, a radioallergo-sorbent test (RAST) for specific immunoglobulin $\mathrm{E}$ (IgE) to HDM allergen was performed to test if subjects were sensitised to HDM. IgE levels above $0.35 \mathrm{kU} / \mathrm{l}$ were considered to be positive for HDM allergy. Moreover, patients received a 
questionnaire on their educational and employment level, smoking habits, and medication use. Socio-economic status (SES) was derived from educational and employment level. Both educational level and employment level were divided into the categories low, middle and high. SES was calculated as the mean of employment and educational level and also divided into the categories low, middle and high. Smoking was defined as current smoking, ex smoking or never smoking. This questionnaire was also sent to a sample of patients not willing to participate in the trial, to compare some characteristics between the study group and non participants in order to assess the external validity of the sample studied. A random sample of $10 \%$ of the total number of patients invited to the trial was produced with assistance of a randomisation program. The two groups were compared on the following variables: gender, age, smoking status, and socioeconomic status.

The Medical Ethical Committee of the University Hospital Maastricht approved the trial, and all responders willing to participate gave written informed consent. A sample of patients who were originally not willing to participate in the trial, volunteered to complete the patient characteristics questionnaire.

\section{Statistical analysis}

The percentages of patients sensitised to HDM allergen and patients using HDM impermeable bed covers were calculated. The patient characteristics of participants and non-participants are presented as percentages or mean with $95 \%$ confidential intervals (CI). Variables were compared by means of a Student's t-test or a chi-square-test, depending on the type of variable, to see whether there were any significant differences between participants and non-participants. Statistical significance was defined as p-value $<0.05$. Statistical analyses were performed with SPSS for Windows, Version 11.0 (SPSS, Inc. Chicago, ill.).

\section{Results}

\section{HDM sensitisation}

Five hundred and thirty four asthma patients from 15 practices were invited to participate in the trial. 160 patients were willing to participate in the trial. From the group of patients not willing to participate, a random sample of 53 patients
completed the patient characteristics questionnaire.

The results of the comparison on patient characteristics between the participants and non-participants are shown in Table 2.1.

There was a statistically significant difference in age between the participants and non-participants $(p=0.004)$. The other variables did not differ significantly. 
The RAST was performed in 160 patients. 78 patients $(48.8 \%$ ) had a positive test for HDM allergens ( $95 \%$ Cl $41.1-56.5)$.

Table 2.1 Patient characteristics of the participants and a random sample from the patients not willing to participate in the trial.

\begin{tabular}{lccc} 
& $\begin{array}{c}\text { Participants } \\
N=160\end{array}$ & Non-participants & p-value \\
\hline Age in yrs $(S D)$ & $41.5(13.2)$ & $35.4(12.6)$ & $p=0.004$ \\
Gendler M/F (\%) & $47.8 / 52.2$ & $41.5 / 58.5$ & $p=0.448$ \\
Smoking (\%) & & & \\
Current smoking & $43(26.9)$ & $10(18.9)$ & \\
Ex-smoking & $48(30.0)$ & $12(22.6)$ & $p=0.115$ \\
Newer smoking & $66(41.3)$ & $31(58.5)$ & \\
missing & $3(1.9)$ & 0 & \\
SES (\%) & & & \\
Low & $63(39.4)$ & $17(32.1)$ & \\
Middle & $66(41.3)$ & $29(54.7)$ & $p=0.292$ \\
High & $27(16.9)$ & $7(13.2)$ & \\
missing & $4(2.5)$ & 0 & \\
\hline
\end{tabular}

SD: standard deviation, M: male, Fi femalle, SES: socio-economic status.

Use of covers

In the total group of responders the use of house dust mite impermeable covers was $12.5 \%(95 \% \mathrm{Cl}$ 9.3-15.7). With our prevalence figure for HDM allergy of $48.8 \%$, this implies that the use of HDM impermeable covers is $25.6 \%(95 \% \mathrm{Cl} 18.8-32.4)$ in the HDM allergic asthma patients.

If the data on the use of HDM impermeable covers and prevalence of HDM allergy are extrapolated to the total asthmatic population, this would suggest that almost $75 \%$ of asthmatic patients allergic to HDM do not use HDM impermeable bed covers.

\section{Discussion}

This study shows that $48.8 \%$ of this population of asthma patients is sensitised to HDM. In the literature, 45 to $85 \%$ of asthmatic patients have been shown to be HDM allergic ${ }^{1,4.5}$. Accordingly, our figure of $48.8 \%$ is at the lower end of the range. In a population of more severe asthma patients a higher prevalence might be expected, and also in asthmatic children a higher prevalence is to be expected. 
We found the estimated use of HDM impermeable bed covers by HDM sensitised asthma patients to be $25.6 \%$. Several HDM impermeable covers have been tested before with promising results on reduction of HDM allergen exposure 16,17,22-24. Therefore, it is likely that the covers patients are using, are actually reducing allergen exposure.

This study shows, that there is room for improvement in HDM impermeable bed covers use in asthmatic patients with HDM allergy. These numbers were extrapolated from the use of bed covers in the whole group of responders, together with the prevalence of sensitisation to HDM allergen, assuming that only patients sensitised to HDM allergens are using bed covers. It could be that in the total group of responders patients not sensitised are using covers. Furthermore, patients could possess covers but not be using them. The estimated figure of $25.6 \%$ could therefore be an overestimation, suggesting that there is even more room for improvement. An underestimation seems very unlikely.

Nevertheless, at least $75 \%$ of HDM allergic asthmatic patients using inhaled steroids, are not using HDM impermeable bed covers, even though the use of these covers could lead to better lung function and less symptoms $10,14,16,25$.

A wide range of reasons for not using these covers can be assumed. Patients may not be aware of the benefits of HDM impermeable covers or the effect of these covers might have on their asthma. Furthermore, patients might have had negative experiences with uncomfortable covers. As manufacture techniques progress this reason should be a passing concern. Moreover, patients may not be aware of the fact that insurance companies compensate the cost of covers.

In addition, doctors might not prescribe HDM impermeable covers because of various reasons: firstly, not all patients are examined for the presence of HDM allergy; and secondly, although possible benefits of HDM impermeable bed covers are described in the literature, there are also studies showing no benefit from covers, as summarised in a Cochrane Review ${ }^{12}$. The negative effects might be explained by the fact that in some studies, patients not sensitised to HDM allergens were included, or that other sensitising allergens were present and patients were actually exposed to these allergens; for example patients sensitised to cat dander allergen, with a cat in the house, participating in a trial investigating the effects of HDM impermeable bed covers.

Apart from exposure to HDM allergen, exposure to other triggers or allergens can cause symptoms 26,27 . In this study, we focused specifically on HDM allergens.
The patients who were willing to participate were representative with regard to
gender, smoking status, and socib-economich gender, smoking status, and socio-economic status of the average asthmatic population in primary care. However, the participants were older than the sample of non-participants (average age 41 years compared to 35 years). In younger patilents one could expect a higher prevalence of HDM allergy. However, we think be minimal and that the group of patients in which we assessed the prevalence of 
HDM allergy is representative for patients with mild to moderate asthma between 16 and 60 .

In conclusion, the prevalence of HDM allergy in this group of asthma patients in primary care was almost $50 \%$, which is at the lower end of the range compared to other studies. The actual use of HDM impermeable covers in these HDM allergic asthmatic patients was around $25 \%$. 


\section{References}

1. Dust mite allergens and asthma: a worldwide problem. International Workshop report. Bull Worla Heaith Organ $1988 ; 66(6): 769-80$.

2. Platts-Mills TAE, Vervloet D. Thomas WR, Aalberse RC, Chapman MD. Indoor allergens and asthma: report of the third internationa! workshop. I Allergy Clin Immunol $1997 ; 100(6): 51-524$.

3. Bush RK. The role of allergens in asthma. Chest 1992;101(6 Suppl):378S-80S.

4. Smith JM, Disney ME, Williams JD, Goels ZA. Clinical significance of skir reactions to mite extracts in children with asthma. Br Med $J 1969 ; 1$ (659):723-6.

5. Colloff M., Ayres 1, Carswell F, Howarth PH, Merrett TG, Mitchell EB, et al. The control of allergens of dust mites and domestic pets: a position paper. Clin Exp Allergy $1992 ; 22$ Suppl 2:128.

6. Marks BGB, Tovey ER, Green W, Shearer M, Salome CM, Woolcock AJ. The effect of changes in house dust mite allergen exposure on the severity of asthma. Clin Exp Allergy 1995;25:114-8.

7. Garrett MH, Hooper BM, Hooper MA. Indoor environmental factors associated with house-dust-mite allergen (Der $p$ 1) levels in south-eastern Australian houses. Allergy 1998;53:1060-5.

8. Hegarty $J M$, Jessop WJ, Warner JA, Warner Jo. The effect of a bed covering system on airborne levels of house dust mite allergen. Allergy 1993;48:108.

9. Owen S, Morganstern M, Hepworth J, Woodcock A. Control of house dust mite antigen in bedding. Lancet 1990;335(8686):396-7.

10. Van der Heide $S_{n}$ Kauffman HF, Dubois AE, De Monchy JG. Allergen reduction measures in houses of allergic asthmatic patients: effects of air-cleaners and allergemimpermeable mattress covers. Eur Respir J 1997;10(6):1217-23.

11. Rijssenbeek-Nouwens LHM, Dosting AJ, de Bruin-Weller MS, Bregman I, de Monchy JG, Postma DS. Clinical evaluation of the effect of anti-allergic mattress covers in patients with moderate to severe asthma and house dust mite allergy: a randomised double blind placebo controlled study. Thorax 2002;57:784-90.

12. Gotzsche PC, Johansen HK, Schmidt LM, Burr ML. House dust mite control measures for asthma. Cochrane Database of Syst Rev 2004(4):Art. No.: CD001187.pub2. DOI: 10.1002/14651858.CDO01187.pub2.

13. Woodcock A, Forster L, Matthews E, Martin J, Letley L, Vickers $M$, et al. Control of exposure to mite allergen and allergen-impermeable bed covers for adults with asthma. N Engl I Med 2003;349(3):225-36.

14. Walshaw MJ, Evans CC. Allergen Avoidance in House Dust Mite Sensitive Adult Asthma. Q J Med 1986;226(New Series 58):199-215.

15. Halken S, Niklassen U, Nansen LG, Nielsen F, Host A, Osterballe O, et al. Encasing of mattress in children with asthma and house dust mite allergy. I Allergy Clin Immunol 1997:99:5320.

16. wan den Bemt $L$, van Knapen $L$, de Vries MP, Jansen M, Cloosterman $S$, van Schayck $C P$. Clinical effectiveness of a mite allergen-impermeable bed-covering system in asthmatic mite-sensitive patients. J Allergy Clin immunol 2004;114(4):858-62.

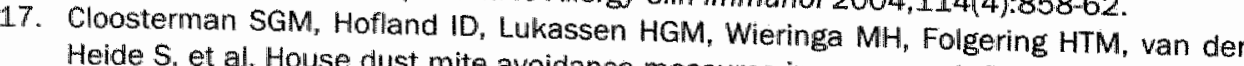
Heide S, et al. House dust mite avoidance measures improve peak flow and symptoms in patlents with allergy but without asthma: A possible delay in the manifestation of clinical asthma? I Allergy Clin /mrnunol 1997;100:313-9.

18. Cloosterman SGM, van Schayck OCP. Effectiveness of measures depends on stage of 
19. Asthma management and prevention. Global Initiative for Asthma. ir Med $J$ 2000; Suppl:i-vi, 1-39.

20. BTS/SIGN British Guideline on the Management of Asthma. Thorax 2003:58(supplement 1):1-83.

21. Geljer RMM, Van Hensbergen W, Bottema BJAM, Van Schayck CP, Sachs APE, Smeele IMM, et al. NHG-Standaard Astma bij Volwassenen: Behandeling (NHG Guideline on Asthma in Adults: Treatment). Huisarts Wet 2001;44(4):153-64.

22. Terreehorst $I_{1}$ Hak E, Oosting Al, Tempels-Pavlica $Z$, de Monchy JG, Bruinzeel-Koomen CA, et al. Evaluation of impermeable covers for bedding in patients with allergic rhinitis. N Engl J Med 2003;349(3):237-46.

23. Van der Heide S, Kauffman HF, Dubois AE, De Monchy JG. Allergenwavoidance measures in homes of house-dust-mite-allergic asthmatic patients: effects of acaricides and mattress encasings. Allergy 1997;52(9):921-7.

24. Schonberger HJAM, Dompeling E, Knottnerus $J A_{n}$ Maas T, Muris JWM, van Weel $C$, et al. The PREVASC study: the clinical effect of a multifaceted educational intervention to prevent childhood asthma. Eur Respir 1 2005;25(4):660-70.

25. Halken $S$, Host $A$, Niklassen $U$, Hansen L, Nielsen $F_{n}$ Pedersen $S_{n}$ et al. Effect of mattress and pillow encasings on children with asthma and house dust mite allergy. $J$ Allergy Clin Immunol 2003;111:169-76.

26. Custovic A, Taggart $\mathrm{SCO}$, Francis HC, Chapman MD, Woodcock A. Exposure to house dust mite allergens and clinical activity of asthma. I Allergy Clin Immunol 1996; 98(1):64-72.

27. Platts Mills TA, Thomas WR, Aalberse $\mathrm{RC}_{\mathrm{v}}$ Vervloet $\mathrm{D}$, Champman MD. Dust mite allergens and asthma: report of a second international workshop. I Allergy Clin Immunol 1992;89(5):1046-60. 


\section{Chapter 3}

Influence of mattress characteristics on house dust mite allergen concentration

$\mathbb{L}$ van den Bemt, MP de Vries, L van Knapen, M Jansen, M Goossens, JWM Muris, CP van Schayck

Accepted for publication in Clinical \& Experimental Allergy 


\section{Abstract}

\section{Background}

Exposure to a high level of house dust mite (HDM) allergens is considered as a risk factor for HDM sensitisation and development of asthma in genetically disposed people. Mattresses are one of the most important sources of HDM allergen in people's living environment.

\section{Objective}

The aim of this study was to evaluate the association between mattress characteristics and HDM allergen concentrations on mattresses.

\section{Methods}

Dust samples of mattress surfaces were taken to evaluate the level of Dermatophagoides pteronyssinus allergen 1 (Der $p 1$ ). All participants filled in a questionnaire about the type of mattress, the type of covering (upper layer) of the mattress, dwelling characteristics, and cleaning habits. Humidity and temperature of the bedroom were measured at the time of dust sampling.

\section{Results}

168 questionnaires were filled in. Synthetic upper fayer of the mattress was associated with a higher level of Der p 1 compared to cotton upper layer (2.6 vs. $0.8 \mathrm{Hg} / \mathrm{g}$ Der $\mathrm{p} 1$ ). Moreover, higher relative humidity was associated with significant higher concentrations and density of Der $p 1$.

\section{Conclusion}

Two factors were associated with lower levels of Der $p 1$ found on mattresses, namely a cotton upper layer of the mattress compared to a layer of a synthetic material and lower relative humidity at the time of sampling. As far as we know, the association between the type of upper layer and the concentration of Der $p 1$ has not been described before and could lead to the formulation of practical advices in order to reduce HDM allergen concentrations on mattresses. 


\section{Introduction}

Exposure to a high concentration of house dust mite (HDM) allergens is considered to be a risk factor for HDM sensitisation and development of asthma in genetically predisposed people ${ }^{1}$. If high exposure to HDM allergens could be avoided, this might lead to a reduction in prevalence of allergic diseases like asthma. in our indoor environment, HDM is present in various places like carpets, furniture, and curtains. Nevertheless, one of the most important sources of HDM allergen is the bed $^{2-6}$. Microenvironment and food supply in bed are ideal for mite growth. Moreover, people spend approximately eight hours each day in bed in close contact with these allergens.

The allergen load on various types of mattresses might differ. This variance might be caused by differences in accumulation of moisture and adjusting temperature, which are important factors for mite growth and may consequently lead to different Dermatophagoides pteronyssinus allergen 1 (Der $p$ 1) levels. Contradictory results on the relation between HDM allergen levels and type of mattress were found ${ }^{2,7-11}$. The type of upper layer of the mattress could influence the concentration of HDM allergen. Recent research of Siebers et al. on permeability of different types of pillow covers for dust and HDM penetration showed that feather pillows are less permeable for dust and HDM compared to synthetic pillow covers ${ }^{12}$. As far as we know, until now no attention has been paid to the influence of type of upper layer of a mattress on concentration of HDM allergen.

In addition, some evidence for a relation between the level of HDM allergen on mattresses and other factors like relative humidity $(\mathrm{RH})$, temperature, mould growth, age of mattresses, ventilation, and the use of a sheepskin or synthetic under blanket was found $8,10,11,13-20$.

If mattress characteristics could be identified which could influence the concentration of HDM allergen prominently, minimising exposure to HDM allergen would become possible for a large section of society. The aim of this study was to evaluate mattress characteristics and other factors associated with HDM allergen levels on mattresses.

\section{Methods}

Dust samples were taken from mattresses during home visits. The 175 participants were all adults with asthmatic complaints who did not use HDM impermeable covers for mattresses, duvets, and pillows. All dust samples were collected with a vacuum cleaner (Bosch activa 60, type BS6, 1300 Watt). A special dust collector with a filter paper for mattress samples was attached to the vacuum cleaner. The upper surface of the whole bare mattress was sampled in a standardised way with an intensity of two minutes per $\mathrm{m}^{2}$. The amount of dust was weighed and a $10 \%$ 
(w/v) extraction in 0,01 mol// $\mathrm{NH} 4 \mathrm{HCO} 3$ was performed by overnight rotation at $4^{\circ} \mathrm{C}$. The samples were centrifuged and supernatants were used for detection of Der $p 1$ by ELISA. Der $p 1$ is a heat-labile glycoprotein excreted in faeces by HDM and can be seen as a predictor for the total exposure to HDM allergens. Der $p 1$ was expressed as $\mu \mathrm{g} / \mathrm{gram}$ dust (concentration) and $\mu \mathrm{g} / \mathrm{m}^{2}$ mattress surface (density) with a focus on reporting $\mu \mathrm{g} / \mathrm{gram}$ dust as recommended by Platts Mills et al. 1.

A questionnaire on bedding, type of mattress, type of covering (upper layer) of the mattress, age of mattress, floor covering, cleaning habits, and home characteristics was filled in by every participant. Relative humidity and temperature of the bedroom were measured using a Vaisala hygrometer (serial no 596488, Finland) at the time of dust sampling. Mattresses were divided into 4 types: inner sprung mattress, latex mattress, polyether mattress, and waterbed. The upper layer of the mattress was divided into 4 categories: synthetic, synthetic/cotton, cotton, and others.

\section{Statistical analysis}

Der $p 1$ concentration and amount of dust were not normally distributed and were therefore ${ }^{10} \mathrm{log}$ transformed and results are presented as geometric means (GM). Relative humidity (RH) was not normally distributed and was therefore dichotomised ( $\leq 50 \% \mathrm{RH}$ and $>50 \% \mathrm{RH}$ ). These categories were chosen because $50 \%$ relative humidity is the round figure most closely related to the median relative humidity of the bedrooms in this trial. Age of mattresses was dichotomised in a group $<5$ year old and $\geq 5$ year old, following other studies regarding this subject $14,16,17,20$. The difference in proportions of mattresses that exceeded the HDM allergen threshold levels $(2 \mu \mathrm{g} / \mathrm{g}=$ sensitisation level and $10 \mu \mathrm{g} / \mathrm{g}=$ risk factor for acute asthma) was analysed with a chi-square test. Differences of mean Der $p 1$ concentrations for dichotome factors were analysed with an unpaired $t$-test. The difference between mean Der $p 1$ concentrations of the other nominal variables was tested with an one-way analysis of variance. Linear regression models were used to determine the association between Der $p 1$ concentrations

Factors that were possible associated with HDM allergen levels $(p<0.10)$ were added to a multiple linear regression model with log transformed Der $p 1$ level in $\mu \mathrm{g} / \mathrm{gram}$ as dependent variable to identify the explanatory variables for the variance in Der $\mathrm{p} 1$ level. Factors were eliminated with a stepwise backward
procedure. SPSS for Windows, version 11.0 was used to analyse the data (SPSS, Inc. Chicago,
III.).

The Medical Ethical committee of the Academic Hospital Maastricht approved the study. All participants had given written informed consent. 


\section{Results}

168 patients completed the questionnaire, which was $96 \%$ of all subjects of whom dust samples from the mattresses were taken. 11 mattresses were excluded from the analyses because they were made of materials that are seldom used (like horse hair filled mattresses). Four samples of dust were too small to sample (2 samples of latex mattresses and 2 samples of inner sprung mattresses / 2 samples of cotton upper layer, 1 sample of synthetic/cotton upper layer, and 1 sample of other material). Ultimately, the data for 153 cases on type of mattress was complete. Dust samples were collected from 41 inner sprung mattresses, 54 latex mattresses, 43 polyester mattresses, and 15 water mattresses. The upper layer of the mattresses was cotton in 41 cases, synthetic in 28 cases; a combination of cotton and synthetic in 52 cases, and made of other material in 26 cases (upper layers with wool $(n=13)$ or damask $(n=10)$ ).

The correlation between Der $\mathrm{p} 1$ expressed as $\mu \mathrm{g} / \mathrm{g}$ dust and $\mu \mathrm{g} / \mathrm{m}^{2}$ was 0.94 ( $p<0.01$ ). Almost $42 \%$ of all mattresses contained allergen levels above $2 \mu \mathrm{g} / \mathrm{g}$. Nearly $14 \%$ of mattresses had HDM allergen levels above the risk level for asthma exacerbations $(10 \mu \mathrm{g} / \mathrm{g})$. Occurrence of HDM concentrations above $2 \mu \mathrm{g} / \mathrm{g}$ and 10 $\mu \mathrm{g} / \mathrm{g}$ did not differ significantly between the four types of mattresses $(p=0.48$ and $\mathrm{p}=0.12)$. Geometric mean Der p 1 was $1.133 \mu \mathrm{g} / \mathrm{g}(\mathrm{Cl} 0.768-1.670)$ and 0.192 $\mu \mathrm{g} / \mathrm{m}^{2}(\mathrm{Cl} 0.124-0.296)$. Relatively small amounts of dust (GM $0.50 \mathrm{~g}, \mathrm{Cl} 0.43-$ 0.58) were found on mattresses and seem to be responsible for the low density of HDM allergen.

Table 3.1 shows the geometric means and 95 percent confidence intervals $(\mathrm{Cl})$ for all variables. The type of upper layer of the mattress was associated with the concentration of Der $p 1(p=0.04)$. A cotton upper layer of the mattress was associated with a significantly lower concentration of Der $\mathrm{p} 1$ compared to a synthetic upper layer. Thet type of mattress was not associated with the concentration of Der $p 1$. Moreover, the concentration of Der $p 1$ differed significantly between the relative humidity categories $(p=0.02)$. Also density of Der p 1, expressed as $\mu \mathrm{g} / \mathrm{m}^{2}$, was associated with relative humidity $(p<0.01)$. Furthermore, seasonal changes of Der $p 1$ were seen, although not significant $(p=0.09)$. Temperature of the bedroom was not associated with Der $p 1$ in this study. No other significant association between density of HDM allergen $\left(\mu \mathrm{gg} / \mathrm{m}^{2}\right)$ and any of the variables was seen.

The results of the multiple linear regression model are given in Table 3.2.

The two variables; upper layer of mattress and relative humidity, explained approximately $9 \%$ of the variance in the concentration of Der $p 1$ found on mattresses. 
Table 3.1 The geometric mean and $95 \% \mathrm{Cl}$ of 10logarithmic transformed Der $\mathrm{p} 1$ levels found on mattresses expressed in $\mu g / E$ for mattress characteristics and various other variables. Variables in bold differed significantly between groups $(p<0.05)$ variables in thalic are borderline significant $(p<0.10)$.

\begin{tabular}{|c|c|c|c|}
\hline \multirow[b]{2}{*}{ Variabie } & \multirow[b]{2}{*}{$n$} & \multicolumn{2}{|c|}{ Der $p 1$ in $\mu g / g$} \\
\hline & & Geometric Mean & $95 \% \mathrm{Cl}$ \\
\hline \multicolumn{4}{|l|}{ Type of Mattress } \\
\hline Latex & 54 & 1.191 & $(0.744-1.908)$ \\
\hline Waterbed & 15 & 0.433 & $(0.073-2.559)$ \\
\hline Polyether & 43 & 1.199 & $(0.592-2.431)$ \\
\hline Inner spruing & 41 & 1.418 & $(0.594-3.387)$ \\
\hline \multicolumn{4}{|c|}{ Type of upper layer of mattress } \\
\hline Cotton & 41 & 0.801 & $(0.343-1.873)$ \\
\hline Synthetic & 28 & 2.606 & $(1.527-4.448)$ \\
\hline Cotton/synthetic & 52 & 1.382 & $(0.885-2.158)$ \\
\hline Other & 26 & 0.447 & $(0.111-1.792)$ \\
\hline missing & 6 & & \\
\hline \multicolumn{4}{|l|}{ Age mattress } \\
\hline$\leq 5$ years old & 57 & 0.986 & $(0.517-1.883)$ \\
\hline$>5$ years old & 95 & $1: 190$ & $(0.731-1.939)$ \\
\hline missing & 1 & & \\
\hline \multicolumn{4}{|l|}{ Use of Sheepskin } \\
\hline Yes & 92 & 1.144 & $(0.742-1.764)$ \\
\hline No & 54 & 1.169 & $(0.602-2.267)$ \\
\hline missing & 7 & & \\
\hline \multicolumn{4}{|l|}{ Bedroam carpet } \\
\hline Yes & 47 & 0.817 & $(0.342-1.952)$ \\
\hline No & 106 & 1.309 & $(0.872-1.965)$ \\
\hline \multicolumn{4}{|c|}{$\begin{array}{l}\text { Condensation on windows in winter } \\
\text { yes. }\end{array}$} \\
\hline Yes & 54 & 1.160 & $(0.5342 .517)$ \\
\hline No & 97 & 1.065 & $(0.694-1.635)$ \\
\hline missing & 2 & & \\
\hline \multicolumn{4}{|c|}{$\begin{array}{l}\text { Relative humidity }(\%) \text { bedroom } \\
550\end{array}$} \\
\hline 550 & 79 & 0.796 & $(0.444-1.426)$ \\
\hline $\begin{array}{l}>50 \\
\text { missing }\end{array}$ & 65 & 1.975 & $(1.312-2.974)$ \\
\hline \multirow{2}{*}{\multicolumn{4}{|c|}{$\begin{array}{l}\text { eason } \\
\text { Winter }\end{array}$}} \\
\hline & & & \\
\hline Winter & 48 & 1.491 & $(0.772-2.882)$ \\
\hline Spring & 46 & 0.568 & $(0.293-1.100)$ \\
\hline Summer & 39 & 1.207 & $(0.488-2.98 .2)$ \\
\hline Autumn & 20 & 2.531 & $(1.111-5.768)$ \\
\hline
\end{tabular}


Table 3.2 Factors associated with logtransformed $\mu \mathrm{g} / \mathrm{gram}$ mattresses Der $\mathrm{p} 1$ levels in a multipte linear regression model.

\begin{tabular}{lccccc}
\hline & Estimate ( $\beta$ ) & std Error & t & p-value \\
\hline Constant & 2.41 & 0.28 & 8.63 & 0.000 \\
Cotton ws. other upper layer & -0.07 & 0.25 & -0.29 & 0.77 \\
Cotton ws. synthetic upper layer & 0.50 & 0.24 & 2.09 & 0.04 \\
Cotton ws. combination synthetic / cotton & 0.16 & 0.20 & 0.80 & 0.42 \\
Relative humidity high ws. low & 0.37 & 0.16 & 2.26 & 0.03 \\
\hline
\end{tabular}

\section{Discussion}

This study showed an association between type of upper layer of mattresses and the concentration of HDM allergen found on mattresses. Synthetic upper layers had higher levels of HDM allergen than cotton upper layers. Moreover, $>50 \%$ relative humidity was associated with higher levels of HDM allergen in this study. No significant difference in Der p $1\left(\mu \mathrm{g} / \mathrm{g}\right.$ and $\left.\mu \mathrm{g} / \mathrm{m}^{2}\right)$ between water, latex, polyether, and sprung mattresses was seen. Nevertheless, concentrations of HDM allergen in sprung mattresses tended to be higher compared to the other types of mattresses.

Some other studies investigated the relation between mattress types and HDM allergen levels. Sometimes, higher concentrations of HDM allergen were found on sprung mattresses compared to foam mattresses and/or water mattresses 27,8 . Use of sprung mattresses was also slignificantly associated with increased airway responsiveness and mite sensitivity 23 . In other studies, no difference in HDM levels on water, sprung, and foam mattresses was found 9.20.21. Surprisingly, Shel et al. found the opposite relation, and concluded that more foam mattresses were heavily infested with HDM allergen than sprung mattresses ${ }^{11}$. In their study a guanine colorimetric paper test (Aciarex test) was used to determine mite infestation, which is less accurate than the methods used in the other referenced studies (concentration of Der 1, mite count). Moreover, in one other study, sprung mattress was associated with lower levels of Dermatophagoides farinae allergen 1 (Der $f 1$ ), although this relation was not found for Der $p 1^{17}$. Der $f 1$ is excreted in faeces of Dermatophagoides farinae, which is another HDM species. In our study. no significant relation between type of mattress and concentration of HDM allergen was seen. Nevertheless, a trend towards a higher concentration of HDM allergen on sprung mattresses compared to the other types, was observed.

The type of upper layer of the mattresses was significantly associated with the concentration of Der $p 1$ found on mattresses. As far as we know, this is the first study that takes this variable into account. However, the same results were found when comparing materials used for blankets. Synthetic blankets contain more 
house dust mite allergen than cotton blankets $(22,1 \text { vs. } 15,4 \mu \mathrm{g} / \mathrm{g} \text { Der } p 1)^{18}$. This difference was not significant. Synthetic material is known to absorb moisture less than cotton 22. Therefore, it was expected that the material of the upper layer of the mattress might influence Der p 1 levels. In addition, the differences in the concentration of Der $p 1$ might be caused by the differences in weave/texture of synthetic material compared to cotton material 12,21. The study by Siebers et al. showed that house dust mites did not penetrate a feather pillow cover and synthetic/cotton pillow cover. In contrast, all house dust mites penetrated a synthetic outer layer of the pillow. Moreover, the dust permeability of synthetic cover was much higher $(0.88 \%)$ than the dust permeability of the other materials $(0.07 \%$ for feather pillow cover and synthetic/cotton pillow cover). Feather pillow covers are usually made of cotton.

The concentration of HDM allergen found in this study was low. $41.8 \%$ of the mattresses contained allergy levels above $2 \mu \mathrm{g} / \mathrm{g}$. Relatively low concentrations of HDM allergen were also seen in other studies in the Netherlands 24,25 . On the other hand, occasionally, higher concentrations of HDM allergen are found, like approximately $5 \mu \mathrm{g} / \mathrm{g}$ Der $\mathrm{p} 1$ and Der $\mathrm{f} 1 \mathrm{in}$ the study of Terreehorst et al. ${ }^{26}$. The higher concentration HDM allergen found in the study by Terreehorst could also be a result of the additional analysis of concentration Der $f 1$. However, this concentration is still much lower than concentrations found in Australia and New Zealand. Results of studies in these countries indicate that the percentage of mattresses with HDM allergen levels above the sensitisation level is above ninety percent ${ }^{8,14}$. Different climate and other housing characteristics can contribute to large differences. For example, the study of Garrett (Australia) found that $97 \%$ of the bedrooms in their study had fitted carpet ${ }^{2}$. In our study, less than $31 \%$ of the population had fitted carpet in their bedrooms. A second reason why the concentration of HDM allergen is relatively low on mattresses might be the inclusion criteria of our trial. All participants had asthma. In a Dutch study on concentrations of HDM allergen found in homes of families with young children, the concentration of HDM allergen was significantly lower on the mattress surface of infants of atopic parents compared to infants of non-atopic parents ${ }^{27}$. In the present study, different humidity parameters were measured. Higher concentrations of Der $\mathrm{p} \mathbb{1}$ were found on mattresses in bedrooms of the high long-term levels of humidity (like condensation on the windows of the bedroom), were not associated with Der $p \mathbb{1}$ levels in this study. In contrast, other studies found a positive association between some of these parameters and Der $p 1$ levels on mattresses 8,10,13,14,18.20. Nonetheless, none of these results were significant. Moreover, no association was found between the level of HDM allergen on mattresses and age of mattress, bedroom carpet or use of Sheepskin. Other studies showed significant relations between Der $p 1$ levels and some of these variables $8,14,16,18,20$. Larger study populations and higher HDM allergen levels might 
explain why other studies did find relations between these factors and Der $p 1$ concentrations. An explanation for the higher concentration of Der $p 1$ in rooms with no carpet could not be given, although this is not the first study to find these results ${ }^{18}$.

Concentration of HDM allergen depends on the period of sampling. The concentration of Der $p 1$ was higher during autumn in this study although this result was not significant. It is generally known that HDM allergen levels are higher during autumn 28.29 .

In this study we looked for Der $p 1$ concentration on mattress surfaces. We did not consider the contribution of dust reservoirs present in other items of bedding. These undoubtedly add to the allergen pool in the bedroom environment. It seems that pillows and duvets contribute highly to the total allergen pool30-31. Most people sleep with their head closer to the pillow than to the mattress so the distance between allergens and airways is smaller. Therefore, the results on exposure to HDM allergien on the mattress might not be representative for the actual exposure to HDM allergen in bed. However, a study by Custovic and et al. 5 found a high correlation between HDM allergen levels on mattresses and bedding $(r=0.68$, $p<0.001$ ) while occasionally high HDM allergen levels in bedding were found in combination with low HDM allergen levels on mattresses and vice versa.

The findings of this study should be interpreted in the light of the limitations of the study like the cross sectional design. Moreover, the determination of the concentration of HDM allergen was just a random indication and varied widely in time. Also, it is possible that participants failed to fill in the correct type of mattress, which is difficult to retrieve, especially in older mattresses. Finally, the type of mattresses was divided into four categories in this study. There are two types of latex, which were combined in this study, namely natural latex and synthetic latex. However, no difference in concentration of HDM allergen was seen between these two groups ( $F=0.001, p=0.98$ ).

The most important finding of this study is the association between the type of upper layer of the mattress and the concentration of HDM allergens. We believe that more research is needed to confirm the results. If the results are confirmed by further research, choosing cotton material for mattresses and maybe even for pillows and duvets is a relatively easy and inexpensive way to lower the exposure to HDM allergens. 


\section{References}

1. Platts-Mils TAE, Vervoet $D$, Thomas WR, Aalberse RC, Chapman MD. Indoor allergens and asthma: report of the third international workshop. I Allergy Clin Immunol 1997:100(suppl):S1-24.

2. Garrett $M_{*}$ Hooper $B$, Hooper M. Indoor environmental factors assaciated with housedust-mite allergen (Der $p$ 1) levels in south-eastern Australian houses. Allergy 1998;53:1060-5.

3. Marks B. Tovey E, Green W, Shearer M, Salome C, Woolcock A. The effect of changes in house dust mite allergen exposure on the severity of asthma. Clin Exp Allergy $1995: 25: 114-8$.

4. Marks GB, Tovey ER, Green W, Shearer M, Salome CM, Woolcock Al. House dust mite allergen avoidance: a randomized controlled trial of surface chemical treatment and encasement of bedding. Clin Exp Allergy 1994:24(11):1078-83.

5. Custovic $\mathrm{A}_{\text {y }}$ Taggart SCO, Francis HC, Chapman MD, Woodcock A. Exposure to house dust mite allergens and the climical activity of asthma. I Allergy ciln Immunol 1996;98:64-72.

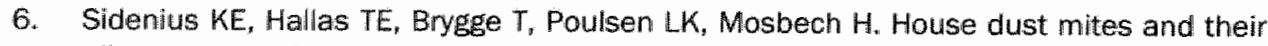
allergens at selected places of homes of house dust mite-allergic patients. Clin Exp Allergy 2002;32:1299-1304.

7. Abbott J, Cameron J. Taylor B. House dust mite counts in different types of mattresses, sheepskins and carpets, and comparison of brushing and vacuuming collection methods. Clin Allergy 1981;11:589-95.

8. Wickens $K$, Siebers $R$, Ellis I, Lewis $S$, Sawyer $G$, Tohill $S$, Stone L, Kent $R$, Kennedy $J$, Slater T. Crothall A, Trethowen H, Pearce N, Fitzharris P, Crane J. Determinants of house dust mite allergen in homes in Wellington, New Zealand. Clin Exp Allergy $1997 ; 27: 1077-85$.

9. Mosbech $H$, Jenssen A, Heinig J, Schou C. House dust mite on different types of mattresses. Clin Exp Allergy 1991;21:351-3.

10. Couper $D$, Ponsonby $L$. Dwyer $T$. Determinants of dust mite allergen concentrations in infant bedrooms in Tasmania. Clin Exp Allergy 1998;28:715-23.

11. Shei MA, Hessen JO, Lund E. House-dust mites and mattresses. Allergy $2002: 57: 538$ w 42.

12. Siebers $R$, Nam HS, Crane J. Permeability of synthetic and feather pillows to live house dust mites and house dust. Clin Exp Aliergy 2004;34:888-90

13. Arbes $S J$, Cohn RD, Yin M, Mullenberg ML, Burge HA, Friedman $W$, Zeldin DC. House dust mite allergen in US beds: results from the first national survey of lead and allergens in housing. $J$ Alkergy Clin Immunol 2003;111:408-14.

14. Dharmage $S$, Bailey $M$, Raven J. Cheng $A$, Rolland $J$, Thien $F$, et al. Residential characteristics influence Der p 1 levels in homes in Melbourne, Australia. Clin Exp

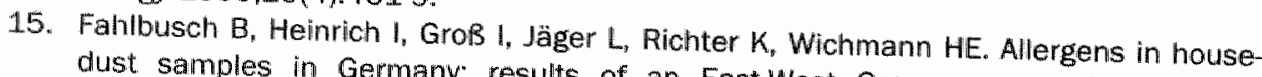
dust samples in Germany: results of an East-West German comparison. Allergy

16. Matheson MC, Dharmage SC, Forbes AB, Raven JM, Woods RK, Thien FCK, Guest DI, Rolland JM, Haydn Waiters $E$, Abramson MJ. Residential characteristics predict changes in Der p 1. Fel d 1 and ergosterol but not fungi over time. Clin Exp Allergy
$2003 ; 33: 1281-8$. 
17. Kuehr J, Frischer T, Karmaus $W_{*}$ Meinert $R_{\text {, B }}$ Barth R, Schraub S, Daschner A, Urbanek $\mathrm{R}_{\mathrm{v}}$ Forster J. Natural variation in mite antigen density in house dust and relationship to residential factors. Clin Exp Allergy 1994;24(3):207-9.

18. Mihrshahi $\mathrm{S}$, Marks $\mathrm{G}$, Vanlaar $\mathrm{C}$, Tovey $\mathrm{E}$, Peat J. Predictors of high house dust mite allergen concentrations in residential homes in Sydney. Allergy 2002;57:137-42.

19. Simpson $A$, Simpson $B$, Custovic $A$, Cain $G$, Craven $M$, Woodcock $A$. Household characteristics and mite allergen levels in Manchester, UK. Clin Exp Allergy,32:1413-9.

20. Vanlaar $\mathrm{CH}$, Downs CH, Mitakakis $\mathrm{TZ}$, Leuppi JD, Car NG, Peat JK, Marks GB. Predictors of house-dust-mite allergen concentrations in dry regions in Australia. Allergy 2001;56:1211-5

21. Siebers $R$, Fitzharris $P$, Crane J. Feather bedding and allergic disease in children: a cover story? Clin Exp Allergy 2002;32:1119-23.

22. Consumentenbond. Mattresses (matrassen) Consumentengids 1999;0ctober. (Available at: http://www.consumentenbond.nl).

23. Flannery $E$, Herbison G, Hewitt $C$, Holdaway M, Jones D, Sears M. Sheepskins and bedding in childhood, and the risk of development of bronchial asthma. Aust NZ J Med $1994: 24: 687-92$

24. Strien RT van, Koopman LP, Kerkhof $M$, Oldenwening $M$, Jongste JC de, Gerritsen $J$, Neijens HJ, Aalberse RC, Smit HA, Brunekreef B. Mattress encasement and mite allergen levels in the prevalence and incidence of asthma and mile allergy study. Clin Exp Allergy 2003;33:490-5.

25. Cloosterman SGM, Schermer TRJ, Bijl-Hofland $\mathrm{ID}_{\text {, }}$ Heide $S$ van der, Birunekreef $B$, Elshout FJJ van den, Herwaarden CLA van, Schayck CP wan. Effects of house-dust mite avoidance measures on Der p 1 concentrations and clinical condition of mild adult house-dust mite-allergic asthmatic patients, using no inhaled steroids. Clin Exp Allergy 1999;29:1336-46.

26. Terreehorst I, Hak E, Oosting AJ, Tempels-Pawlica Z, Monchy JGR de, Bruijnzeel-Koomen CAFM, Aalberse RC, Wijk RG van. Evaluation of impermeable covers for bedding in patients with allergic rhinitis. N Engl I Med 2003;349:237-46.

27. Strien RT van, Verhoeff AP, Wijnen $\mathrm{JH}$ van, Doekes $\mathrm{G}$, Meer GEA de, Brunekreef B. Der $p$ 1 concentrations in mattress surface and floor dust collected from infants' bedrooms. Clin Exp Allergy 1995;25:1184-9.

28. Chew GL, Higgins KM. Gold DR, Muiltenberg ML. Burge HA. Monthly measurements of indoor allergens and the influence of housing type in a northeastern US city. Allergy 1999;54:1058-66.

29. Heide $S$ van der, Monchy $J G$ de, Vries $K$ de, Bruggink TM, Kauffman HF. Seasonal variation in airway hyperresponsiveness and natural exposure to house dust mite allergens in patients with asthma. $J$ Allergy Clin Immunol 1994;93(2):470-5.

30. Kemp TJ, Siebers RW, Fishwick D, O'Grady GB, Fitzharris P, Crane J. House dust mite allergen in pillows. Br Med J 1996;313:916.

31. Hegarty JM, Jessop WJ, Warner JA, Warner JO. The effect of a bed covering system on airborne levels of house dust mite allergen. Allergy 1993;16:suppl abstract 2050:108. 


\section{Chapter 4}

\section{Factors associated with asthma control}

MP de Vries, L van den Bemt, S Lince, JWM Muris, BPA Thoonen, CP van Schayck Journal of Asthma, 2005;42:659-665 


\section{Abstract}

Mim

The aim of this study was to evaluate which factors are associated with asthma control experienced by asthma patients.

\section{Methods}

In a cross-sectional study patients aged $16-60$ years with mild to moderate asthma were selected. The influence of the following factors on asthma control was studied in a multivariate model: age, gender, socioeconomic status (SES), smoking perceived hyperresponsiveness (PHR, responding with asthma symptoms to one or more triggers), allergy (phadiatop), long-acting bronchodilating agents (LABA) and inhaled corticosteroids (ICS). Asthma control was measured by means of the Asthma Control Questionnaire (ACQ) as developed by Juniper. Forced expiratory volume in 1 second ( $F E V_{1}$ ) was measured by means of a portable spirometer.

\section{Results}

In this study with 311 patients, mean ACQ score was 1.39 (range 0-4.43). A stepwise backward linear regression analysis showed that low SES (beta $=0.425 ; p=0.001$ ), current smoking (beta $=0.555 ; p<0.001$ ), high dose of ICS (beta $=0.364 ; p=0.04$ ) and PHR for increasing number of different triggers (PHR for 1 trigger beta $=0.833 ; p=0.03 ; 2$ triggers beta $=0.810 ; p=0.03 ; 3$ triggers beta $=0.995 ; p=0.01 ; 4$ triggers beta $=1.131 ; p=0.002 ; 5$ triggers beta $=1.182 ; p=0.002$ ) are independent predictors for poorer asthma control.

\section{Conclusion}

Beside treatment with medication, stopping smoking and avoidance of triggers are factors, which may have a high impact on asthma control. 


\section{Introduction}

According to international asthma guidelines ${ }^{14}$, the primary goal of asthma treatment is optimal asthma control. Optimal control can be characterised by minimisation of chronic asthma symptoms during day and night, prevention of asthma exacerbations, maintaining normal activity levels, optimising lung function, reducing the need for relieving $\beta_{2}$-agonist therapy, and minimising side effects of medication. Optimal control contributes to a reduction of the risk of life threatening exacerbations and long-term morbidity. Optimal asthma control can be achieved through preventive measures and maintenance therapy with inhaled corticosteroids (ICS) and long-acting bronchodilating agents (LABA). Optimal asthma control is the goal for all degrees of asthma severity. Asthma severity is defined by factors including frequency and duration of symptoms, degree of airflow limitation, and the dose of medication required to maintain acceptable control 4,5 . Although there is a clear distinction between the concepts of asthma control and asthma severity, these concepts are still confused sometimes.

Improving disease control leads to significant cost reduction, because the costs of asthma are largely due to uncontrolled disease ${ }^{6}$. The main costs of uncontrolled disease are costs of hospitalisation and absence from work or school. Therefore, not only do patients benefit but also society as a whole can profit from better asthma control.

A survey in several European countries demonstrated that asthma control was not optimal in many patients; overall, only $5.3 \%$ of all patients met all the criteria for asthma control ${ }^{7}$.

Since the publication of the Asthma Control Questionnaire $(A C Q)^{8}$, a vallidated instrument for measuring asthma control is available. The ACQ integrates different aspects of asthma control in one instrument. This questionnaire contains questions about asthma symptom severity (wheezing, shortness of breath, waking up at night, limitation of daily activities, and symptom severity in the morning), bronchodilator use, and lung function (see Appendix B on page 133).

In the past, several factors have been identified as individually associated with asthma control. The relationship between sensitivity to indoor allergens and asthma severity was investigated ${ }^{9}$. All patients with severe asthma were sensitised to at least one allergen compared to $54 \%$ of the subjects with mild asthma. Moreover, $71 \%$ of the severe asthmatics showed multiple sensitisations to mite, cat, and dog allergen, in contrast to only $4 \%$ of the subjects with mild asthma. Other studies showed that lower income class and lower social class were associated with poor asthma control and higher rates of hospitalisation due to asthma10.11. Some studies show that current smokers have a higher frequency of bothersome asthma symptoms, asthma attacks and a higher asthma severity score than nonsmokers ${ }^{11-13}$. However, little is known about the extent of interaction of these factors regarding asthma control. Recently, a large study about gaining 
asthma control also subscribes to the importance of analysis of factors associated with asthma control ${ }^{14}$.

A better insight in the relative importance of factors influencing asthma control may help to target preventive measures more efficiently, to those factors that have the greatest impact on disease control.

The objective of this study was to evaluate which factors are associated with asthma control by using a standardized method to measure asthma control (ACQ), and to evaluate the relative importance of these factors when combined in a multivariate model.

\section{Methods}

\section{Subjects}

In this cross-sectional study, factors influencing asthma control were explored. Asthma patients in the south-eastern part of the Netherlands were enrolled from registration networks of general practitioners (GPs) and by means of an open recruitment through advertisements in the local press. Patients who were willing to participate were screened on inclusion and exclusion criteria.

Inclusion criteria were age between 16 and 60 years, a GP-based diagnosis of asthma and requirement of ICS. The latter was defined according to Dutch GP. practice guidelines for the treatment of asthma ${ }^{15}$, comparable with international guidelines as GINA ${ }^{16}$.

Exclusion criteria were serious diseases other than asthma with a low survival rate; other diseases that influence bronchial symptoms and/or lung function, having had an exacerbation during a period of 1 month before the start of the study, and the use of oral steroids or inhaled cromoglycates. Patients already using house dust mite impermeable mattress and bedding covers were exclunded because of the fact this study was part of a larger trial.

The study was approved by the local Medical Ethical Committee. All patients agreed by written informed consent to participate in the study.

\section{Independent variables}

The influence of the following variables was studied: age. gender, socio-economic status (SES), smoking, perceived hyperresponsiveness (PHR), allergy, long-acting bronchodilating agents (LABA), and inhaled corticosteroids (ICS). A questionnaire was used to identify educational and employment level, current and past smoking habits, and perceived hyperresponsiveness (PHR). SES was derived from educational and employment level. Both educational level and employment level were divided into the categories low, middle, and high. SES was calculated as the mean of employment and educational level and also divided into the categories of 
low, middle, and high. Smoking was defined as current smoking, ex smoking, or never smoking. PHR was defined as responding with asthma symptoms to one or more of the following five triggers: changes in weather circumstances, humidity in the house, open fireplace, strong odours, and exercise. A Phadiatop test, specific Immunoglabulin $E$ ( $(\mathrm{gE})$ to a group of common aeroallergens, was carried out to determine allergy. If positive, radio-allergo-sorbent tests (RASTs) were done for specific IgE for grasses, pollen, house dust mite, cat, and dog. IgE levels below $0.35 \mathrm{kU} / \|$ (class 0 ) were considered to be negative. Asthma medication use during the past year was recorded. The usage of ICS was defined in the following categories: none, low dosage $(<400 \mu \mathrm{g}$ ), intermediate dosage (from 400 till $800 \mu \mathrm{g})$ and high dosage ( $\geq 800 \mu \mathrm{g})$. The use of LABA was defined as current use or not. Total amount of daily used ICS was calculated as the amount of ICS per dose (iin micrograms) times the total number of puffs used a day. Dose equivalents for different types of ICS and delivery devices were calculated. For the calculations, the dosage of a dry powder inhaler was halved to obtain equipotent dosages with metered dose inhalers ${ }^{17}$.

\section{Dependent variable}

Asthma control was measured by means of the Asthma Control Questionnaire $(\mathrm{ACQ})^{8}$. In Appendix B on page 133 an example of the ACQ is shown. Patients had to answer five questions about experienced symptoms during the past week. Furthermore, a question was asked about the use of short-acting $\beta_{2}$-agonists during the same period. The last item included the score of forced expiratory volume in 1 second $\left(F E V_{1}\right) \%$ predicted. $F E V_{1}$ was measured by means of a portable spirometer (Microloop II) at a lung function laboratory, and then the FEV $\%$ predicted was calculated. This FEV 1 score is divided into the following categories: $>95 \%, 90-95 \%, 80-89 \%, 70-79 \%, 60-69 \%, 50-59 \%$ and $<50 \%$. All questions were scored on a 7 -point scale from 0 to 6 . All items were equally weighted. The overall score was the mean of the seven responses, ranging from 0 (well-controlled asthma) to 6 (extremely poorly controlled asthma).

\section{Statistical analysis}

Mean ACQ score and standard deviation were calculated for the study population. For the categorical variables, one category was used as reference: for SES this was high SES, for PHR it was zero triggers, for ICS it was $0 \mu \mathrm{g}$, and for smoking it was never smoking.

Conditions for linearity were fulfilled. Linear regression analyses were performed for every independent variable to establish which independent variables showed an association with the total ACQ score Interaction between smoking, PHR, LABA and ICS dosage was taken into account. Variables with a $p$-value $<0.10$ were introduced in a stepwise backward linear regression model. In the multivariate model, variables with a $p$-value $<0.05$ were retained in the final model. 
Statistical analyses were performed with SPSS for Windows, Version 10.0 (SPSS, Inc. Chicago, (II.).

\section{Results}

Three hundred nineteen patients were enrolled in this study; 138 patients were selected from 18 GP practices, and 181 patients were selected by open recruitment. Eight patients dropped out because they falled to complete all questions of the $A C Q$, so their $A C Q$ score could not be calculated. Finally, the results of 311 patients were analysed.

Table 4.1 shows the patient characteristics.

Tablo 4.1 Patient characteristics $(n-311)$.

\begin{tabular}{|c|c|c|}
\hline Gender & & $148(47.6 \%)$ male \\
\hline Age & & 43.3 yrs SD 12.2 \\
\hline \multirow[t]{4}{*}{ Socio-economic status: } & low & $115(37.0 \%)$ \\
\hline & middle & $109(35.0 \%)$ \\
\hline & high & $80(25.7 \%)$ \\
\hline & missing & $7(2.3 \%)$ \\
\hline FEV $\%$ predicted & & $88.9 \%$ SD 20.4 \\
\hline \multirow[t]{3}{*}{ Current use of LABA: } & yes & $69(22.2 \%)$ \\
\hline & no & $(73.0 \%)$ \\
\hline & missing & $15(4.8 \%)$ \\
\hline \multicolumn{3}{|l|}{ Current use of ICS } \\
\hline & low dose & $28.3(90.9 \%)$ \\
\hline & Intermediate dose & $88(28.3 \%)$ \\
\hline & high dose & $108(34.7 \%)$ \\
\hline & milssing & $59(19.0 \%)$ \\
\hline & & $28(8.9 \%)$ \\
\hline \multirow[t]{4}{*}{ Smoking: } & never & $(43.4 \%)$ \\
\hline & ex & $121(38.9 \%)$ \\
\hline & current & $51(16.4 \%)$ \\
\hline & missing & $4(1.3 \%)$ \\
\hline Phadiatop (positive) & & $195(62.7 \%)$ \\
\hline \multicolumn{3}{|c|}{ Perceived hyperresponsiveness } \\
\hline & 0 triggers & $6(1.9 \%)$ \\
\hline & 1 trigger & $26(8.4 \%)$ \\
\hline & 2 triggers & $63(20.3 \%)$ \\
\hline & 3 triggers & $76(24.4 \%)$ \\
\hline & 4 triggers & $89(28.6 \%)$ \\
\hline & 5 triggers & $44(14.1 \%)$ \\
\hline & missing & $7(2.3 \%)$ \\
\hline
\end{tabular}


Mean score of the ACQ was 1.39 (range 0-4.43). Median amount of triggers for which patients reported hyperresponsiveness was 3 .

Figure 4.1-4.4 show the mean ACQ score and $95 \%$ confidence intervals (CI) for each category of the variables SES, smoking, PHR, and ICS. Asthma control was decreasing with decreasing SES. It was similar in previous smokers and patients who have never smoked $(p=0.53)$; current smokers had a worse asthma control $(p<0.001)$. It was decreasing with PHR for increasing number of triggers and with increasing dose of ICS.

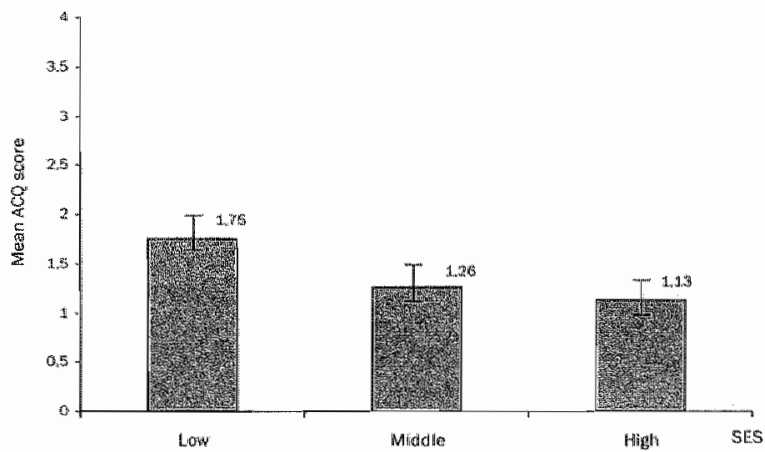

Figtire 4. 1. Mean ACQ score and 95\% Cl for socio-economic status.

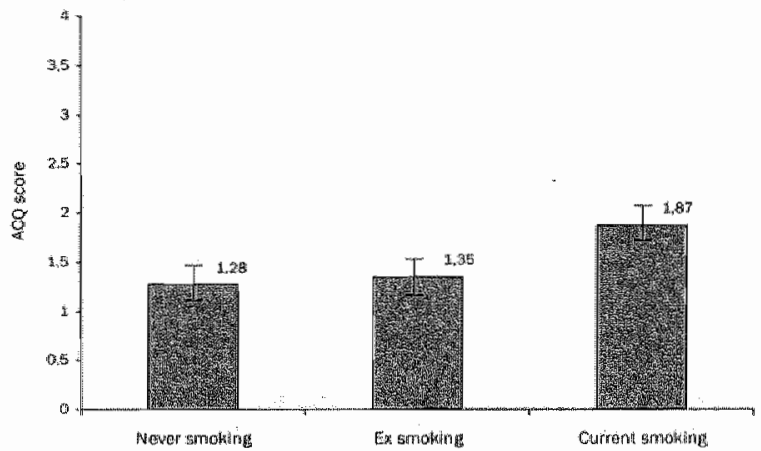

Figure 4.2 Meam ACQ score and $95 \%$ ol for smoking status.

The results of the univariate regression analyses of the independent variables showed a significant effect of all tested variables but gender; age $(p=0.04)^{\text {; }}$ gender $(p=0.53)$; allergy $(p=0.03)$, SES ( $p<0.001)$; smoking $(p<0.001)$; PHR ( $p<0.001)$ $\angle A B A(p=0.01)$ and ICS $(p=0.01)$. The following variables were introduced in a multivariate linear regression model: age, SES, smoking, PHR, allergy, LABA, and ICS. There was no significant interaction between smoking, PHR, LABA, and ICS. 


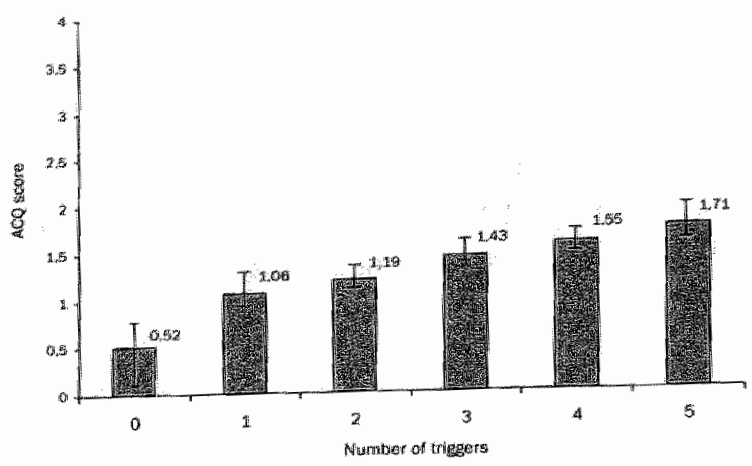

Figure 4.3 Mean ACQ score and $95 \%$ ol for number of triggers for which hyperresponsiveness is perceived by patients.

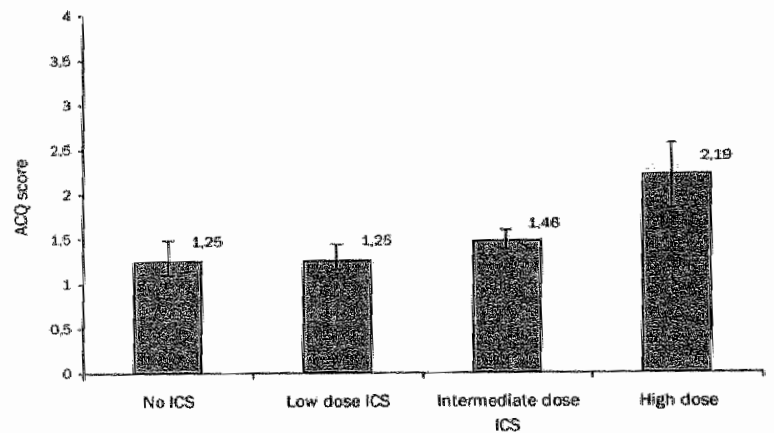

Figure 4.4 Mean ACQ-score and $95 \%$ Cl for dose of inhaled corticosteroids.

In Table 4.2, the B-coefficients and p-values of the independent variables found in the multiple regression model are shown.

Table 4.2 also shows that PHR for multiple triggers, current smoking, low SES, and high dose of ICS are associated with a higher ACQ score and, therefore, with poorer asthma control. 
Table 42 Bicoefficients and p-values of the independent variables found in the multiple regression model.

\begin{tabular}{lccc}
\hline Variable & B-coefficient & $95 \% \mathrm{Cl}$ & p-value \\
\hline Constant $\alpha$ & 0.078 & $-0.64-0.80$ & 0.83 \\
SES low & 0.425 & $0.18-0.67$ & 0.001 \\
SES middle & 0.063 & $-0.17-0.30$ & 0.60 \\
Ex smoking & 0.061 & $-0.14-0.26$ & 0.54 \\
Current smoking & 0.555 & $0.27-0.84$ & $<0.001$ \\
ICS low & 0.054 & $-0.39-0.28$ & 0.75 \\
ICS intermediate & 0.031 & $-0.36-0.29$ & 0.85 \\
ICS high & 0.364 & $0.01-0.71$ & 0.04 \\
PHR 1 positive & 0.833 & $0.06-1.60$ & 0.03 \\
PHR 2 positive & 0.810 & $0.08-1.54$ & 0.03 \\
PHR 3 positive & 0.995 & $0.27-1.72$ & 0.01 \\
PHR 4 positive & 1.131 & $0.41-1.86$ & 0.002 \\
PHR 5 positive & 1.182 & $0.43-1.94$ & 0.002 \\
\hline
\end{tabular}

\section{Discussion}

In this study different factors that are probably associated with asthma control have been investigated. Low SES, current smoking, high dose of ICS, and perceived hyperresponsiveness for multiple triggers were independently associated with poorer asthma control. Age, gender, allergy, and LABA did not show an association with asthma control in the multivariate model. These findings are consistent with other studies investigating the influence of SES ${ }^{10,11}$, smoking ${ }^{12,13}$, and bronchial hyperresponsiveness ${ }^{18}$ on asthma symptoms and asthma control.

Lin and colleagues ${ }^{10}$ demonstrated that rates of hospitalisation because of asthma were generally higher among the unemployed, poorly educated residents of New York in the lowest income classes. Connolly et al. ${ }^{11}$ also showed that poor asthma control was strongly associated with lower social class. In that study, asthma control was assessed by means of the actual and maximum peak flow. His study also indicated that current smoking had a strong negative effect on the control of asthma. This is consistent with results from other studies ${ }^{12,13}$, showing that current smokers have a higher frequency of bothersome asthma symptoms, asthma attacks, and a higher asthma severity score than non-smokers. These studies investigated only individual factors; in the present study, they were combined in a multivariate model.

An association between asthma control and PHR, defined as responding with asthma symptoms to triggers, was demonstrated in the present study. This association, however, is not unexpected. Patients with a poorer asthma control are 
more mey to tespond with symptoms when exposed to triggers. On the other hand, whentwe have an hreased airway responsiveness exposure to triggers can again lead to symptoms and, therefore, worse asthma control ${ }^{19}$. Both administering medcavin and reducing exposure to triggers can improve asthma control. There Wight even be a synergistic effect if these two approaches are combined. This should be westigated in further research.

Hyperresponsiveness was not an objective measurement in this study. Patients were asked about expenenced symptoms when exposed to certain triggers. Brooks et showed that there is a significant correlation between airway hyperreactivity measured by means of a questionnaire and metacholin challenge test. In this study. we did not perform histamine provocation tests. Because asthma control comprises control experienced by patients, we were interested in the hyperresponsiveness perceived by patients. Patients seem to be capable of perceiving well to which triggers they respond, which is an important aspect of history taking. There is a clear dose-response relation between the number of riggers to which patients respond and the extent of asthma control.

The ACQ contains questions about specific symptoms during night and wake up, wheteas the questionnaire about perceived hyperresponsiveness asks whether patients respond with symptoms when being exposed to specific triggers. So there is a clear distinction between the questions in the ACQ and the questionnaire on percekved hyperresponsiveness and, therefore, the risk of collinearity seems Imited.

This study showed an association between high dosage of ICS and poorer asthma control. Patients with a more severe asthma are often prescribed a higher dose of $1 \mathrm{CS}$, but this does not necessarily lead to a better asthma control. It could be that patients are using higher doses of ICS because of their poorer asthma control. In patients who are using high dose ICS, adding for example LABA might lead to a better asthma control than raising the dosage of the ICS. Several studies have now clearly shown that the addition of LABA to IOW to moderate dose ICS Improves lung function, decreases symptoms, and lowers the number of exacerbations 2123 . In the present study, the group that was using LABA had a slightly worse mean asthma control compared to the group that was not using this medication (1.64 vs. 1.33). In the multivariate model, LABA appeared not to be associated with asthma
control.

In our study, allergy did not appear to be associated with asthma control. A possible explanation is that the exposure to allergens is not taken into account. Exposure to grasses and pollen, for instance, are subject to seasonal influences. The RASTs we performed for grasses and pollen consist of a group of allergens, and patients with an allergy for cats or dogs might not be exposed to these allergens at all. We have no appropriate information on the actual exposure of our patients to the specific allergens. Another explanation could be that patients who were already using house dust mite impermeable bedcovers were excluded. This 
could affect the possible association between asthma control and allergy. It might be possible that patients with many complaints from their house dust mite allergy are already using the covers and were excluded from participation in the present study.

Tunnicliffe et al. ${ }^{9}$ demonstrated that severe asthma was associated with clearly more sensitisation to one or multiple allergens than mild asthma. This study did not investigate a possible association with asthma control.

Exsmokers had an asthma control that was comparable to patients who had never smoked, whereas current smokers showed a poorer asthma control. The duration of quitting was not taken into account. It might be interesting to investigate how long it takes before patients who quit smokking have reached the level of asthma control that never smokers have. According to literature, current cigarette smoking might impair the effect of treatment with $\mathrm{CSS}^{24}$. However, in the present study there was no significant interaction between smoking and ICS.

In the present study, patients with mild to moderate persistent asthma were included. The goal of treatment for all degrees of asthma severity is optimal asthma control ${ }^{1-4}$. The mean ACQ score was 1.39; this is a rather low score, most patients were quite well controlled, because a score of 0 means well-controlled disease. However, the range was from 0 to 4.43 , meaning there were also patients with uncontrolled disease.

Because this study was cross-sectional in design, only associations could be demonstrated. To prove causal relationships longitudinal studies should be performed.

The ACQ is easy to use in daily practice, particularly since more and more practices possess spirometers to measure $F E V_{1}$ and the $A C Q$ only takes a few minutes to complete. Physicians should be aware of the fact that patients with a lower socioeconomic status, which are currently smoking, using high dose of inhaled corticosterolds and/or perceiving hyperresponsiveness for multiple triggers are prone to poorer asthma control. The findings from our study suggest that asthma management should not only aim at prescribing medication. Stop smoking and the avoildance of triggers are also factors, which may have a high impact on asthma management. Thus, our findings support the current understanding that a combined approach, which integrates both medical and behavioural elements (e.g., stop smoking and reduce exposure to triggers), is needed to optimise asthma control. 


\section{References}

1. U.S. Department of Health and Human Services, Public Health Service National Institutes of Health, National Heart $L$, and Blood Institute. Practical Guide for the Diagnosis and Management of Asthma. Based on the Expert Panel Report 2: guidelimes for the Diagnosis and Management of Asthma. NH Publication 1997(No. 97-4053): $1-52$.

2. Society BT. The British Guidelines on Asthma Management 1995 Review and Position Statement. Thorax 1997;52(Supplement 1):S1-S21.

3. Society BT. Guidelines for management of asthma in adults: 1 - chronic persistent asthma. Br Med J 1990;301:651-3.

4. D'urzo A. Controlling asthma, Highlights of the 1999 Canadian Asthma Consensus Repart. Canadian Family Physician 2000;46:895-8.

5. Cockcioft D, Swystun V. Asthma control versus asthma severity. I Allergy Clin Immunol 1996;98(6 part 1):10168.

6. Barnes $P_{y}$ Jonsson B, Klim J. The costs of asthma. Eur Respir J 1996;9(4):636-42.

7. Rabe KF, Vermeire PA, Soriano JB, Maier WC. Clinical management of asthma in 1999: the Asthma Insights and Reality in Europe (AIRE) study. Eur Respir $/ 2000 ; 16(5): 802-7$.

8. Juniper EF, OByrne PM, Guyatt GH, Ferrie PJ, King DR. Development and validation of a questionnaire to measure asthma control. Eur Respir / 1999;14(4):902-7.

9. Tunnicliffe W, Fletcher $T$, Hammond $K$, Roberts $K$, Custovic $A$, Simpson $A$, et al. Sensitivity and exposure to indoor allergens in adults with differing asthma severity. Eur Respir 1 1999;13:654 9.

10. Lin $S$, Fitzgerald $E$, Hwang SA, Munsie JP, Stark A. Asthma hospitalization rates and socioeconomic status in New York State (1987-1993). J Asthma 1999;36(3):239-51.

11. Connolly $\mathrm{C}$, Chan $\mathrm{N}$, Prescott $\mathrm{R}$. The influence of social factors on the control of asthma. Postgrad Med' 1989;65:282-5.

12. Siroux V, Pin I, Oryszczyn M, Moual Le N, Kauffmann F. Relationships of active smoking to asthma and asthma severity in the EGEA study. Epidemiologicall study on the Genetics and Environment of Asthma. Eur Respir J 2000;15:470-7.

13. Althuis $M D$, Sexton $M$, Prybylski $D$. Cigarette smoking and asthma symptom severity among adult asthmatics. J Asthma 1999;36(3):257-64.

14. Bateman ED, Boushey HA, Bousquet J, Busse WW, Clark TJ, Pauwels RA, et al. Can Guideline-defined Asthma Control be Achieved? The Gaining Optimal Asthma ControL Study. Am J Respir Crit Care Med 2004:170:836m44.

15. Geljer RMM, Van Hensbergen W, Bottema BJAM, Van Schayck CP, Sachs APE, Smeele UM, et al. NHG-Standaard Astma bij Volwassenen: Behandeling (NHG Guideline on Asthma in Adults: Treatment). Huisarts Wet 2001:44(4):153-64.

16. Anonymous. Globall Initiative for Asthma: pocket guide for asthma management and prevention. Report No. 95-36598. Bethesda, MD: National Institutes of Health, National Heart Lung and Blood Institute, 1998.

17. Lipworth BJ. Pharmacokinetics of inhaled dirugs. Br I Clin Pharmacol 1996;42(6): $697-705$.

18. Groll MH, Gerritsen J, Vonk JM, Schouten JP, Koeter GJ, Rijcken $B$, et al. Risk factor for growth and decline of lung function in asthmatic individuals up to age 42 years. A 30 year Follow-up Study. Am J. Respir Crit Care Med 1999;160:1830-7.

19. Juniper EF, Frith PA, Hargreave FE. Airway responsiveness to histamine and methacholine: relationship to minimum treatment to control symptoms of asthma Thorax 1981;36(8):575-9. 
20. Brooks SM, Bernstein IL, Raghuprasad PK, Maccia CA, Mieczkowskil L. Assessment of airway hyperresponsiveness in chronic stable asthma. J Allergy Clin Immunol 1990; 85(1 Pt 1):17-26.

21. Pauwels $R$, Löfdahl $C_{1}$ Postma $D$, Tattersfield $A$, OByrne $P$, Barnes $P$, et al. Effect of inhaled formoterol and budesonide on exacerbations of asthma. New Engl $/$ Med 1997; $337(20): 1405-11$.

22. Shrewsbury $S$, Pyke $S$, Britton $M$. Meta-analysis of increased dose of inhaled steroid or addition of salmeterol in symptomatic asthma (MIASMA). Br Med J 2000;320:1368-73.

23. Matz M, Emmett A, Rickard K, Kalberg C. Addition of salmeterol to low-dose fluticasone versus higher-dose fluticasone: An analysis of asthma exacerbations, J Allergy Clin Immunol 2001;107(5):783-9.

24. Chalmers GW, Macleod KJ, Little SA, Thomson $U$, MoSharry CP, Thomson NC. Influence of cigarette smoking on inhaled corticosteroid treatment in mild asthma. Thorax $2002 ; 57(3): 226-30$. 


\section{Chapter 5}

\section{Asthma control in patients with different severity degrees of asthma in primary care and the effect of a self-management plan on asthma control}

MP de Vries, BPA Thoonen, JWM Muris, L wan den Bemt, CP van Schayck 


\title{
Abstract
}

\begin{abstract}
Aim
The objective of this observational study was to explore the level of asthma control for different severity categories of asthma in a primary care population of asthma patients and to evaluate which patients" benefits most from using a self-management plan.
\end{abstract}

\section{Methods}

Asthma severity was determined by means of dose of inhaled corticosteroids (ICS), current use of long-acting bronchodilating agents and forced expiratory valume in one-second (FEV 1 ) percentage of predicted. Asthma control was measured by means of the five items Asthma Control Questionnalre. Patients were trained to use a self-management plan to adjust the dose of ICS to symptoms and peak expiratory flow (PEF) value.

\section{Results}

67 patients were included. Baseline asthma control score was good in all severity categories imean asthma control score in mild persistent: 0.54 ; moderate: 0.96 ; severe: 1.61; ANOVA $p=0.001$, asthma control score on a scale from 0 , well controlled through 6 , extremely poor controlled). After one year of self-management asthma control was maintained in the mild persistent group and was improved in the other patients (mill persistent: 0.58 ; moderate: 0.71 ; severe: 1.27 ; ANOVA $p=0.014$ )

\section{Conclusion}

Asthma control was adequate in patients with persistent asthma. A self-management plan might to be able to maintain or improve asthma control in this type of patients, especially in patients with severe persistent asthma. 


\section{Introduction}

In the management of asthma, severity and control play an important role. Asthma severity is a diagnostic feature, whereas asthma control is an important outcome for disease management. However, severity and control are interrelated and this can cause confusion. At the moment, there is an ongoing discussion whether the treatment steps, which are advised in guidelines, should be severity-based or control-based.

Asthma severity has been defined by a combination of symptoms, medication requirements, physiologic abnormalities and morbidity ${ }^{1}$. Ideally, severity is defined before the use of medication. If patients are receiving anti-inflammatory medication, the dose of inhaled corticosteroids (ICS) or the need for oral corticosteroids also determines the level of severity. Severity is categorised as follows: intermittent, mild persistent, moderate persistent and severe persistent. Asthma severity can change over time.

Several guidelines state the importance of categorising asthma severity adequately ${ }^{1-3}$. It has implications for starting the right treatment according to the stepwise pharmacological approach. It also enables health care professionals to recognise patients at risk for fatal episodes and hospitalisations.

Optimal asthma control is the primary goal of asthma treatment according to international asthma guidelines ${ }^{1.3}$. Optimal control can be characterised by minimisation of chronic asthma symptoms during day and night, prevention of asthma exacerbations, maintaining normal activity levels, optimising lung function, reducing the need for relieving $\beta_{2}$-agonist therapy, and minimising side effects of medication.

A recent survey showed that asthma control was poor in several European countries, among which the Netherlands ${ }^{4,5}$. In this survey, patients were asked by telephone if they were being treated for asthma. The question rises if this sample taken from the general population is similar to a sample enrolled from general practices. There seems to be a clear difference between physician-diagnosed and self-reported asthma by patients ${ }^{6}$. However, a study in the Netherlands showed that asthma control in general practice was not adequate as well ${ }^{7}$. We know of no studies that assess whether the degree of asthma control is equal for the different severity categories.

In a recent study, it was demonstrated that total asthma control could be achieved, following a physician-driven step-up dose regimen ${ }^{8}$. Another study showed that adjustable maintenance dosing with a combination inhaler provided better asthma control compared with fixed dose combination inhaler. Additionally selfmanagement or written action plans are proposed in several guidelines in order to optimise asthma outcomes ${ }^{2.3}$. Self-management plans have the advantage of incorporating both individual patient-defined goals as well as the physician's goal to achieve total asthma control into one disease management strategy. As such, 
self-management plans have demonstrated to lead to improved health outcomes and disease control10-12. However, which asthma patients benefit most from selfmanagement plans is not yet clear.

The objective of this observational study was to explore the level of asthma control for the different severity categories of persistent asthma in patients, treated for asthma by their general practitioner (GP) and to evaluate in which severity category of patients using a self-management plan, asthma control improves the most.

\section{Methods}

\section{Subjects}

Patients with persistent asthma between 16 and 60 years old, primarily treated by general practitioners (GPS), living in the south-eastem part of the Netherlands were invited to participate in this study.

The study was approved by the local Medical Ethical Committee. All patients agreed by written informed consent to participate in the study.

\section{Asthma Severity}

As all patients were treated already by their GP, asthma severity was determined by means of dose of ICS taken, current use of long-acting bronchodilating agents (LABA) and forced expiratory volume in one second ( $\left.F E V_{1}\right)$ percentage of predicted. The usage of ICS was defined in the following categories: low dosage ( $<400 \mu \mathrm{g})$, intermediate dosage (from 400 until $800 \mu \mathrm{g}$ ) and high dosage $(\geq 800 \mu \mathrm{g}$ ). Total amount of daily used ICS was calculated as the amount of ICS per dose (in $\mu g$ ) times the total number of puffs used a day. Dose equivalents for different drug molecules of ICS and delivery devices were calculated. For the calculations the dosage of metered dose inhalers was doubled to obtain equipotent dosages with a dry powder inhaler13.

The use of LABA was registered as current use or not.

FEV 1 was measured by means of a Microloop II spirometer at a lung function llaboratory.

Patients were divided into one of the following categories: mild persistent, moderate persistent, and severe persistent, according to GINA guidelines?2.

\section{Asthma Control}

Asthma control was measured by means of the Asthma Control Questionnaire $(A C Q)^{14}$. In Appendix B on page 133 an example of the ACQ is shown. Since omission of the items FEV 1 and use of $\beta_{2}$-agonists has shown not to alter the validity or measurement properties of the questionnaire, we decided only to use the five items version of the $A C Q$ in order to calculate an asthma control score ${ }^{15}$. 
This reduces the risk of collinearity between severity and control and control can still be measured in a rellable manner.

Patients had to answer five questions about experienced symptoms during the past week. All questions were scored on a 7 -point scale from 0 to 6 . All items were equally weighted. The overall score was the mean of the five responses, ranging from 0 (well-controlled asthma) to 6 (extremely poorly controlled asthma).

The difference in asthma control was calculated as asthma control score at one year minus asthma control score at baseline. A difference of 0.5 is considered as minimal clinically important difference ${ }^{16}$.

\section{Other variables}

A questionnaire was used to identify gender, age, educational and employment level, and smoking habits. Socio-economic status (SES) was derived from educational and employment level. Both educational level and employment level were divided into the categories low, middle, and high. SES was calculated using employment and educational data, and divided into the categories low, middle, and high. Smoking was defined as current smoking or non-smoking.

\section{Self-management plan}

Patients were trained to use a self-management plan to adjust the dose of ICS to symptoms and peak expiratory flow (PEF) value. General practitioners and trained research nurses gave instructions according to a standardised method. PEF was measured by means of a portable peak flow meter (Asmaplan+; Vitalograph ${ }^{\oplus}$, Buckingham, UK). Most participants used budesonide $200 \mu \mathrm{g}$ in Turbuhaler. Details of this plan are described by Thoonen et al. ${ }^{12}$. In Appendix A on page $129 \mathrm{a}$ summary of the self-management plan is shown.

\section{Statistical analysis}

For each category of severity, the mean asthma control score at baseline was calculated. Mean asthma control scores and patient characteristics of different severity categories were compared with an one-way analysis of variance, a Chisquare test or a Kruskal-Wallis test.

After one year, the mean asthma control score for each category of severity was calculated again and the groups were compared with an one-way analysis of variance.

The difference in number of patients with improved, equal or deteriorated asthma control between the severity categories was compared with a test for linear trend. Statistical significance was defined as a p-value $<0.05$. Statistical analyses were performed with SPSS for Windows, Version 11.0 (SPSS, Inc. Chicago, III.). 


\section{Results}

Sixty-seven patients were included. in Table 5.1 patient characteristics are shown.

Table 5.1 Patient characteristics and asthma control score at baseline per severity category (Nm67)

\begin{tabular}{|c|c|c|c|c|}
\hline & $\begin{array}{l}\text { Mild persistent } \\
\qquad N=15\end{array}$ & $\begin{array}{l}\text { Moderate persistent } \\
\qquad N=31\end{array}$ & $\begin{array}{l}\text { Severe persistent } \\
\qquad N=21\end{array}$ & p-walue \\
\hline Gender: $M / F$ & $9 / 6$ & $13 / 18$ & $13 / 8$ & NS \\
\hline Age: yoars (SO) & $36.8(13.2)$ & $40.0(13.5)$ & $42.8(13.7)$ & NS \\
\hline SES & & & & NS \\
\hline low & $1(6.7 \%)$ & $7(22.6 \%)$ & $6(28.6 \%)$ & \\
\hline medium & $7(46.7 \%)$ & $19(61.3 \%)$ & $10(47.6 \%)$ & \\
\hline high & $6(40,0 \%)$ & $5(16.1 \%)$ & $5(23.8 \%)$ & \\
\hline missing & $1(6.7 \%)$ & 0 & 0 & \\
\hline Long acting beta agonists & 0 & $5(16.1 \%)$ & $15(71.4 \%)$ & $<0.01$ \\
\hline Current smoking & 0 & $2(6.5 \%)$ & $3(14.3 \%)$ & NS \\
\hline $\begin{array}{l}\text { Mean asthma control score at } \\
\text { start (SD) }\end{array}$ & $0.54(0.34)$ & $0.96(0.69)$ & $1.61(1.12)$ & $<0.01$ \\
\hline
\end{tabular}

M malle, F female, SES socio-economic status, SD standard deviation, NS not significant

Apart from severity classifying features such as medication use, there were no significant differences in patient characteristics.

The mean asthma control score at baseline in all severity groups was below 2 on a scale from 0 (well controlled) to 6 (extremely poorly controlled astinma). Control was better in less severe asthma. The oneway analysis of variance showed a significant difference between groups ( $p<0.01$ ), in spite of the small number of patients.

After one year of self-management the asthma control scores were calculated again. Mean scores were for the category mild persistent 0.58 (SD 0.48 ), moderate persistent 0.71 (SD 0.48 ) and severe persistent 1.27 (SD 1.12). The moderate and severe persistent categories showed improvement in asthma control. The one-way analysis of variance showed again a significant difference between groups $(p=0.01)$.

In Figure 5.1 the changes in asthma control after one year of performing selfmanagement for each severity category are shown.

The mean differences between baseline and one year for the different categories were respectively 0.05 (SD 0.57), 0.25 (SD 0.70) and 0.34 (SD 1.13).

A trend seems noticeable that more patients with severe persistent asthma have improved asthma control; however, this was not significant when tested for linear trend $(p=0.09)$. 
difference in asthma control after one year self-management

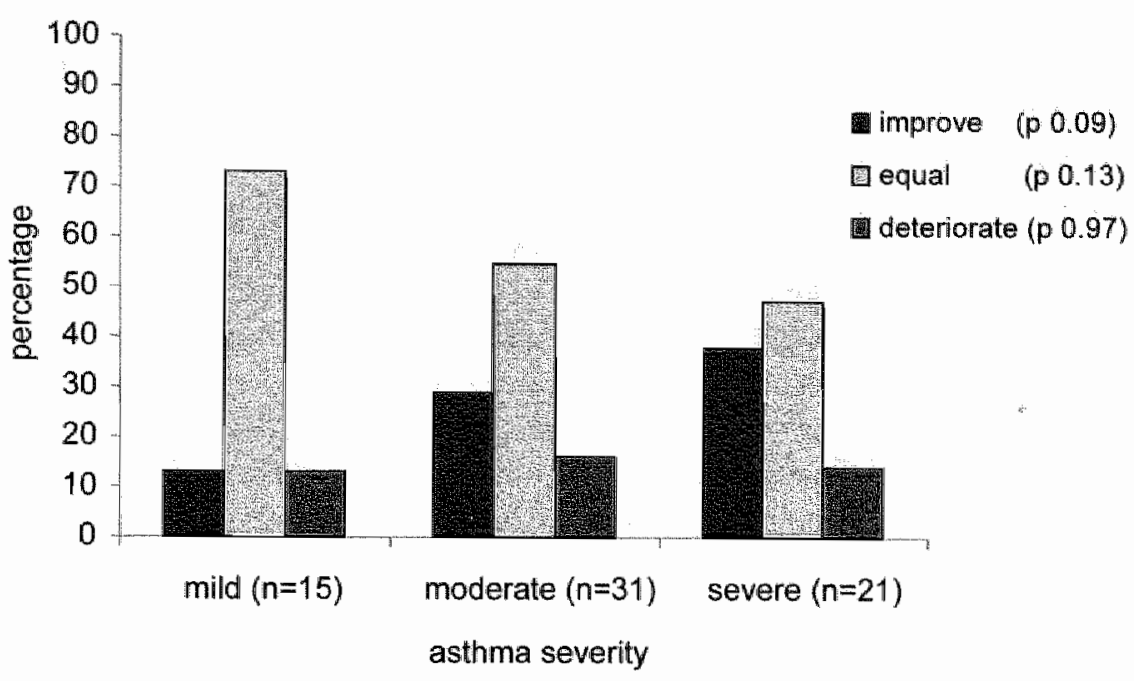

Figure 5. Percentage of patients that show improvement, equality or declime In asthma control after one year of self-management for each category of severity

\section{Discussion}

The present study showed that baseline asthma control was good in the mild and moderate persistent group of asthma patients. In the severe persistent group, asthma control was lower, but still quite well controlled. Furthermore we found indications that the introduction of a self-management plan in the treatment of asthma seems to be able to maintain or improve asthma control, especially in patients with severe persistent asthma.

These baseline results are not consistent with results from literature. A recent survey showed that asthma control was poor in several European countries, among which the Netherlands 4.5 . Patients were asked by telephone if they were being treated for asthma. Not all patients were treated by a general practitioner. There is an obvious difference in self-reported asthma by patients and physician-diagnosed asthma ${ }^{\circ}$. In our study, asthma control in patients that are diagnosed and treated by general practitioners seems adequate.

Especially in the severe persistent asthma group, control seems to improve during the use of a self-management plan. In this group control was worse at baseline compared to mild and moderate group, so, there was more room for improvement in the severe group. In the mild persistent group, the control at baseline is to such 
an extent that there is almost no room for improvement. Particularly not when mean asthma control score at baseline is 0.54 and only a difference larger than 0.5 is determined as a clinical relevant change in control ${ }^{16}$. So, in the mild persistent group asthma control is optimal at start and remains optimal during the study. If patients with more uncontrolled disease would have been included, more effect of the self-management plan on asthma control could have been expected.

Limitations of the present study are the lack of a control group and the small number of patients. Due to lack of a control group, effects might be partly explained by regression to the mean, although, only improvement in severe patients but no deterioration in mild patients is observed. A self-management plan seems to be able to maintain asthma control or lead to improvement even in patients with severe persistent asthma. However, one cannot rule out the effect of participation in a study on the patients" well being, a so-called "in care" effect. Assuming the positive effects of self-management plans on disease control10-12, a control group is not absolutely needed to detect differences between severity categories in the effect of these plans on asthma control.

A trend was noticeable that more patients with severe persistent asthma had improved asthma control after one year compared with the other severity categories, however the differences were too small to be significant.

Because patients were already treated for asthma we have chosen to determine severity based on dosage ICS, use of LABA, and lung function. With adjusting the dose of ICS by using the self-management plan one could classify patients in amother severity category, but we have chosen to keep patients in the same category, to see what was happening to the asthma control in these patients. Classifying severity in patients that are on asthma treatment is difficult partly because of the great overlap with asthma control, the treatment goal. Furthermore, if patients are over treated, they can be wrongly classified in a more severe category. The same holds for patients that are under treated, although this risk is less. When patients are under treated, the asthma control will not be optimal, so the treatment has to be intensified.

Asthma control was measured by means of the Asthma Control Questionnaire developed by Juniper et al. ${ }^{14}$. To avoid overlap between control and severity we decided only to use the items about symptoms and not to use the items about rescue medication and lung function. The original Asthma Control Questionnaire consists of seven items about symptoms, rescue medication, and lung function. Analyses have shown that the modified questionnaire without the questions about rescue medication and lung function has the same validity 15 .

We advocate using asthma severity to classify newly diagnosed patients, but for the follow up of asthma patients, one should focus on asthma control. Future guidelines should target more on contral than severity. Classifying severity in patients that are allready on asthma treatment is difficult. If patients are on asthma treatment, more focus should be on asthma control instead of asthma severity. 
The present observational study indicates that the introduction of a selfmanagement plan might be able to maintain or improve asthma control ${ }_{8}$ especially in patients with severe persistent asthma. Self-management plans have also demonstrated to be effective on other outcomes and to be costueffective ${ }^{12,17}$. Therefore, self-management plans seem to be useful in achieving optimal control in asthma patients with mild to severe persistent asthma. 


\section{References}

1. U.S. Department of Health and Human Services, Public Health Service National Institutes of Health, National Heart Lung, and Blood Institute. Practical Guide for the Diagnosis and Management of Asthma. Based on the Expert Panel Report 2: guidelines for the Diagnosis and Management of Asthma. NHH Publication 1997(No. 97-4053):152.

2. Global Initiative for Asthma (GINA). Global Strategy for asthma management and prevention: NHLBI/WHO Workshop Report. Bethesda: National Institutes of Health, National Heart, Lung and Blood Institute, 2002:Publication No. 02-3659.

3. BTS / SIGN. British guideline on the management of asthma. Thorax 2003;58 Suppl 1:11:94.

4. Rabe KF, Vermeire $P A$, Soriano $J B$, Maier WC. Clinical management of asthma in 1999: the Asthma Insights and Reality in Europe (AIRE) study. Eur Respir / 2000;16(5):802-7.

5. Vermeire $P A_{r}$ Rabe KF, Soriano JB, Maier WC. Asthma control and differences in management practices across seven European countries. Respir Med 2002;96(3):1429.

6. Linden van der MW. Schellevis FG, Mahangoo AD, Raat $H$. Measuring the prevalence of asthma and COPD by self-report and from routine general practice care: what's the difference? Eur J Public Health 2003:13(4):99.

7. Wijnhoven HAH, Kriegsman DMW, Hessellink A, Haan M de, Stalman W. Disease control in general practice patients with asthma. Prim Care Respir J 2004;13:89-98.

8. Bateman ED, Boushey HA, Bousquet J, Busse WW, Clark TJ, Pauwels RA, et al. Can Guideline-defined Asthma Control be Achieved? The Gaining Optimal Asthma ControL Study. Am J Respir Crit Care Med 2004;170:836-44.

9. Aalbers $R$, Backer $V$, Kava $T$, Omenaas ER, Sandstrom $T$, Jorup $C$, et al. Adjustable maintenance dosing with budesonide/formoterol compared with fixed-dose salmeterol/fluticasone in moderate to severe asthma. Curr Med Res Opin $2004 ; 20(2): 225-40$.

10. Gibson PG, Powell H, Coughlan J, Wilson AJ, Abramson M, Haywood P, et al. Selfmanagement education and regular practitioner review for adults with asthma. Cochrane Database Syst Rev 2002(3):Art.No:: CD001117. DOI: 10.1002/14651858.CDO01117.

11. Lahdensuo A, Haahtela T, Herrala J, Kava T, Kiviranta K, Kuusisto $P$, et al. Randomised comparison of guided self management and traditional treatment of asthma over one year. Br Med J 1996;312(7033):748-52.

12. Thoonen BP, Schermer TR, van den Boom $G$, Molema J, Folgering $H$, Akkermans RP, et al. Selt-management of asthma in general practice, asthma control and quality of life: a randomised controlled trial. Thorax 2003;58(1):30-6.

13. Lipworth BJ. Pharmacokinetics of inhaled drugs. Br f Clin Pharmacol 1996;42(6):697705.

14. Juniper EF, O'Byrne PM, Guyatt GH, Ferrie PJ, King DR. Development and validation of a questionnaire to measure asthma control. Eur Respir $J 1999 ; 14(4): 902-7$.

15. Juriper EF, Svensson K, Mork A-C, Stahl E. Measurement properties and interpretation of three shortened versions of the asthma contral questionnaire. Respir Med 2005:99(5):553-8.

16. Juniper EF, Stahl E, O'Byrne PM. Minimal important difference for the asthma control questionnaire. Am J Respir Crit Care Med 2001;163:642 (A). 
17. Schermer $T R$, Thoonen BP, van den Boom G, Akkermans RP, Grol RP, Folgering $H T$, et al. Randomized controlled economic evaluation of asthma self-management in primaly health care. Am J Respir Crit Care Med 2002;166(8):1062-72. 


\section{Chapter}

Could high exposure to house dust mite allergen be an obstacle for tapering off inhaled corticosteroids in a self-management plan?

MP de Vries, $L$ van den Bemt, BPA Thoonen, JWM Muris, CP van Schayck Accepted for publication in Primary Care Respiratory Journal 


\section{Abstract}

Aim

In this observational study, we try to find out whether high exposure to house dust mite (HDM) allergen is hampering tapering off inhaled corticosteroids (ICS).

\section{Methods}

Asthma patients sensitised to HDM allergen and using ICS were selected from general practice. From the mattresses dust samples were taken to assess exposure (no, low, intermediate or high) to HDM allergen with a semi-quantitative test (Acarex). Patients were trained to use a self-management plan to adjust the dose of ICS to symptoms and peak flow. The observation period was 3 months.

\section{Resuls}

The outcomes of 123 patients were analysed. Within the no and low exposure to HDM allergen group the proportion of patients that raised the dosage of their medication was significantly lower than the proportion that tapered off or remained on the same dose of ICS. The group with high exposure to HDM allergen had the highest proportion of patients that had to raise the dose of $1 C S(p=0.055)$.

Conchusion

High exposure to HDM allergen seems to coincide with the use of higher dose of ICS in asthma patients sensitised to HDM allergen. 


\section{Introduction}

Inflammation of the airways is a major underlying pathophysiological mechanism of asthma ${ }^{1}$. This inflammation leads to bronchoconstriction, which causes symptoms. Since inhaled corticosteroids (ICS) treat the inflammation of the airways, they can improve the long-term course of asthma ${ }^{2-5}$. For that reason ICS are the keystone in the pharmacological treatment of asthma.

It is recommended to use the lowest possible dose of ICS that provides adlequate control of the disease. Still, long-term side effects of ICS are not completely clear. Some harmful effects of long-term use of high dose of ICS have been shown. Higher doses of ICS during a longer period may increase the risk of e.g. cataract ${ }^{6}$ and affect bone mineral density ${ }^{7}$. This emphasises the importance of keeping the dose at an optimal low level.

Self-management plans or written action plans have proved to lead to improved health outcomes ${ }^{8}$. In a self-management plan it is important that desired behaviour is positively reinforced. If reinforcement occurs early in the learning process, the desired behaviour is more easily maintained.

A self-management plan has shown reduction of the amount of ICS needed ${ }^{9}$.

By adjusting the dose of ICS to their self-assessed degree of asthma, patients can use the lowest possible dose of ICS with achieving adequate control. Some patients are not able to taper off their medication, possibly due to exposure to irritants. Exposure to relevant irritants such as allergens or non-specific irritants can cause inflammation and consequently bronchoconstriction ${ }^{10.11}$. Exposure to such triggers may be a reason for the need of higher medication use or the impossibility of tapering off medication. House dust mite (HDM) allergens have appeared to be one of the most important triggers in asthmatic patients. Therefore, high exposure to HDM allergens might be a reason why sensitised patients cannot taper off their dose of ICS adequately or experience problems with carrying out self-management adequately.

In this study we want to investigate whether there is a relation between exposure to HDM allergens and the dosage of ICS needed, in the context of a self-management plan in asthmatic patients sensitised to HDM allergens.

\section{Methods}

\section{Subjects}

Asthma patients in the south-eastern part of the Netherlands were enrolled from registration networks of general practitioners (GPs) and by means of an open recruitment through advertisements in the local press. Recruitment took place all year round. Patients who were willing to participate were screened on in- and exclusion criteria. 
Inclusion criteria were age between 16 and 60 years, a GP-based diagnosis of asthma, sensitised to HDM allergens and requirement of ICS. The need for ICS was defined according to guidelines of the Dutch College of General Practitioners for the treatment of asthma12, which is comparable to the international GINA guidelines ${ }^{13}$.

Sensitisation was determined with a Phadiatop test (specific Immunoglobulin E (IgE) to a group of common aeroallergens). If positive, radio-allergo-sorbent tests (RASTs) were carried out for specific lgE for grasses, pollen, house dust mite, cat, and dog. IgE levels below $0.35 \mathrm{kU} / \mathrm{I}$ (class 0 ) were considered to be negative.

Exclusion criterla were serious diseases other than asthma with a low survival rate; other diseases, which influence bronchial symptoms and/or lung function; an exacerbation during a period of one month preceding the start of the study; the use of oral steroids or inhaled cromoglycates; already using HDM impermeable covers for mattresses; pillows and bedding; and allergy to domestic pets while keeping these pets.

A questionnaire was used to identify educational and employment level, smoking habits, and perceived airway hyper responsiveness.

The local Medical Ethical Committee approved the study. All patients agreed by written informed consent to participate in the study.

\section{Exposure to house dust mite allergen}

During a home visit a dust sample was taken from the patients' mattress in a standardised way. Dust samples were taken from the mattresses with a vacuum cleaner (Bosch, 1300 watt) equipped with a nozzle containing a collector with a filter paper. Mattresses were totally vacuumed in a standardised way with duration of 2 minutes per $\mathrm{m}^{2}$ of the mattress ${ }^{14}$. Both the upper surface of the bare mattress of the patient and the upper surface of the bare mattress of the partner (if present) were sampled.

A semi-quantitative test (Acarex) was carried out with the dust sample to assess the guanine dosage. Guanine is an excretion product of mites. The Acarex test gives reliable information about the presence of house dust mite (HDM) allergens, among which Dermatophagoides pteronyssinus allergen 1 (Der $p$ 1), one of the most common HDM allergens.

The exposure to HDM allergens is divided into the following categories: none, low, intermediate and high. These categories are corresponding more or less with the following concentrations of Der $p 1$ per gram dust: none $\leq 0.33 \mu \mathrm{g} / \mathrm{g}$, low 0.33 $2 \mu \mathrm{g} / \mathrm{g}$, intermediate $2-8.33 \mu \mathrm{g} / \mathrm{g}$ and high $\geq 33 \mu \mathrm{g} / \mathrm{g}^{15-17}$.

\section{Medication use}

The usage of ICS at the start of the trial was categorised as: none $(0 \mu \mathrm{g} / \mathrm{day})$, low dosage ( $<400 \mu \mathrm{g} /$ day), intermediate dosage (from 400 till $800 \mu \mathrm{g} /$ day), and high 
dosage $(\geq 800 \mu \mathrm{g} /$ day). The total amount of daily used ICS was calculated as the amount of ICS per dose (in $\mu \mathrm{g}$ ) times the total number of puffs used per day. Dose equivalents for different types of ICS (drug molecules) and delivery devices were calculated. The dosage of metered dose inhalers was doubled in order to obtain equipotent dosages with dry powder inhalers ${ }^{18}$. The dose of ICS at the start of the trial was subtracted from the dose of ICS after three months and the result was divided in the categories tapering off, equal dose or raising.

Forced expiratory volume in one second $\left(\mathrm{FEV}_{1}\right)$ was measured at the start of the study by means of a portable spirometer (Microloop II) at a lung function laboratory, and the $\mathrm{FEV}_{1} \%$ predicted was calculated.

Patients were trained to use a self-management plan to adjust the dose of ICS to symptoms and peak expiratory flow (PEF) value. General practitioners and trained research nurses gave instructions according to a standardised method. PEF was measured by means of a portable peak flow meter (Asmaplant; Vitalograph , Buckingham, UK). Most participants used budesonide $200 \mu \mathrm{g}$ in Turbuhaler ${ }^{(\oplus)}$. Details of this plan are described by Thoonen et al.9. See Appendix A on page 129 for a summary of the self-management plan.

Information on symptoms, PEF, and medication use (ICS, bronchodilators and other medication) were recorded in diaries on a weekly base.

The observation period was 3 months.

\section{Statistical analysis}

Baseline characteristics were tested with a Student's t-test, a Chi-square test or an analysis of variance to find significant differences in baseline characteristics between different HDM allergen exposure groups, and between the groups instructed by general practitioner or research nurse:

Proportions of patients that were able to taper off, remained on the same dose, and that had to raise the dose of ICS were calculated for each HDM allergen exposure group. Differences within each exposure group were compared with a chisquare test. Differences between the exposure groups for number of patients that tapered off, remained on the same dose, and raised the dose of ICS were compared with a test for linear trend.

Statistical significance was defined as p-value $<0.05$.

Statistical analyses were performed with SPSS for Windows, Version 11.0 (SPSS, Inc.. Chicago, III.).

\section{Results}

One hundred and twenty three patients were included.

In Table 6.1 patient characteristics at baseline are displayed. 
Table 6.1 Basellne characteristics.

\begin{tabular}{|c|c|c|c|c|c|}
\hline$N-123$ exposure to HDM ahergens & none & low & Intermediate & high & p-value \\
\hline Number of patients $(\%)$ & $36(29.3 \%)$ & $38(30.9 \%)$ & $31(25.2 \%)$ & $18(14.6 \%)$ & \\
\hline Gender (male) ( & $19(52.8 \%)$ & $21(55.3 \%)$ & $16\{516 \%\}$ & $10(55.6 \%)$ & 0.88 \\
\hline Mean age (yrs) & 41.4 & 45.9 & 41,4 & 41.5 & 0.50 \\
\hline Dosie ICS at start ( $4 \mathrm{~g} / \mathrm{day}$ ) & & & & & 0.33 \\
\hline \multicolumn{6}{|l|}{ Categaries: $(\%)$} \\
\hline O $\mathrm{jg}$ & $3(8,3)$ & $1(2.6)$ & $3(9.7)$ & $0(0.0)$ & \\
\hline low $(<400$ ug & $7(19.4)$ & $6(15.8)$ & $1(3.2)$ & $1(5.6)$ & \\
\hline intermediate $(400-800 \mathrm{wg})$ & $1.4(38.9)$ & $8(21.1)$ & $11(35.5)$ & $9(50.0)$ & \\
\hline nigh ( $\geq 800 \mu g)$ & $12(33.3)$ & $23(60.5)$ & $16(51.6)$ & $8(44.4)$ & \\
\hline Long-acting bronchodilators & $9(25.0 \%)$ & $10(26.3 \%)$ & $7(22.6 \%)$ & $5(27.8 \%)$ & 0.78 \\
\hline FEV $1 \%$ predicited & 90.5 & 88.6 & 90.4 & 92.0 & 0.64 \\
\hline Smoking (\%) & & & & & 0,16 \\
\hline Never & $25(69.4 \%)$ & $20(52.6 \%)$ & $21(67.7 \%)$ & $9(50,0 \%)$ & \\
\hline Ex & $9(25,0 \%)$ & $17(44.7 \%)$ & $9(29.0 \%)$ & $5(27.896)$ & \\
\hline Current & $1(2.8 \%)$ & $3(7.9 \%)$ & $1(3.2 \%)$ & $4(22.2 \%)$ & \\
\hline Other sensitisations (mean number) & 2.3 & 1.8 & 1.7 & 1.3 & 0.11 \\
\hline
\end{tabular}

HDM house dust mite, ICS inhaled corticosteridis, FEV forced expiratory volume in one second

General practitioners instructed 31 participants, two research nurses instructed the other 92 subjects. The instruction was standardised and the same for both groups. Patient characteristics did not differ significantly between these two groups $(0.10<p<0.59)$.

From the dust samples of the mattresses that were taken; $29.3 \%$ contained no HDM allergens, $30.9 \%$ contained a low level of HDM allergens, $25.2 \%$ contained an intermediate level of HDM allergens, and $14.6 \%$ contained a high level of HDM allergens.

Gender, age, use of long-acting bronchodilating agents, $\mathrm{FEV} \%$ predicted, smoking status, and number of other sensitisations did not differ significantly between the exposure groups.

Forty-eight $(39.0 \%)$ patients could taper off their dose of ICS, 53 (43.1\%) patients remained on the same dose after 3 months, and $22(17.9 \%)$ patients had to increase the dose of ICS. Figure 6.1 shows the percentage of patients which could taper off the dose of ICS, which remained on an equal dose and which had to raise the dose after three months in different exposure categories of level of HDM allergens. 


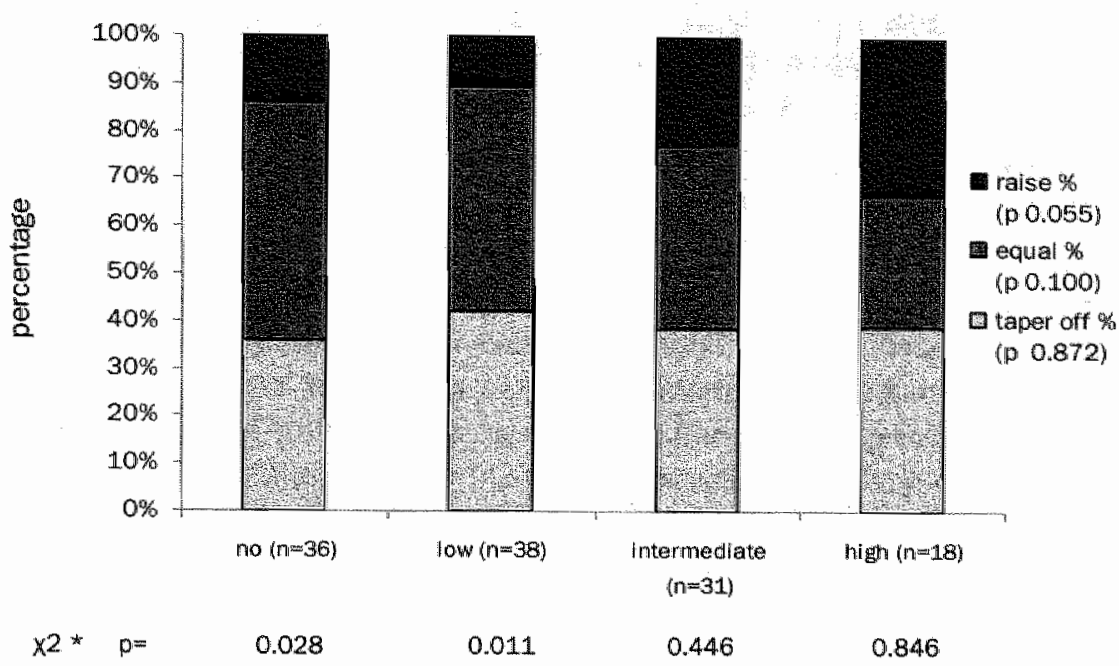

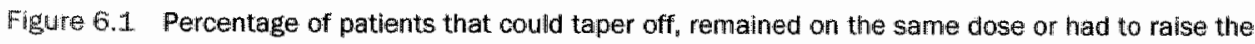
dose of ICS in different categories of exposure to HDM allergens.

* Within exposure groups' comparison using a chi-square test for difference in tapering off, equal dose or raising the dose of iCS.

ICS inhaled corticosteroids, HDM house dust mite.

Within the no and low exposure group there was a statisticaliy significant difference between tapering off, equal dose, and raising dose.

A trend seemed noticeable that the higher the exposure to HDM allergens, the higher the proportion of patients that had to raise the dose of ICS. When tested for linear trend, this trend was not significant $(p=0.055)$. Trend analyses showed no significant difference for tapering off and equal dose $(p=0.872$ and $p=0.100)$. When performing the analyses without smokers, the same trend for larger proportion that raised the dose of ICS when the exposure to HDM allergens was higher was noticeable.

\section{Discussion}

In this observational study, we found indications that high exposure to HDM allergens might lead to the use of a higher dosage of ICS.

The introduction of a self-management plan led, particularly, in the high exposure group to increased use of ICS.

Because of the relatively high number of current smokers in the high exposure group, and the possible negative interaction between smoking and the effect of 
allergen exposure on the use of $1 \mathrm{CS}$, we also performed analyses without the smokers. These data showed the same trend $(p=0.091)$.

No difference was found in the proportion of patients that could taper off ICS in the different exposure groups to HDM allergens. We did not expect this finding. The goal of self-management plans is to achieve an optimal treatment, with the lowest possible dose, that gives optimal control. We were expecting an overall reduction of medication required, instead of an increase in the amount of medication in a substantial part of the study population. This finding raises the question if there was under-treatment in the period before starting the self-management plan. All patients received usual care before the start of the study. The relatively high numbers of patients using intermediate or high dosages of ICS at the start of the observation period do not seem to indicate under-treatment. lf exposure to high concentrations of allergens leads to the need for higher doses of ICS, avoidance measures to these particular allergens could be useful to reduce the need for ICS.

The small number of patients is a limitation of this study. Especially, the number of patients in the high exposure group was very low $(n=18)$. This number of patients may have been inadequate to detect a significant difference in ICS use between the exposure groups. As this study was a pilot study no power calculations were made beforehand.

The observation period of the present study was three months, which is probably not. long enough to examine the possibility of tapering off ICS between the groups with different exposure to HDM allergens. It might take a longer period for patients to achieve a steady state of medication use when they are exposed to a specific level of allergens. However, we were especially interested in the begin period of self-management to see if exposure to a high concentration of HDM allergens might prevent persons to carry out the self-management plan well, because of lack of positive reinforcement. Recruitment took place all year round and patients recruited in different seasons were equally divided over the different exposure groups.

A study using the same self-management pian as in the present study, showed a saving of more than 200 puffs ICS per patient over a period of two years in the selfmanagement compared to the usual care group 9 . A significantly higher proportion of subjects from the self-management group took domestic HDM avoidance measures. This may have contributed to the beneficial effects of the selfmanagement plan.

We could not correct for exposure to other possible triggers, which might have hampered tapering off $\| C S$. However, we did exclude patients with a positive RAST for cats or dogs in case of keeping these pets.

In the present study, the Acarex test was used to determine exposure to HDM allergen. This test is semi-quantitative and it is not possible to distinguish between different mite species. However, it has proven to give reliable information about the presence of HDM allergens in settled dust ${ }^{16,17}$. Der $p 1$ is one of the most common 
HDM allergens. The different exposure groups are corresponding more or less with the following concentrations of Der $p 1$ per gram dust: none $\leq 0.33 \mu \mathrm{g} / \mathrm{g}$, low 0.33 $2 \mu \mathrm{g} / \mathrm{g}$, intermediate $2-8.33 \mu \mathrm{g} / \mathrm{g}$ and high $\geq 33 \mu \mathrm{g} / \mathrm{g}$. Exposure to a concentration higher than $2 \mu \mathrm{g} / \mathrm{g}$ Der $\mathrm{p} 1$ is a risk factor for sensitisation to HDM allergens, whereas exposure to a concentration higher than $10 \mu \mathrm{g} / \mathrm{g}$ is a major risk factor for the development of acute asthma in mite allergic patients ${ }^{19}$. This might explain why relatively many patients in the low exposure group managed to taper off the dose of ICS. They are sensitised to HDM allergens, but are exposed to a lower concentration of HDM allergen than the threshold level that is expected to cause symptoms. Patients in the intermediate and high exposure group were exposed to a concentration HDM allergens that might induce asthmatic symptoms. This might be the reason why in this group relatively many patients had to raise the dose of ICS. Reducing the exposure to allergens by using allergen avoidance measures e.g. encasing mattresses and bedding could prevent the need for raising the dose of ICS in these circumstances. General Practitioners (GPs) and trained research nurses gave instructions about the self-management plan to the patients. The instructions were standardised. A study using the same self-management plan showed that there was no influence of the different GPs on the outcome of the intervention; as there was a very low intra-cluster correlation ${ }^{20}$. Therefore, we did not expect any difference between the GP-instructed group and the group , which was instructed by the research nurses on the outcome of the self-management plan. Moreover, the patients of the different instruction groups were comparably divided over the HDM allergen exposure categories and the patient characteristics did not differ significantly.

We conclude that in the present observational study, exposure to HDM allergens seems to be associated with the dose of ICS needed.

Findings from this study seem to indicate that exposure to high levels of HDM allergens leads to the need for more ICS.

This study is, to our knowledge, the first to investigate the relation between natural exposure to allergens and the need for ICS in asthmatic patients. Although many factors influence the need of ICS, the high exposure group to one important allergen (HDM allergen) is related to higher level of ICS use in asthmatic patients, although not statistically significant. More research in this area with information on additional factors influencing medication use, a longer observation period and a larger study population could lead to better understanding of the relation between exposure to allergens and medication use with the goal to optimise medication use. 


\section{References}

1. Djukanovic R, Roche WR, Wilson JW, et al. Mucosal inflammation in asthma. Am Rev Respir Dis 1990;142(2):434-57.

2. Kerstjens $\mathrm{HA}_{\mathrm{A}}$, Brand $\mathrm{PL}$, Hughes $\mathrm{MD}$, et al. A comparison of bronchodilator therapy with or without inhaled corticosteroid therapy for obstructive airways disease: Dutch Chronic Non-Specific Lung Disease Study Group. N Engl I Med 1992;327(20):1413-9.

3. Juniper $E F$, Kline $P A$, Vanzieleghem MA, et al. Effect of long-term treatment with an intialed corticosteroid (budesonide) on airway hyperresponsiveness and clinical asthma in nonsteroid-dependent asthmatics. Am Rev Respir Dis 1990;142(4):832-6.

4. Haahtela $T$, Jarvinen $M$; Kava $T$, et al. Comparison of a beta2-agonist, terbutaline, with an inhaled corticosteroid, budesonide, in newly detected asthma. $N$ Engl $/ \mathrm{Med}$ $1991 ; 325(6): 388-92$.

5. Dompeling $E$, Schayck CP van, Grunsven PM van et al. Slowing the deterioration of asthma and chronic obstructive pulmanary disease observed during bronchadilator therapy by adding inhaled corticosteroids. A 4-year prospective study. Ann intern Med $1993 ; 118(10): 770-8$.

6. Smeeth $L$, Boulis $M$. Hubbard R, Fletcher AE. A population based case-control study of cataract and inhaled corticosteroids. Br J Ophthalmol 2003:87(10):1247-51.

7. Kelly HW, Nelson HS. Potential adverse effects of the inhaled corticosteroids. I Allergy Clin Immunol 2003;112(3):469-78.

8. Gibson PG, Powell $H$, Coughlan 1, et all. Self-management education and regular practitioner review for adults with asthma. Cochrane Database Syst Rev 2003(1): CD001117.

9. Thoonen BP, Schermer TR, Boom G van den, et al. Self-management of asthma in general practice, asthma control and quality of life: a randomised controlled trial. Thorax 2003;58(1):30-6.

10. Custovic A, Taggant SCO, Francis $\mathrm{HC}$, et al. Exposure to house dust mite allergens and clinical activity of asthma. J Allergy Clin Immunol 1996;98(1):64-72.

11. Platts Mills TA, Thomas WR, Aalberse RC, et al. Dust mite allergens and asthma: report of a second international workshop. J Allergy Clin Immunol 1992;89(5):1046-60.

12. Geijer RMM, Hensbergen W van. Bottema BIAM, et al. NHG-Standaard Astma bij Volwassenen: Behandeling (NHG Guideline on Asthma in Adults: Treatment). Huisarts Wet 2001:44(4):153-64.

13. Global Initiative for Asthma. Global Strategy for asthma management and prevention: NiH publication No. 02-3659 Issued January, 1995(updated 2002).

14. Dust mite allergens and asthma: a worldwide problem. International Workshop report. Bull World Health Organ 1988;66(6):769-80.

15. Bischoff $E$, Schirmacher $W$. Investigations of allergen-containing dust samples from the interior of the house. Experientia Suppl 1987;51:189-96.

16. Paull $G$, Tenabene $A$, Bessol $J C$, Hoyet $C$. Guanine dosage in house dust samples and quantification of mite allergens. Experientia Supp/ 1987;51:203-9.

17. Bronswijk $J E$ van, Bischoff $E$, Schirmacher W, Kniest FM. Evaluating mite (Acari) allergenicity of house dust by guanine quantification. J Med Entomol 1989;26(1):55-9.

18. Lipworth BJ. Pharmacokinetics of inhaled drugs. Br J Clin Pharmacol 1996;42(6);697. 705.

19. Pilatts-Mills TAE, Vervloet D, Thomas WR, et al. Indoor allergens and asthma: report of the third international workshop. J Allergy Clin Immunol 1997;100(6):S1-S24. 
20. Schermer TR, Thoonen $\mathrm{BP}_{\mathrm{n}}$ Boom G van den, et al. Randomized controlled economic evaluation of asthma self-management in primary health care. Am J Respir Crit Care Med 2002;166(8):1062.72. 


\section{Chapter 7}

Does house dust mite allergen avoidance allow tapering off inhaled corticosteroids in allergic asthma patients using a selfmanagement plan?

MP de Vries, $L$ van den Bemt, K Aretz, BPA Thoonen, JWM Muris, ADM Kester, $S$ Cloosterman, CP wan Schayck 


\section{Abstract}

\section{Airn}

The efficacy of house dust mite (HDM) impermeable covers is still a subject of debate. The aim of the present study was to investigate whether the combination of HDM impermeable covers and a self-management plan based on peak flow values and symptoms leads to less use of inhaled corticosteroids (ICS) than self-management alone.

\section{Methods}

Asthme pattents aged between 16 and 60 years with an HDM allergy requiring ICS were included. They were trained to use a self-management plan based on peak flow and symptoms. After a threemonth training period, the intervention with HDM impermeable and placebo bed covers started. The follow-up period was two years. The primary outcome was the use of ICS; secondary outcomes were peak expiratory flow parameters, asthma control and symptoms.

\section{Results}

126 patients started the intervention with HDM impermeable or placebo bed covers. After one and two years, significant differences in allergen exposure were found between the intervention and control groups $(\mathrm{p}<0.001)$. No significant differences between the intervention and control groups were found in the dose of $\operatorname{lCS}(p=0.08)$, morning peak flow $(p=0.52)$, peak flow variability ( $p=0.36)$, dyspnoea $(p=0.46)$, wheezing $(p=0.77)$ or coughing $(p=0.41)$. There was no difference in asthma control between the intervention and control groups.

\section{Conclusion}

HDM impermeable bed covers combined with self-management do not lead to less use of ICS than self-management alone. 


\section{Introduction}

Inflammation is the underlying pathophysiological mechanism of asthma, leading to a variable aifflow limitation, resulting in symptoms ${ }^{1}$. Inhaled corticosteroids (ICS) treat the inflammation, and are therefore the cornerstone of asthma treatment 2.5 . Because of possible side effects, it is important to keep the dose of ICS as low as possible ${ }^{6}$. Reduction of ICS can often be achieved in patients with mild asthma ${ }^{7.8}$.

Self-management plans are appropriate to optimise the dose of inhaled steroids, and have proved to have positive effects on several asthma outcomes 8 -11. Asthma health outcomes are consistently improved especially by individualised written action plans based on personal best peak expiratory flow (PEF), using action points and recommending both inhaled and oral corticosteroids (OCS) for early treatment of exacerbations. These observations support the use of individualised written action plans ${ }^{12}$. Self-management plans are multi-faceted, and often propose allergen avoidance as one of the measures. However, whether allergen avoidance interventions are efficient components of self-management plans is not yet clear. The study by Thoonen et al found that self-management reduced the use of ICS compared with usual care ${ }^{8}$. The authors also reported significantly higher costs for domestic house dust mite (HDM) allergen avoidance measures in the selfmanagement group compared with the usual care group ${ }^{13}$. Whether these avoidance measures contributed to the positive effects of the self-management plan is not clear.

Treatments limited to inflammation inhibitors could be seen as swimming against the tide, because nothing is done to reduce the cause of the inflammatory process. In most asthma patients, exposure to triggers like allergens contributes to the inflammatory process. Exposure to such allergens, including HDM allergens, can cause and maintain inflammation ${ }^{14,15}$. Reduction of exposure to allergens can lead to attenuated inflammation, and bed covers have proved to be the best method of reducing exposure to HDM allergens ${ }^{16-20}$. Nevertheless, the effects of HDM impermeable covers on clinical parameters are under debate21. Studies investigating the effects of HDM impermeable covers have yielded conflicting results $17,2022 \cdot 27$.

The aim of the present study was to investigate whether HDM allergen avoidance by means of encasings provides added value when combined with selfmanagement plans and leads to less use of ICS and improvement of asthina control compared with self-management alone. 


\section{Methods}

\section{Patient selection}

Asthma patients in the southeastern part of the Netherlands were enrolled from registration networks of general practitioners (GPS) and by means of open recruitment through advertisements in the local press. Patients who were willing to participate were screened for inclusion and exclusion criteria.

Inclusion criteria were: agie between 16 and 60 years, a GP-based diagnosis of asthma, being allergic to HDM and requiring ICS. The need for ICS was defined according to guidelines of the Dutch College of General Practitioners for the treatment of asthma28, which are comparable to the international GINA guidelines $^{29}$. Allergy was determined with a Phadiatop test (specific Immunoglobulin $\mathrm{E}$ ( $\mathrm{gEE}$ ) to a group of common aeroallergens). If this test was positive, radioallergo-sorbent tests (RASTs) were done for specific IgEs for grasses, pollen, HDM, cats and dogs. IgE levels above $0.35 \mathrm{kU} / \mathrm{I}$ (class 1 or higher) were considered to be positive. Classes 1 to 3 were regarded as low, while classes 4 to 6 were regarded as high. Exclusion criteria were: serious diseases other than asthma with a low survival rate; other diseases that influence bronchial symptoms and/or lung function; an exacerbation during a period of one month before the start of the study; the use of oral steroids or inhaled cromoglycates; already using HDM impermeable mattress and bedding covers and allergy to cats or dogs while still keeping these pets.

The local Medical Ethics Committee approved the study. All patients agreed by written informed consent to participate in the study.

\section{Sudy design}

This study was a prospective, double-blind, placebo-controlled clinical trial with a run-in period of three months, followed by a two-year intervention period. Patients were randomly allocated to the intervention or the control group. The intervention group used active allergen avoidance measures, applying encasings for mattresses, duvets and pillows, consisting of non-polyurethane moisturepermeable covers impermeable to HDM allergens. The placebo group received encasings for mattresses, duvets and pillows consisting of covers permeable to HDM allergens. Both intervention and placebo covers were supplied by Cara C'air and were indistinguishable from each other. Patients did not receive information on other methods of allergen avoidance.

\section{Self ritanagement}

Patients were trained to use a self-management plan to adjust the dose of ICS to symptoms and peak expiratory flow (PEF) value during a run-in period. General practitioners or trained research nurses gave instructions according to a 
standardised method. PEF was measured by means of a portable peak flow meter (Asmaplant; Vitalograph "Buckingham, UK). Most participants used budesonide $200 \mu \mathrm{g}$ in a Turbuhaler. Dose equivalents for different types of $1 \mathrm{CS}$ and delivery devices were calculated. The dosage of metered dose inhalers was doubled in the calculations to obtain equipotent dosages with a dry powder inhaler ${ }^{30}$. Details of the plan have been provided by Thoonen et al. ${ }^{8}$. Box 1 presents a summary of the self-mamagement plan. In Appendix A on page 129 a summary of the selfmanagement plan is shown.

Details of symptoms, morning and evening peak flow and medication use (inhaled corticosteroids, bronchodilators and other medication) were recorded in diaries on a weekly basis.

After a three-month rum-in period, the intervention period with placebo-controlled allergen avoidance started, with a two-year follow-up period. During the run-in period, patients were trained to use the self-management plan. In three visits, they were taught how to fill in the diary, use the peak flow meter and make stepwise adjustments to their medication. After the training period, they started the alleirgen avoidance measures. During the intervention period, patients were visited at home every six months to check the implementation of the self-management plan.

\section{Dust collection and Der $\mathrm{p} 1$ assessment}

Dust samples were taken from mattresses at the start of the intervention period (before the covers were put on), after one year and after two years of intervention. Compliance with the use of the encasings was checked at the time of sampling. All dust samples were collected with a vacuum cleaner (Bosch Activa 60, type BS6, 1300 Watt). The upper surface of the entire bare mattress (or the upper surface of the mattress covers after encasing) was sampled in a standardised way at an intensity of two minutes per $\mathrm{m}^{2}$. Dust samples were stored in the freezer until they were analysed. The amount of dust was weighed and a $10 \%(\mathrm{w} / \mathrm{v})$ extraction in $0.01 \mathrm{~mol} / \mathrm{N} \mathrm{NH} 4 \mathrm{HCO} 3$ was performed by overnight rotation at $4^{\circ} \mathrm{C}$. The samples were centrifuged and supernatants were used for detection of Dermatophagoides pteronyssinus allergen 1 (Der $p 1$ ) by ELISA.

\section{Asthma control}

Asthma control was assessed by means of the ACQ (Asthma Control Questionnairej31. In Appendix B on page 133 an example of the ACQ is shown. Seven items were scored on a seven-point scale from 0 to 6 . All items were equally weighted. The overall score was the mean of the seven responses, ranging from 0 (well-controlled asthma) to 6 (extremely poorly controlied asthma). 


\section{Statistical analysis}

The primary effect parameter was the difference between the two groups in the ICS dosages over the two-year period. With an assumed difference of $250 \mu \mathrm{g}$ between the intervention and control groups and a standard deviation of $485 \mu \mathrm{g}$, to achieve a power of $80 \%$ with $\alpha=0.05,120$ patients were needed. Assuming a drop out rate of $20 \%$, we therefore needed to recruit 150 patients. To check whether there was a significant difference between the two selection methods (GPS or open) or instruction groups (GPS or nurses), patient characteristics for the different recruitment and instruction groups were tested with Student's t-test or Chi-square test depending on the type of variable. Since the distributions of the Der $p 1$ concentrations (in $\mu \mathrm{g} / \mathrm{g}$ and in $\mu \mathrm{g} / \mathrm{m}^{2}$ ) and amounts of dust $(\mathrm{g}$ ) were positively skewed, which could not be normalised by log transformation, we presented the medians as data-summary and tested the differences between the active and placebo group for Der $p 1$ concentrations $\left(\mu \mathrm{g} / \mathrm{g}\right.$ and $\mu \mathrm{g} / \mathrm{m}^{2}$ ) and amounts of dust (g), by means of the nonparametric Mann-Whitney $U$ test.

For the following variables quarterly means per patient were calculated from diary data: daily dose of ICS, morning peak flow, peak flow variability, dyspnoea, wheezing and coughing. In view of the lack of normal distribution, we used nonparametric analyses to evaluate the patient's mean response over time. The last observation carried forward method was used to replace missing values. A Mann-Whitney $U$ test was used for between-group comparisons, for the entire intervention period as well as for each three-month period. These analyses were also performed for subgroups based on different smoking status, mono versus multiple allergies, HDM allergy low (RAST category 1 to 3) versus high (RAST category 4 to 6) and different categories of Der p 1 concentration at baseline $(<2,000 \mathrm{ng} / \mathrm{g}, 2,000-10,000 \mathrm{ng} / \mathrm{g}, \geq 10,000 \mathrm{ng} / \mathrm{g})$.

All analyses were based on the intention-to-treat principle. Statistical significance was defined as p-value <0.05. We used SPSS for Windows, Version 12.0 (SPSS, Inc. Chicago, III.).

\section{Results}

Patients were selected either from general practices or by means of open recruitment. Figure 7.1 displays the patient flow for the selection, inclusion and study stages.

One hundred and forty-three patients were included. Eleven patients dropped out before the start of the study, and six patients dropped out during the run-in period. Hence, 126 patients started the intervention with HDM impermeable or placebo
covers.

Table 7.1 shows the characteristics of patients who started the intervention. 
Inclusion from $G P$ practice

In 24 practices 865 patients were invited

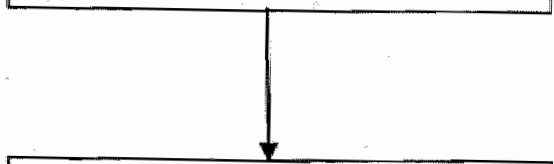

$309 \mathrm{pts}$ willing to participate

Exclusion: 31 already used covers.

58 using no $1 \mathrm{CS}, 17$ miscellaneous
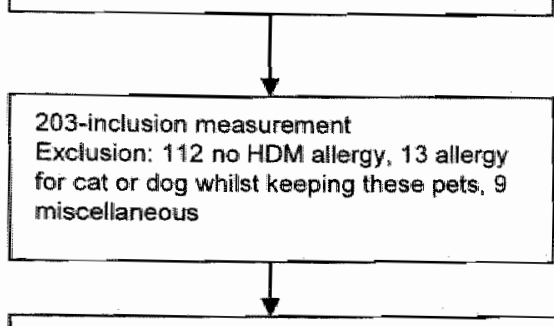

691 included

total of 143 patients inclucied

11 drop-outs before start of run-in: 4 no time, 2 no longer interested, 5 unknown/ lost to follow-itp

Exclusion: 90 no HDM allergy. 13 allergy for cat or dog

whilst keeping these pets, 7 miscellaneous

433 pts asked information: exclusion:

113 pts not interested after information, 43 no daily use

of liCS

32 already used covers, 18 used oral steroids or cromoglycates

207 pts filled in questionnaire

Exclusion: 20 too time-consurming or not interested anymore, 2 moved to another city, 1 negative advice from $\mathrm{GP}$
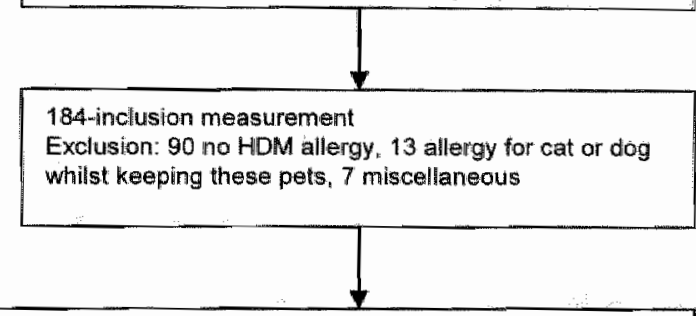

\section{4 included}

\#32 patients started run-in period: 6 dropouts during run-in because of problems with self-management

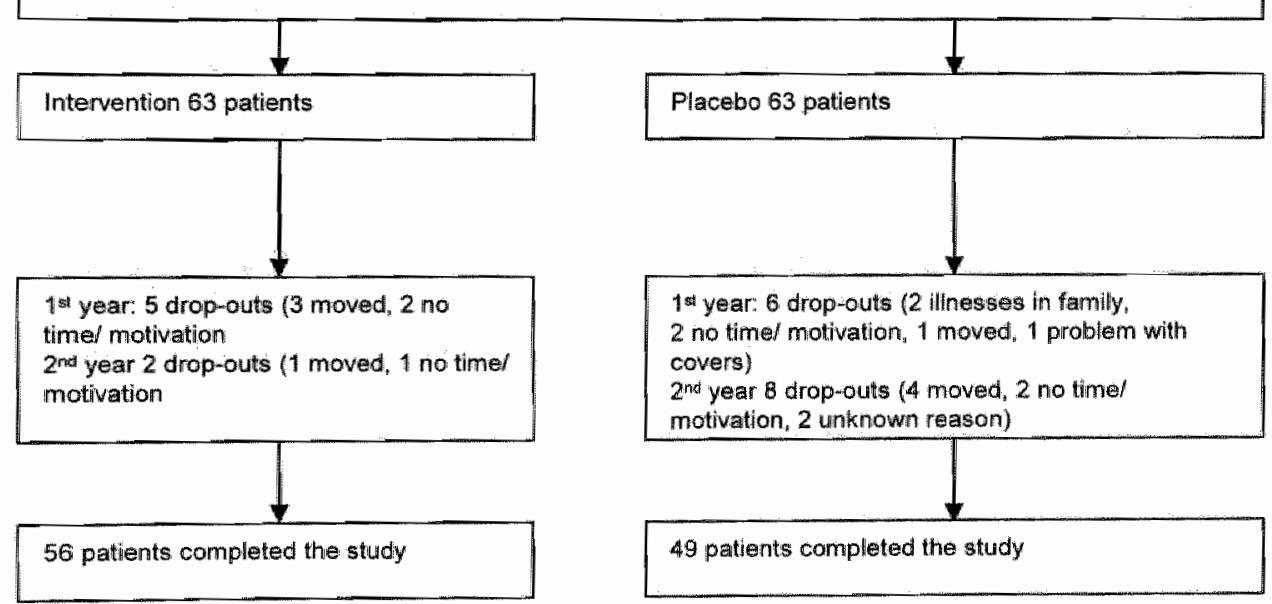

Figure 7.1. Patient flow 
Table 7.1 Baseline characteristics intervention and placebo groups.

\begin{tabular}{|c|c|c|}
\hline 2 & Intervention & Placebo \\
\hline Number of patients & 63 & 63 \\
\hline Age in yrs (SD) & $39.8(13.2)$ & $43.9(11.7)$ \\
\hline Gender $M / F$ & $32 / 31$ & $41 / 22$ \\
\hline FEV $\%$ predicted inclusion (SD) & $86.5(16.1)$ & $89.1(14.6)$ \\
\hline FEV $\%$ predicted at start intervention covers (SD) & $85.0(17.7)$ & $85.4(14.7)$ \\
\hline Mean dose of ICS at inclusion (SD) micrograms per day & $656(448)$ & $657(474)$ \\
\hline $\begin{array}{l}\text { Mean dose of ICS at start intervention covers (SD) } \\
\text { micrograms per day }\end{array}$ & $519(441)$ & $532(420)$ \\
\hline \multicolumn{3}{|l|}{ Class house dust mite allergy } \\
\hline Class 1 & $3(4.8 \%)$ & $7(11.1 \%)$ \\
\hline Class 2 & $9(14.3 \%)$ & $11(17.5 \%)$ \\
\hline Class 3 & $21(33.3 \%)$ & $22(34.9 \%)$ \\
\hline Class 4 & $20(31.7 \%)$ & $20(31.7 \%)$ \\
\hline Class 5 & $2(3.2 \%)$ & - \\
\hline Class 6 & $4(6.3 \%)$ & $3(4.8 \%)$ \\
\hline Missing & $4(6.3 \%)$ & 。 \\
\hline Mean number of other allergies (SD) & $2.0(1.4)$ & $1.6(1.6)$ \\
\hline \multicolumn{3}{|l|}{ Smoking } \\
\hline Never & $44(69.8 \%)$ & $32(50.8 \%)$ \\
\hline Ex & $16(25.4 \%)$ & $25(39.7 \%)$ \\
\hline Current & $3(4.8 \%)$ & $6(9.5 \%)$ \\
\hline Use of long-acting beta agonists & $15(23.8 \%)$ & $9(14.3 \%)$ \\
\hline
\end{tabular}
SD standard deviation, $M$ male, F female ${ }_{n}$ ICS inhaled corticosteroids, FEV $V_{1}$ forced expiratory volume in
ane second

There was a significant difference in smoking status between the intervention and control groups. Other variables did not differ significantly. Patient characteristics were also compared between the GP-selected group and the open recruitment group, and between instruction by GPs and by nurses. The only significant difference found related to age (recruitment by GPs vs. open: 37.7 yrs vs. 45.3 yrs; instruction by GPS vs. nurses: 36.6 yrs vs. 43.6 ). As this was not a clinically relevant difference, we pooled the analyses for the different selection and instruction groups.

The allergen avoidance measures were carried out after a run-in period of 3 months, in which patients learned about and became familiar with the use of the self-management plan. The results of the dust samples were expressed as the total 
amount of dust in grams. Der $p 1$ concentrations in nanogram per gram of dust ( $\mathrm{ng} / \mathrm{g}$ ) and Der $\mathrm{p} 1$ densities in nanogram per square metre of mattress $\left(\mathrm{ng} / \mathrm{m}^{2}\right)$.

At the start of the intervention, there was hardly any difference between the intervention and placebo groups as regards the amounts of dust (0.53 vs. $0.54 \mathrm{~g})$, Der p 1 concentrations ( 863 vs. $806 \mathrm{ng} / \mathrm{g}$ ) or Der p 1 densities (52 vs. $61 \mathrm{ng} / \mathrm{m} 2$ ). After one and two years, significant differences between the intervention and placebo groups were found in Der p 1 concentrations ( 377 vs. $1070 \mathrm{ng} / \mathrm{g} ; \mathrm{p}<0.001$ and 115 vs. $895 \mathrm{ng} / \mathrm{g} ; \mathrm{p}<0.001$ ) and Der $\mathrm{p} 1$ densities ( $9 \mathrm{vs} .82 \mathrm{ng} / \mathrm{m}^{2} ; \mathrm{p}<0.001$ and 10 vs. $115 \mathrm{ng} / \mathrm{m}^{2} ; \mathrm{p}<0.001$ ). Figure 7.2 shows the Der $\mathrm{p} 1$ concentrations in $\mathrm{ng} / \mathrm{g}$ for the intervention and placebo groups during the study.

Der $p 1$ (nglgram dust)

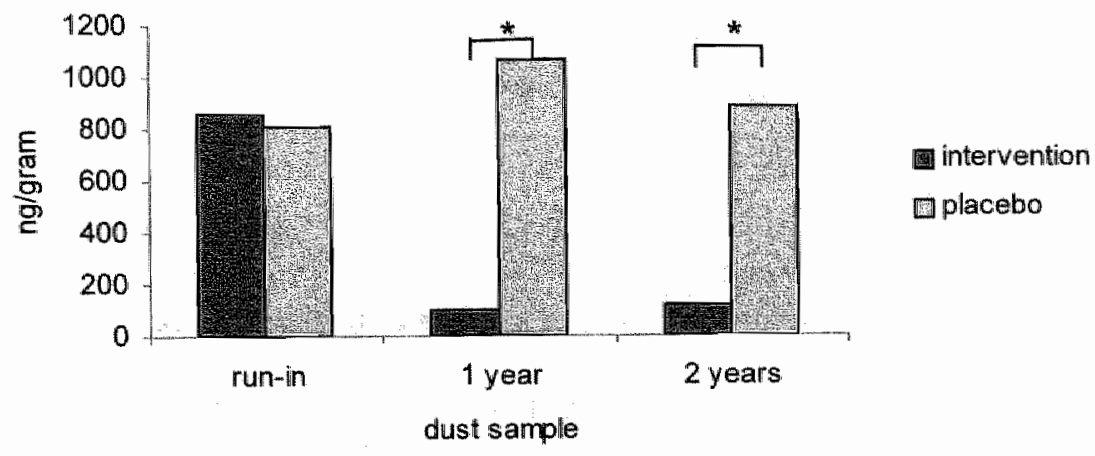

Figure 7.2 Median Der $p 1$ concentrations in $\mathrm{ng} / \mathrm{gram}$ dust for intervention and placebo groups at runin and after one and two years.

No significant difference in ICS dose was found between the intervention and control groups during the two-year follow-up $(p=0.08)$. Figure 7.3 shows the mean ICS use in the intervention and control groups during the two-year follow-up. 


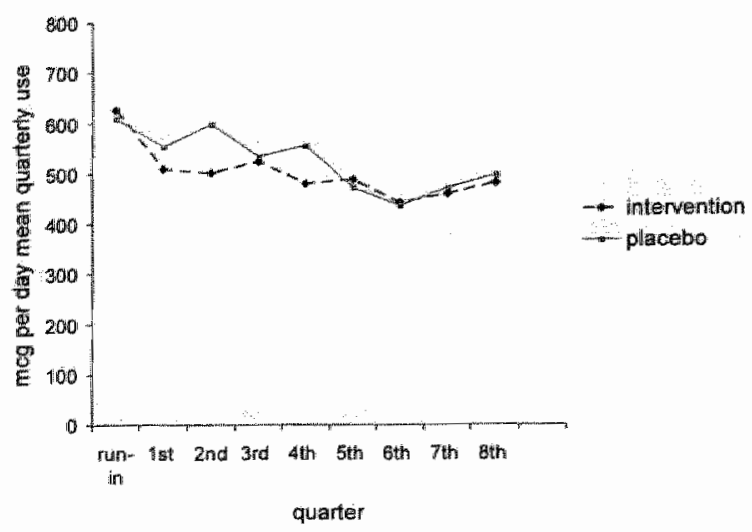

Figure 7.3 ICS use during the study- the mean 3 monthly (quarterly) use of inhaled corticosteroids in mcg per day between intervention and placebo group Differences were tested with a Mann Whitney test; $p=0.08$.

Furthermore, no significant differences between the intervention and control groups were found in morning peak flow $(p=0.52)$, peak flow variability $(p=0.36)$, dyspnoea $(p=0.46)$, wheezing $(p=0.77)$ or coughing $(p=0.41)$ during the follow-up period.

Subgroup analyses did not yield any significant differences for smoking status (current, ex or never smoking), mono versus multiple allergies, HDM allergy low (RAST class 1-3) versus high (RAST class 4-6) or Der $p 1$ concentration at run-in $(<2000 \mathrm{ng} / \mathrm{g}, 2000-10,000 \mathrm{ng} / \mathrm{g}$ or $\geq 10,000 \mathrm{ng} / \mathrm{g}$ ).

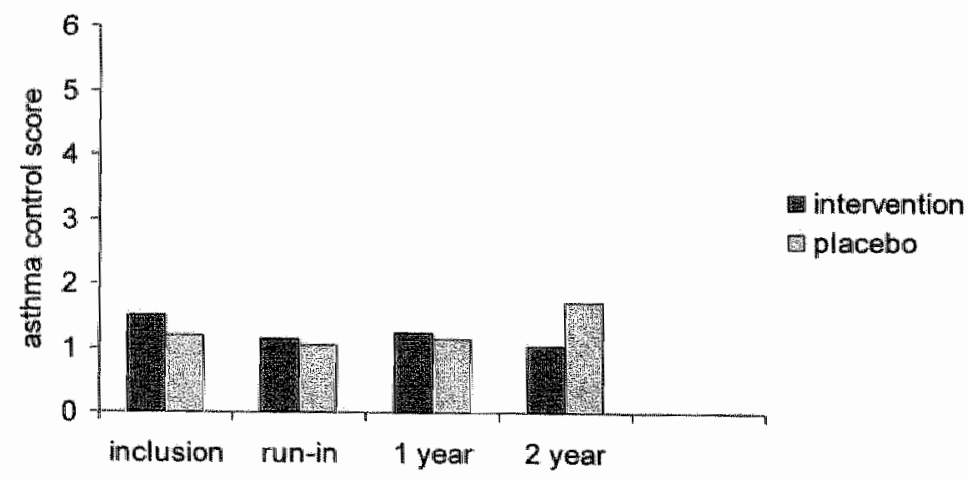

Fightra 7.4 Asthma control during the study - the mean astinma control score between intervention and placebo group. Differences between intervention and placebo group were tested with a Student's t-test, $p=0.27$. 
Figure 7.4 shows asthma control scores for the intervention and control groups during the study.

At run-in, asthma control was good in both the intervention and control groups (mean ACQ score 1.13 vs. 1.05, on a scale from 0 to 6). Mean ACQ scores for the intervention group after one and two years were 1.23 and 1.03 , while the control group had scores of 1.13 and 1.71. Although a difference in asthma control score of more than 0.5 can be regarded as clinically significant ${ }^{32}$, these differences were not statistically significant $(p=0.27)$.

\section{Discussion}

The present study did not find a clear difference in ICS doses between the intervention and control groups during two years of follow-up. Nor were significant differences found in asthma control, morning peak flow, peak flow variability or symptoms.

Symptom scores were already very low during the run-in period, not leaving much room for improvement. HDM allergen concentrations were also very low. At baseline, the majority of patients $(66 \%)$ were exposed to Der $p 1$ concentrations below $2000 \mathrm{ng} / \mathrm{g}$ dust. Other studies in the Netherlands have also found low allergen concentrations ${ }^{26.27}$. A study in a country with a climate comparable to that in the Netherlands found a percentage of $50 \%$ exposed to HDM allergen concentrations below $2000 \mathrm{ng} / \mathrm{g}$ dust at baseline ${ }^{22}$.

The statistically significant difference in allergen exposure between the intervention and control groups does not seem to have led to clinically relevant outcomes. It has been demonstrated before that mattress encasings have a significant but modest effect on HDM allergen llevels for mattresses that already have low mite allergen levels ${ }^{33}$.

A Der p 1 concentration above $2000 \mathrm{ng} / \mathrm{g}$ dust is considered to be the threshold level for sensitisation to HDM allergen, whereas concentrations above $10,000 \mathrm{ng} / \mathrm{g}$ dust can cause acute asthmatic symptoms in sensitised individuals ${ }^{24}$. It could be expected that patients with a high baseline exposure to HDM allergens would benefit more from allergen avoidance than patients who already had a low exposure to these allergens. The number of patients with a baseline exposure higher than $10,000 \mathrm{ng} / \mathrm{g}$ dust was very small $(9 \%)$. Our subgroup analysis of patients with a baseline exposure higher than $10,000 \mathrm{ng} / \mathrm{g}$ did not yield a significant difference in ICS use between the intervention and control groups during the follow-up period.

The majority of the patients $(74.5 \%)$ had already made adjustments to their houses, such as hard-surface floors and limited use of uphoistered furniture, adjustments, which lower Der $\mathrm{p} 1$ concentrations. This large percentage could be due to well-organised asthma care. The Dutch GP practice guidelines for the 
treatment of asthma recommend sanitation measures in patients ${ }^{3}$ homes 28 . lt has been demonstrated before that the concentrations of HDM allergens are lower in homes of atopic patients than in those of non-atopic patients ${ }^{35}$.

Studies of the effects of HDM avoidance measures have shown conflicting results. Several studies, including a Cochrane review, failed to show beneficial effects of HDM avoidance measures $21: 23,30$. However, other studies have reported positive effects on several outcomes $17,20,2427$. One study among children found a reduction in the need for ICS after encasings were applied to mattresses and pillows ${ }^{24}$. Nevertheless, none of the abovementioned studies featured avoidance measures in the context of a self-management plan.

The use of HDM impermeable covers might allow patients in other countries, with a warmer, more humid climate and therefore higher levels of HDM allergens, to taper off ICS.

The self-management plan we used had previously been shown to lower ICS dosages $^{8}$. Another finding of this study was that the costs of domestic HDM allergen avoidance measures were significantly higher in the self-management group than in the usual care group ${ }^{13}$.

It does not seem likely that the results of the present study can be explained by a lack of power, although we did have a relatively high drop-out rate. A post-hoc power calculation showed that with 50 patients in each group completing the study, a difference of $270 \mu g$ was still demonstrated, which we think is reasonable. We used rather stringent selection criteria. All patients had to be sensitised to HDM allergens. Patients with allergies to cats or dogs who were nevertheless keeping these pets were excluded, as well as patients already using impermeable bed covers. This selection has resulted in a population that might profit most from HDM allergen avoidance, without dilution of the effect due to exposure to other relevant allergens. It is therefore likely that the actual effect of the intervention in real life is even smaller than the effect found in this trial.

Asthma control was measured by means of the Asthma Control Questionnaire by Juniper et al. ${ }^{31}$. Asthma was well controlled at baseline and continued to be well controlled during the study in both the intervention and control groups. Asthma control scores were below 2 on a scale from 0 (well-controlled asthma) to 6 (extremely poorly controlled asthma). After two years of follow-up, we found a difference of 0.7 in asthma control scores in favour of the intervention group. Although this is a clinically important difference, it was not statistically significant. Positive effects of self-management on asthma control and other outcomes have been found before ${ }^{9,11,37}$.

The present study found no additional steroid-saving effect of HDM avoidance measures in a self-management plan. A possible explanation could be that the low baseline allergen concentrations in our study resulted in a small contrast between the intervention and control groups, leaving no room for clinically important improvement. The low allergen concentrations might at least partly explain the high 
level of asthma control in our study. On the basis of this study, we cannot conclude that HDM impermeable covers have an added value in a self-management plan for medication use, asthma control, peak flow parameters or symptoms. 


\section{References}

1. Djukanovic R, Roche WR, Wilson JW, Beasley CR, Twentyman OP, Howarth RH, et al. Mucosal inflammation in asthma. Am Rev Respir Dis 1990;142(2):434-57.

2. Juniper $E F, K$ Kine $P A$, Vanzieleghem $M A$, Ramsdale $E H$, O'Byrne $P M$, Hargreave $F E$. Effect of long-term treatment with an inhaled corticosteroid (budesonide) on airway hyperresponsiveness and clinical asthma in nonsteroid-dependent asthmatics. Am Rev Respir Dis 1990;142(4);832-6.

3. Haahtela $T$, Jarvinen $M$, Kava T, Kiviranta $K$, Koskinen $S$, Lehtonen $K$, et al. Comparison of a beta2-agonist, terbutaline, with an inhaled corticosteroid, budesonide, in newly cletected asthma. N Engl I Med 1991;325(6):388-92.

4. Kerstjens HA, Brand PL, Hughes MD, Robinson NJ, Postma DS, Sluiter HI, et al. A comparison of bronchodilator therapy with or without inhaled corticosteroid therapy for obstructive airways disease. Dutch Chronic Non-Specific Lung Disease Study Group. $N$ Engl J Med 1992;327(20):1413-9.

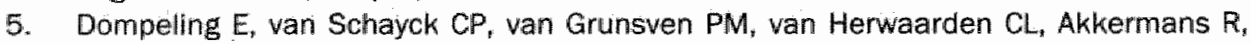
Molema J, et al. Slowing the deterioration of asthma and chronic obstructive pulmonary disease observed during bronchodilator therapy by adding inhaled corticosteraids. A 4year prospective study. Ann Intern Med 1993;118(10):770-8.

6. Kelly HW, Nelson HS. Potential adverse effects of the inhaled corticosteroids. $J$ Allergy Clin Immunol 2003;112(3);469-78.

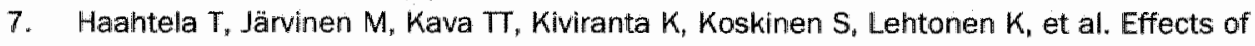
reducing or discontinuing inhaled budesonide in patients with mild asthma. $N$ Engl $J$ Med 1994;331:700-5.

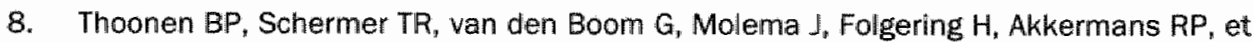
al. Self-management of asthma in general practice, asthma control and quality of life: a randomised controlled trial. Thorax 2003;58(1):30-6.

9. Powell H, Gibson PG. Options for self-management education for adults with asthma. Cochrane Database of Syst Rev 2002(3):Art.No.:CD004107. DOI: 10.1002/ 14651858.CD004107.

10. Lahdensuo A, Haahtela $T$, Herrala J, Kava $T$, Kiviranta $K_{w}$ Kuusisto $P$, et al. Randomised comparison of guided self management and traditional treatment of asthma over one year. Br Med I 1996;312(7033):748-52.

11. Beasly $R$, Cushley $M$, Holgate ST. A self management plan in the treatment of adult asthma. Thorax 1989;44:200-4.

12. Gibson $P G$, Powell $H$. Written action plans for asthma: an evidence-based review of the key components. Thorax 2004;59(2):94-9.

13. Schermer TR, Thoonen $B P$, van den Boom $G$, Akkermans RP, Grol RP, Folgering $H T$, et al. Randomized contralled economic evaluation of asthma self-management in primary health care. Am J Respir Crit Care Med 2002;166(8):1062-72.

14. Colloff MJ, Ayres J, Carswell F. Howarth PH, Merrett TG, Mitchell EB, et all. The control of allergens of dust mites and domestic pets: a position paper. Clin Exp Allergy 1992;22 Suppl 2:1-28.

15. Custovic A, Taggart SCO, Francis HC, Chapman MD, Woodcock A. Exposure to house dust mite allergens and clinical activity of asthma. I Allergy Clin Immunol 1996;98(1):64-72.

16. Hegarty $J M_{1}$ Jessop WJ, Warner JA, Warner JO. The effect of a bed covering system on airborne levels of house dust mite allergen. Allergy 1993;48:108.

17. Walshaw MJ, Evans CC. Allergen Avoidance in House Dust Mite Sensitive Adult Asthina. Q J Med 1986;226(New Series 58):199-215. 
18. Owen $S$, Morganstern $M$, Hepworth J, Woodcock A. Control of house dust mite antigen in bedding. Lancet 1990;335(8686):396-7.

19. Cloosterman SGM, Hofland ID, van der Heide S, Folgering HTM, van den Elshout FJ!, van Schayck CP. Long-term effects of matress covers on house dust mite (Der-p-1). Eur Respir J 1995;8(S19):499S.

20. van der Heide $S$, Kauffman HF, Dubois AE, de Monchy JG. Allergen reduction measures in houses of allergic asthmatic patients: effects of air-cleaners and allergenimpermeable mattress covers. Eur Respir $\ 1997 ; 10(6): 1217-23$.

21. Gotzsche PC, Johansen HK, Schmidt LM, Burr ML. House dust mite control measures for asthma. Cochrane Database of Syst Rev 2004(4):Art. No:: CD001187.pub2. DOI: 10.1002/14651858.C0001187.pub2.

22. Woodcock A, Forster L, Matthews E, Martin J, Letley $L_{n}$ Vickers $M$ et al. Control of exposure to mite allergen and allergen-impermeable bed covers for adults with asthma. N Engl J Med 2003;349(3):225-36.

23. Rijssenbeek-Nouwens LHM, Oosting AJ de Bruin-Weller MS, Bregman I, de Manchy JG, Postma DS. Clinical evaluation of the effect of anti-allergic mattress covers in patients with moderate to severe asthma and house dust mite allergy: a randomised double blind placebo controlled study. Thorax 2002;57:784-90.

24. Halken S, Host A, Niklassen U, Hansen L, Nielsen F, Pedersen S, et al. Effect of mattress and pillow encasings on children with asthma and house dust mite allergy. $J$ Allergy Clin Immunol 2003;111:169-76.

25. Cloosterman SGM, Hofland ID, Lukassen HGM, Wieringa MH, Folgering HTM, van der Heide $S$, et al. House dust mite avoidance measures improve peak flow and symptoms in patients with allergy but without asthma: A possible delay in the manifestation of clinical asthma? J Allergy Clin Immunol 1997;100:313-9.

26. Cloosterman SG, Schermer TR, Bijl Hofland ID, van der Heide S, Brunekreef $B$, van den Elshout $\mathrm{FJ}_{\text {, }}$ et al. Effects of house dust mite avoidance measures on Der $p 1$ concentrations and clinical condition of mild adult house dust mite-allergic asthmatic patients, using no inhaled steroids. Clin Exp Allergy 1999;29(10):1336-46.

27. van den Bemt $L$, van Knapen $L$, de Vries MP, Jansen M, Cloosterman $S$, van Schayck $C P$. Clinical effectiveness of a mite allergen-impermeable bed-covering system in asthmatic mite-sensitive patients. I Allergy Clin Immunol 2004;114(4):858-62.

28. Geijer RMM, Van Hensbergen W, Bottema BJAM, Van Schayck CP, Sachs APE, Smeele IIM, et al. NHG-Standaard Astma bij Volwassenen: Behandeling (NHG Guideline on Asthma in Adults: Treatment). Huisarts Wet 2001:44(4):153-64.

29. Global Initiative for Asthma. Global Strategy for asthma management and prevention: NIH publication No. 02-3659 Issued January, 1995(updated 2002).

30. Lipworth BJ. Pharmacokinetics of inhaled drugs. Br J Clin Pharmacol 1996;42(6):697. 705.

31. Juniper EF, OByme PM, Guyatt GH, Ferrie PJ, King DR. Development and validation of a questionnaire to measure asthma control. Eur Respir J 1999,14(4):902-7.

32. Juniper EF, Stahl E, O'Byrne PM. Minimal important difference for the asthma control questionnaire. Am J Respir Crit Care Med 2001;163:642 (A).

33. van Strien RT, Koopman LP, Kerkhof $M$, Oldenwening $M$, de Jongste $J C_{\text {s }}$ Gerritsen $J$, et al. Mattress encasings and mite allergen levels in the Prevention and Incidence of Astinma and Mite Allergy study. Clin Exp Allergy 2003;33(4):490-5.

34. Platts-Mills TAE, Vervloet $D$, Thomas WR, Aalberse RC, Chapman MD. Indoor allergens and asthma: report of the third international workshop. I Allergy Clin Immunol 1997;100(6):S1-S24. 
35. van Strien $\mathrm{RT}$, Verhoeff AP, van Wijnen $\mathrm{JH}$, Doekes $\mathrm{G}$, de Meer GE, Brunekreef $\mathrm{B}$. Der $\mathrm{p} 1$ concentrations in mattress surface and floor dust collected from infants* bedrooms. Cin Exp Allergy 1995,25(12):1184-9.

36. Terreehorst I, Duivenvoorden HJ, Tempels-Pavlica $Z$, Oosting AJ, Monchy JGR, Bruijnzeel-Koomen CAFM, et al. The effect of encasings on quality of life in adult house dust mite allergic patients with rhinitis, asthma and/or atopic dermatitis. Allergy $2005 ; 60(7): 888-93$.

37. Gibson PG, Powell $H$, Coughlan J, Wilson AJ, Abramson M, Haywood P, et al. Selfmanagement education and regular practitioner review for adults with asthma. Cochrane Database of Syst Rev 2002(3):Art.No.: CD001117. D0ll: 10.1002/ 14651858.00001117. 
Chapter

8

General discussion 


\section{Introduction}

In this thesis, several aspects of asthma control in general practice and the effect of house dust mite (HDM) avoidance measures as part of a self-management plan have been investigated. The main conclusions of the studies described in this thesis were as follows. Chapter 2 showed that almost fifty percent of the patients with asthma in primary care were sensitised to HDM allergen, which is on the lower range according to the international literature. Only a minority of these patients was using HDM impermeable covers. In Chapter 3, we found that a cotton upper layer of the mattress and lower relative humidity were associated with lower levels of Dermatophagoides pteronyssinus allergen 1 (Der $p$ 1) found on mattresses. In Chapter 4 , we found that low socic-economic status (SES), current smoking, high dose of inhaled corticosteroids (ICS) and perceived hyperresponsiveness (PHR) for multiple triggers were independently associated with poorer asthma control. We concluded that stopping smoking and avoidance of triggers are factors that probably have a high impact on asthma control. Chapter 5 demonstrated that a self-management plan seemed to be able to maintain or improve asthma control in patients with persistent asthma. Chapter 6 indicated that high exposure to HDM allergen seemed to coincide with the use of higher dose ICS in asthma patients sensitised to HDM allergen. Finally, in Chapter 7 we concluded that HDM impermeable covers combined with self-management do not lead to less use of ICS or improved asthma control compared to self-management alone.

In this general discussion, these results will be placed in the view of their consequences for daily practice. This chapter will end with recommendations for further research.

\section{Asthma control}

Asthma control is the goal of asthma treatment according to international guidelines ${ }^{1,2}$. Optimal control can be characterised by minimisation of chronic asthma symptoms during day and night, prevention of asthma exacerbations, maintaining normal activity levels, optimising lung function, reducing the need for relieving $\beta_{2}$-agonist therapy, and minimising side effects of medication. Therefore; optimal control contributes to a reduction of the risk of exacerbations and longterm morbidity.

Several studies showed asthma to be poorly controlled in most patients ${ }^{3,4}$. In the study population used for the studies presented in this thesis, asthma was well controlled, as described in Chapter 7, at the start of the trial, and remained well during the trial. Asthma control was measured by means of the Asthma Control Questionnaire $(\mathrm{ACQ})^{5}$. The $\mathrm{ACQ}$ has proved to be a valid instrument with good discriminative properties. It gives a good estimation of asthma control perceived by 
asthma patients. Whereas asking physicians about their patients' disease control often leads to overestimation. "Part of this well controlled asthma could be due to the so-called in care' effect, which means that patients are feeling better when they are participating in a study. Nevertheless, we think that the "in care" effect mainly played a part in the beginning of the study. In the two-year follow-up period patients only received a home visit every six morths.

We found a positive effect of self-management on asthma control, especially in patients with severe asthma. This group had the least well-controlled asthma at the start of the study, which leaves more room for improvement in comparison with patients with less severe asthma. If we would have included less well-controlled patients more effects of self-management might have been found. Positive effects of selfmanagement plans on asthma control and other asthma outcomes have been demonstrated before ${ }^{7-9}$.

Factors associated with asthma control were investigated in a cross-sectional design. Low socio-economic status, current smoking, high dose of inhaled corticosteroids and perceived hyperresponsiveness for multiple triggers demonstrated to be independently associated with poorer asthma control. The largest association demonstrated was with perceived hyperresponsiveness for multiple triggers, followed by current smoking. Interventions focussed on reducing hyperresponsiveness and quitting smoking will probably lead to improvement of asthma control.

\section{Allergen avoidance as a component of self-management}

Self-management plans have shown to lead to positive outcomes in asthma9. Selfmanagement plans are appropriate to keep the dose of imhaled steroids at the optimum level. Furthermore, these self-management plans proved to have positive effects on several asthma outcomes $7,8,10,11$. Especially individualised written action plans based on personal best peak expiratory flow (PEF), using action points, and recommending both inhaled and oral corticosteroids (OCS) for early treatment of exacerbations consistently improve asthma health outcomes. These observations support the use of individualised written action plans ${ }^{12}$. Mast self-management plans are multi-faceted, however, which specific components are effective is not yet completely known. Therefore, the main hypothesis that has been tested in this thesis was whether allergen avoidance is an efficacious component of selfmanagement plans, i.e. whether a combination of allergen avoidance with selfmanagement leads to less use of ICS than self-management alone.

All patients were trained to use a self-management plan, so they could lower the dose of ICS to the lowest possible dose, which kept their asthma well controlled. This self-management plan has shown before to have a steroid saving effect, when compared to usual care ${ }^{11}$. 


\section{Instruction of self-management plan}

In our study trained research nurses carried out the instructions of the selfmanagement plans in the majority of the patients, the other patients were instructed by the general practitioner (GP). We found no differences between the group instructed by the GP and the group instructed by the nurse. Although our study was not designed to compare the possible differences between GPs and nurses, we did not find any indications that the patients receiving instructions by the nurse performed the self-management plan differently than the patients instructed by the GP. Apparently, nurses can do the instructions and follow up of the self-management plan adequately. As the instruction and follow up of the selfmanagement plan do take a lot of time, it might be advisable to dellegate this to a practice nurse or nurse practitioner.

\section{Allergen avoidance}

We could not demonstrate an additional steroid-saving effect of allergen avoidance as component of a self-management plan, compared to self-management without allergen avoidance. Furthermore, we could not find beneficial effects of allergen awoidance on asthma control, symptoms, and peak flow values above the effects of self-management alone. Consequently, on the basis of the results of our study presented in Chapter 7, we cannot recommend the use of HDM impermeable covers as part of a self-management plan to asthma patients sensitised to HDM allergen. Several studies to the effect of HDM allergen avoidance show conflicting results ${ }^{13-20}$. Both positive and lack of effects have been reported.

In this trial, we used stringent criteria for patients to be included. Therefore, the results cannot be extrapolated to all asthma patients. With the present inclusion criteria, however, there was a better chance of finding an effect of the HDM allergen avoidance, as all patients were sensitised to HDM allergen. Moreover, patients with an allergy to pets, whilst keeping them, were excluded. As covers are not giving an additional steroid saving effect in our patients, it is very unlikely that it will give a better result in the general asthma population. Other studies that fail to demonstrate effects of HDM allergen avoidance measures sometimes also included patients, which were not sensitised to HDM allergen ${ }^{14}$.

On the other hand, there is still a possibility that allergen avoidance does work in other patients, than we included in the study. We selected patients between 16 and 60 years old. A study performed in children with asthma showed clear results of allergen avoidance on several outcomes ${ }^{18}$. After one year significantly more children in the active treatment group could reduce the dose of ICS by at least fifty percent compared to the placebo group. Apart from age, another possible 
explanation of this positive result could be the higher baseline concentration of HDM allergen to which patients were exposed in that study.

Cloosterman et al. demonstrated an improvement of peak flow in patients with allergy for HDM allergen, but no diagnosis of asthma (yet)19. This observation implicates that the effectiveness of HDM avoidance measures may depend on the stage of asthma20;21. In an early stage of asthma the clinical threshold of HDM levels to provoke symptoms might be higher than in established asthma. In HDM sensitised patients with established asthma the exposure to HDM allergen may, therefore, be lowered much more radically to achieve an effect on reducing symptoms compared to patients in an early stage of asthma. In an earlier study performed by our group, we also demonstrated a significant improvement of morning peak flow in mild asthma patients between 12 and 60 years old (mean age 33.8 years). Not all of these mild asthma patients were using ICS ${ }^{17}$. These findings, again support the possibility that HDM avoidance could be effective in younger patients or in an earlier stage of asthma.

Our study had a follow-up period of two years, in which also a long-term effect would have been found, when present. Mattress encasings have demonstrated before an improvement on bronchial hyperresponsiveness after six months ${ }^{22}$.

We found some indications in chapter 6 that exposure to higher concentrations of allergens seems to lead to the use of more ICS. This seems contradictory to the results in chapter 7 , where we could not demonstrate an effect of HDM allergen avoidance on inhaled corticosteroid use. It is likely that particularly patients with a high exposure to HDM allergen benefit from allergen avoidance, as these patients seem to use more ICS than patients exposed to lower allergen cancentrations. In case of low concentrations of HDM allergen, further reducing exposure to allergens is not likely to lead to less use of ICS. The association between allergen exposure, allergen avoidance and the use of ICS should therefore be further investigated.

Since the use of higher dosage of ICS leads to more side effects, high dosages should be avoided when possible ${ }^{23.24}$. Mild asthma patients can be treated with intermittent courses of ICS in case symptoms worsen. This can be done without clinically significant deterioration compared to daily treatment with 1 CS25.26. Discontinuation of treatment with ICS should be carefully monitored; atherwise it could lead to exacerbations ${ }^{27}$.

We could not to demonstrate a significant difference in $1 C 5$ use between the exposure groups. Apart from the lack of efficacy one should consider other explanations. It might be explained by lack of contrast in exposure, since the majority of the patients already had low exposure to HDM allergen at baseline. It could be also explained by lack of power, since we only had a small number of patients in the high exposure group. Only if there would have been a very large difference in medication use between intervention and control group we would have been able to detect this difference. 
The allergen concentrations present at baseline were already very low. Most patients had already taken some sanitation measures in their houses. Therefore, the contrast between the intervention and control group was very small. It could be expected that rigorous allergen avoidance compared with no allergen avoidance would have led to a larger contrast in allergen exposure and, maybe, to a difference in medication use. This would mean that allergen avoidance could still be advocated, maybe with covers as a component of allergen avoidance in home.

Probably in other areas of the world, where natural exposure to HDM allergen is higher, encasings would be of more benefit, leading to more contrast in exposure. Perhaps, this could result in less medication use.

\section{Reimbursement of covers}

In the Netherlands insurance companies are reimbursing the cost of HDM impermeable covers when HDM allergy is diagnosed. After a Cochrane review with a negative conclusion towards HDM allergen avoidance ${ }^{13}$, insurance companies are reconsidering this reimbursement. It might well be ended in the very near future, since the Health Care Insurance Board has recently advised to quit the reimbursement of these encasings.

Termination of the reimbursement of covers by insurance companies would definitely lead to an increase in price for patients who still would want to use these covers.

The use of allergen avoidance measures is proposed in several guidelines, in and outside the Netherlands ${ }^{1,28}$. The advice of using HDM impermeable covers might be reconsidered due to the lack of clear results. However, even with the present result of this thesis, we do think there is currently no evidence to discourage actively the use of these covers. We are not aware of any clear disadvantages of the use of covers, and there are several studies showing positive results $\mathbf{s}^{17-19,22}$.

We have studied the association between mattress characteristics and HDM allergen concentrations on mattresses. We have found indications that a cotton upper layer of the mattress seems to be associated with lower HDM allergen concentrations. This finding should be further investigated, but could eventually lead to an advice for patients sensitised to HDM allergen to choose certain types of mattresses.

\section{Consequences for daily practice}

Asthma control is the goal of asthma treatment in national and international guidelines ${ }^{1,2,28}$. We found the Asthma Control Questionnaire very useful in our study; also because the Asthma Control Questionnaire is relatively easy to use in 
daily practice. If there is no measurement of lung function available to quantify airflow limitation, it is also possible to use a shortened version of the questionnaire with omission of the FEV 1 item ${ }^{29}$. Asthma control should be used more often and measured with a standardised method to evaluate the effect of therapy in asthma patients.

One should reconsider the advice to use mattress encasings, especially in circumstances with low allergen exposure. Probably other adjustments indoors might lead to sufficient allergen reduction to this part of the population of asthma patients sensitised to HDM allergen ${ }^{30}$.

The use of self-management plans should be advocated more actively. They have shown to lead to better asthma control. However, one should take into consideration that it is not completely clear at the moment, which patients benefit most or which do not benefit from self-management plans; and which components are effective and which not. Nevertheless, in the study presented in chapter 5, we found indications that especially patients with severe persistent asthma seem to benefit from self-management. Furthermore, in chapter 7 , we have demonstrated that allergen avoidance with mattress encasings have not proved to be an effective component of self-management plans.

\section{Recommendations for future research}

The association between exposure to HDM allergen and the use of ICS should be further investigated. It could be possible that patients with a high exposure to HDM allergen might benefit from mattress encasings. These encasings could lead to larger contrast in exposure in these particular patients, resulting in different medication use, in the sense of a better possibility of tapering off ICS. So, we would recommend repeating this study in circumstances with a higher baseline HDM concentration. It would also be interesting to investigate whether there is a subpopulation within the total group of asthma patients, which might benefit from mattress encasings.

The influence of mattress characteristics on HDM allergen concentrations should be subject of further research, as it could lead to a relatively cheap measure for reduction of allergen exposure.

More research should focus on asthma control as an outcome a measure. Asthma control is the goal of asthma management and is, therefore, a very appropriate outcome measure. We would recommend measuring asthma control in a standardised method, so results of different treatment regimens or different groups of patients can be more easily compared. Asthma control as an outcome measure can demonstrate whether treatment regimens meet guideline criteria.

The effect of self-management on asthma control in previously uncontrolled patients would be another interesting subject to investigate. In Chapter 5, we found 
an indication that self-management plans are able to maintain or improve asthma control in patients with persistent asthma, especially in patients with severe asthma. We would recommend testing this hypothesis in a controlled trial. Which asthma patients do benefit most from self-management? Is there a different effect of self-management in patients with different severity categories of persistent asthma?

This thesis has contributed to the positioning of allergen avoidance as part of selfmanagement plans. HDM impermeable covers have not appeared to be an effective component of self-management plans.

More research should focus on the 'fine-tuning' of self-management plans. Which elements precisely are effective and which are ineffective components has yet to be established. 


\section{References}

1. Global Initiative for Asthma. Global Strategy for asthma management and prevention: NIH publication No: 02-3659 Issued January; 1995(updated 2002\%.

2. BTS/SIGN British Guideline on the Management of Asthma. Thorax 2003,58(supplement 1):1-83.

3. Rabe $K F$, Vermeire $P A$, Sorlano JB, Maier WC. Clinical management of asthma in 1999: the Asthma Insights and Reality in Europe (AIRE) study. Eur Respir $\ 2000 ; 16(5): 802-7$.

4. Wijnhoven HAH, Kriegsman DMW, Hesselink AE, de Haan M, Stalman W. Disease contral in general practice patients with asthma. Prim Care Respir J 2004;13:89-98.

5. Juniper $E F$, O'Byrne PM, Guyatt GH, Ferrie PJ, King DR. Development and vallidation of a questionnaire to measure asthma control. Eur Respir J 1999;14(4):902-7.

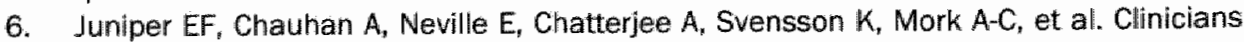
tend to overestimate improvements in asthma control: an unexpected observation. Prim Care Respir $12004 ; 13(4): 181-4$.

7. Powell $H_{1}$ Gibson $P G$. Options for self-management education for adults with asthma. Cochrane Database Syst Rev 2002(3):Art.No.:CD004107. DOl: 10.1002/14651858. CD004107.

8. Beasly $R$, Cushley $M$. Holgate ST. A self management plan in the treatment of adult asthma. Thorax 1989;44:200-4.

9. Gibson PG, Powell H, Coughlan J, Wilson A, Abramson M, Haywood P, et al. Selfmanagement education and regular practitioner review for adults with asthma. Cochrane Database Syst Rev 2002(3):Art. No.: CD001117. Dol: 10.1002/14651858. CD001117.

10. Lahdensuo A, Haahtela T, Herrala J, Kava T, Kiviranta K, Kuusisto P, et al. Randomised comparison of guided self management and traditional treatment of asthma over one year. $\mathrm{Br}$ Med J 1996;312(7033): 748-52.

11. Thoonen BP, Schermer TR, van den Boom G, Molema J, Folgering H, Akkermans RP, et al. Self-management of asthma in general practice, asthma control and qualitity of life: a randomised controlled trial. Thorax 2003;58(1):30-6.

12. Gibson $P G$, Powell $H$. Written action plans for asthma: an evidence-based review of the key components. Thorax $2004 ; 59(2): 94-9$.

13. Gotzsche $\mathrm{PC}$, Johansen HK, Schmidt LM, Burr ML. House dust mite control measures for asthma. Cochrane Database Syst Rev 2004(4):Art. No.: CD001187.pub2. DOl: 10.1002/14651858.CD001187.pub2.

14. Woodcock A, Forster L, Matthews E, Martin J, Letley L, Vickers M, etl al. Control of exposure to mite allergen and allergen-impermeable bed covers for adults with asthma. N Engl J Med 2003;349(3):225-36.

15. Rijssenbeek-Nouwens LHM, Oosting AJ, de Bruin-Weller MS, Bregman I, de Monchy JG, Postma DS. Clinical evaluation of the effect of anti-allergic mattress covers in patients with moderate to severe asthma and house dust mite allergy: a randomised double blind placebo controlled study. Thorax 2002;57:784-90.

16. Terreehórst I, Duiwenvoorden HJ, Tempels-Pavlica $Z$, Oosting AJ, Monchy JGR, Bruijnzeel-Koomen CAFM, et al. The effect of encasings on quality of life in adult house dust mite allergic patients with rhinitis, asthma and/or atopic dermatitis. Allergy $2005 ; 60(7): 888-93$.

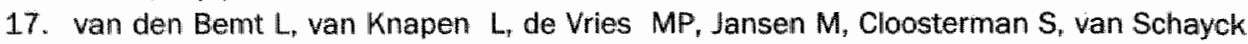
CP. Clinical effectiveness of a mite allergen-impermeable bed-covering system in asthmatic mite-sensitive patients. J Allergy Clin Immunol 2004;114(4):858-62. 
18. Halken $S$, Host $A_{n}$ Niklassen $U_{v}$ Hansen $L$, Nielsen $F$, Pedersen $S$, et al. Effect of mattress and pillow encasings on children with asthma and house dust mite allergy. I Allergy Clin Immunol 2003;111:169-76.

19. Cloosterman SGM, Hofland ID, Lukassen HGM, Wieringa $M H_{*}$, Folgering HTM, van der Heide S, et al. House dust mite avoidance measures improve peak flow and symptoms in patients with allergy but without asthma: A possible delay in the manifestation of clinical asthma? J Allergy Clin Immunol 1997;100:313-9.

20. Cloosterman SG, Schermer TR, Bijl Hofland ID, van der Heide S, Brunekreef B, van den Elshout FJ, et al. Effects of house dust mite avoidance measures on Der $\mathrm{p} 1$ concentrations and clinical condition of mild adult house dust mite-allergic asthmatic patients, using no inhaled steroids. Clin Exp Allergy 1999;29(10):1336-46.

21. Cloosterman SGM, van Schayck OCP. Effectiveness of measures depends on stage of asthma. Br Med J 1999;318:870.

22. van der Heide S, Kauffman HF, Dubois AE, de Monchy JG. Allergen-avoidance measures in homes of house-dust-mite-allergic asthmatic patients: effects of acaricides and mattress encasings. Allergy 1997;52(9):921-7.

23. Kelly HW, Nelson HS. Potential adverse effects of the inhaled corticosteroids. J Allergy" Clin Immunol 2003;112(3):469-78.

24. Allen $\mathrm{DB}$, Bielory L, Derendorf $H$, Dluhy $R$, Colice GL, Szefler SJ. Inthaled corticosteroids: past lessons and future issues. I Allergy Clin Immunol 2003;112(3 Supp)):S1-40.

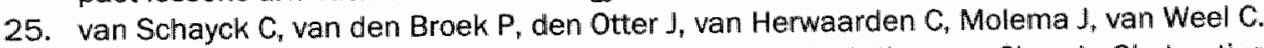
Periodic Treatment Regimens With Inhaled Steroids in Asthma or Chronic Obstructive Pulmonary Disease: Is It possible? JAMA 1995;274:161-4.

26. Boushey HA, Sorkness CA, King TS, Sullivan SD, Fahy JV, Lazarus SC, et al. Daily versus As-Needed Corticosteroids for Mild Persistent Asthma. $N$ Engl J Med 2005;352(15):1519-28.

27. Haahtela $T$, Järvinen $M$, Kava $T$, Kiviranta $K$, Koskinen $S$, Lehtonen $K$, et all. Effects of reducing or discontinuing inhaled budesonide in patients with mild asthma. $N$ Eng $J$ Med 1994;331:700-5.

28. Geijer RMM, van Hensbergen W, Bottema BJAM, van Schayck CP, Sachs APE, Smeele UIM, et al. NHG-Standaard Astma bij Volwassenen: Behandeling (NHG Guideline on Asthma in Adults: Treatment). Huisarts Wet 2001;44(4):153-64.

29. Juniper EF, Svensson $K$, Mork $A-C_{n}$ Stahl E. Measurement properties and interpretation of three shortened versions of the asthma control questionnaire. Respir Med $2005 ; 99(5): 553-8$.

30. Custovic A, Simpson BM, Simpson A, Hallam $C_{n}$ Craven $M$, Brutsche $M$, et al. Nanchester Asthma and Allergy Study: low-allergen environment can be achieved and maintained during pregnancy and in early life. $\$ Allergy Clin Immunol 2000"105(2 Pt 1):252-8. 
Summary 
In this thesis, several aspects of asthma control in general practice are presented: The main focus, however, is on self-management and allergen avoidance. More specific, the main question is whether house dust mite (HDM) allergen avoidance by means of mattress encasings is an effective component of a self-management plan.

In Chapter 1 some general aspects of asthma and the aim of the thesis are discussed. The goal of asthma management is achieving asthma control for all types of severity of asthma. Asthma control can be characterised by minimisation of chronic asthma symptoms during day and night, prevention of asthma exacerbations, maintaining normal activity levels, optimising lung function, reducing the need for relieving $\beta$-agonist therapy, and minimising side effects of medication. Since the publication of the Asthma Control Questionnaire ${ }^{\circ}$ (ACQ) a validated instrument for measuring asthma control is available. The ACQ integrates different aspects of asthma control in one instrument. In Appendix B on page 133 an example of the ACQ is shown. The asthma control score is ranging from $O$ (wellcontrolled asthma) to 6 (extremely poorly controlled asthma).

Inhaled corticosteroids (ICS) are the cornerstone of asthma treatment, since these drugs treat the underlying inflammatory process. Because of possible side effects it is important to keep the dose as low as possible.

Self-management is defined as effective behaviour regarding asthma, based on sufficient knowledge about asthma and its provoking factors, adequate coping behaviour, compliance with inhaled medication, attention to changes in severity of the disease, adequate technique of inhaling medicines, and the correct use of a peak flow meter. Especially individualised written action plans based on personal best peak expiratory flow (PEF), using some action points, and recommending both ICS and oral corticosteroids (OCS) for treatment of exacerbations consistently improve asthma health outcomes.

HDM allergy plays an important role in asthma. Reducing exposure to allergens in sensitised patients might lead to fewer symptoms. Covers around mattresses, pillow and bedding have shown to be the best way of reducing exposure to HDM allergen. The results of studies investigating the effect of HDM impermeable covers on several clinical outcomes are, however, conflicting.

The main question of this thesis is whether we can achieve use of less ICS and better asthma control in general practice by combining self-management and allergen avoidance.

In Chapter 2 the results of a study investigating the prevalence of HDM sensitisation in a primary care population were presented. Furthermore, the current use of HDM impermeable mattress encasings was assessed.

In literature figures of HDM sensitisation are varying widely, from 45 till $85 \%$. Various guidelines support the use of HDM impermeable covers in different 
countries. In the Netherlands, insurance companies are reimbursing the cost of covers when HDM allergy is diagnosed. As a consequence, a setting for widespread use by allergic asthmatic patients is provided. However, it is uncertain to which extent HDM allergic asthmatic patients in the Netherlands are using these covers at the moment.

From general practices a random sample of asthma patients between 16 and 60 years old was taken. Allergy was assessed with a RAST (radio-allergo-sorbent test). A questionnaire was used to identify demographic characteristics and the actual use of bed covers. 534 patients were invited and 160 patients participated. 53 patients not willing to participate were randomly selected to test the external validity of our findings. The sample was representative for the primary care asthma population. Almost half of the patients (48.8\%) with asthma were sensitised to HDM allergen. Only a minority of the patients sensitised to HDM allergen (25.6\%) used HDM impermeable bed covers.

In Chapter 3 the results of a study assessing the influence of mattress characteristics on HDM allergen concentration are presented. Mattresses are one of the most important sources of HDM allergen in people's living environment. Microenvironment and food supply in bed are ideal for mite growth. Moreover; people spend approximately eight hours each day in bed in close contact with these allergens.

Dust samples of mattress surfaces were taken to evaluate the level of Dermatophagoides pteronyssinus allergen 1 (Der $\mathrm{p} 1$ ). 168 participants filled in a questionnaire about the type of mattress, the type of covering (upper layer) of the mattress, dwelling characteristics and cleaning habits. Humidity and temperature of the bedroom were measured at the time of dust sampling. Two factors were associated with lower levels of Der $\mathrm{p} 1$ found on mattresses, namely a cotton upper layer of the mattress compared to a layer of synthetic material $10.8 \mathrm{vs} .2 .6 \mu \mathrm{g} / \mathrm{g}$ Der $p$ 1, $p<0.05)$ ) and lower relative humidity at the time of sampling. The association between type of upper layer and concentration of Der $p 1$ should be further investigated, but could lead to the formulation of practical advices in order to reduce HDM allergen concentrations on mattresses.

In Chapter 4 the results of a study evaluating which factors are associated with asthma control experienced by asthma patients, are presented. In a cross-sectional study patients aged 16 till 60 years with mild to moderate asthma were selected. The influence of the following factors on asthma control was studied in a multivariate model: age, gender, socio-economic status (SES), smoking, perceived hyperresponsiveness (PHR, responding with asthma symptoms to one or more of the following triggers: changes in weather circumstances, humidity in the house, open fireplace, strong odours, and exercise), allergy (phadiatop ${ }^{\circledast 1}$ ), long-acting 
bronchodilating agents (LABA), and ICS. Asthma control was measured by means of the Asthma Control Questionnaire (ACQ, Appendix B on page 133).

In this study with 311 patients, mean $A C Q$ score was 1.39 (range 0-4.43). A stepwise backward linear regression analysis showed that low SES, current smoking, high dose of ICS, and PHR for increasing number of different triggers are independent predictors for poorer asthma control.

The findings from this study suggest that asthma management should not only aim at prescribing medication. Stop smoking and the avoidance of triggers are also factors, which may have a high impact on asthma management. Our findings thus support the current understanding that a combined approach, which integrates both medical and behavioural elements e.g. stop smoking and reduce exposure to triggers, is needed to optimise asthma control.

In Chapter 5, we explored the level of asthma control for different severity categories of asthma in a primary care population of asthma patients and evaluated which patients' benefit most from using a self-management plan.

In this study, asthma severity was determined by means of dose of ICS, current use of $\angle A B A$ and forced expiratory volume in one-second (FEV 1 ) percentage of predicted. Patients were divided in one of the following categories: mill persistent, moderate persistent, or severe persistent, according to GINA guidelines.

Asthma contral was measured by means of the five items Asthma Control Questionnaire (ACQ, Appendix B on page 133). Patients were trained to use the self-management plan to adjust the dose of ICS to symptoms and peak expiratory flow (PEF) value. In Appendix A on page 129 a summary of the self-management plan is displayed. Sixty-seven patients were included. Baseline asthma control score was good in all severity categories (mean asthma control score in mild persistent: 0.54; moderate: 0.96; severe: 1.61 ; analysis of variance (difference between groups) $p=0.001$, asthma control score on a scale from 0 , well controlled through 6, extremely poor controlled). After one year of self-management, asthma control was maintained in the mild persistent group, and was improved in the patients with moderate and severe persistent asthma (mild persistent: 0.58 ; moderate: 0.71 ; severe: 1.27 ; analysis of variance (difference within groups) $p=0.014$ ).

On the basis of this study, we conclude that a self-management plan might to be able to maintain or improve asthma control in patients with persistent asthma, especially in the group with severe persistent asthma.

In Chapter 6 the results of an observational study are presented. in this observational study we try to find out whether high exposure to house dust mite (HDM) allergens is hampering tapering off ICS. Asthma patients sensitised to HDM allergen and using ICS were selected from primary care practices. From the 
mattresses dust samples were taken to assess exposure (no, low, intermediate, or high) to HDM allergen with a semi-quantitative test (Acarex).

Patients were trained to use a self-management plan (Appendix A on page 129) to adjust the dose of ICS to symptoms and peak flow. The observation period was 3 months.

The outcomes of 123 patients were analysed. Within the no and low exposure to HDM allergen group the proportion of patients that raised the dosage of their medication was significantly lower than the proportion that tapered off or remained on the same dose of ICS. The group with high exposure to HDM allergen had the highest proportion of patients that had to raise the dose of ICS.

On the basis of this study we conclude that high exposure to HDM allergen seems to coincide with the use of higher dose of ICS in HDM sensitised asthma patients.

The efficacy of HDM impermeable covers is still subject of debate. The aim of the study presented in Chapter 7 was to investigate whether the combination of HDM impermeable covers and a self-management plan based on peak flow values and symptoms leads to less use of ICS than self-management alone. Asthma patients between 16 and 60 years with an allergy to HDM and requirement of ICS were included. They were trained to use a self-management plan based on peak flow and symptoms. in Appendix A on page 129 a summary of the self-management plan is shown. After a three-month training period, the intervention with HDM impermeable and placebo bed covers started. The follow-up period was two years.

The primary outcome was the use of ICS; secondary outcomes were peak expiratory flow (PEF) parameters, asthma control and symptoms.

126 patients started the intervention with covers. After one and two years, significant differences were found on allergen exposure between the intervention and control group $(p<0.001)$. Baseline allergen concentrations were very low, which was probably haps due to sanitation measures patients had already taken in their houses. Therefore, the contrast between the intervention and control group was very small.

No significant differences were found in the dose of ICS, morning PEF, PEF variability, dyspnoea, wheezing and coughing between the intervention and thecontrol group $(0.08<p<0.77)$. Furthermore, there was no statistically difference in asthma control between the intervention and the control group.

We concluded that the use of HDM impermeable covers combined with selfmanagement does not lead to less use of ICS compared to self-management alione. 
In Chapter 8 the general discussion is presented.

The main conclusions of this thesis are:

- The prevalence of house dust mite sensitisation in patients with asthma in primary care is almost $50 \%$, which is on the lower range. A minority of these patients is currently using house dust mite impermeable covers.

- A cotton upper layer of the mattress and lower relative humidity in the room is associated with lower levels of Der $p 1$ found on matresses.

- Low socio-economic status, current smoking, high dose of $1 \mathrm{CS}$, and perceived hyperresponsiveness for multiple triggers are independently associated with poorer asthma control. Stopping smoking and avoidance of thiggers are factors that probably have a high impact on asthma control.

- A self-management plan seems to be able to maintain or improve asthma control in patients with persistent asthma.

- High exposure to house dust mite allergen seems to coincide with the use of higher dose ICS in asthma patients sensitised to HDM allergen.

- House dust impermeable covers combined with seif-management do not lead to less use of ICS or improved asthma control compared to self-management alone.

We found a positive effect of self-management on asthma control especially in patients with severe persistent asthma. This group had the least well-controlled asthma at start, which leaves more room for improvement. Asthma was well controlled at start of the study. If we would have included less well-controlled patients more effects of self-management might have been observed.

HDM allergen avoidance does not seem to be an effective component of selfmanagement plans. Mattress encasings do not have an additional effect on reducing the dose of ICS or improving asthma control compared to selfmanagement alone.

On the basis of the findings of this thesis, we would not advocate the use of mattress encasings in all HDM sensitised asthma patients. Possibly, encasings. might be effective in a sub-group of asthma patients, e.g. younger patients or patients in an early stage of the disease. This should be further investigated.

The exposure to HDM allergen was very low in this study. Perhaps in other areas in the world with higher concentrations of HDM allergen, encasings would be of benefit.

The use of self-management plans should be advocated more actively in daily practice. They have shown to lead to better asthma control. However, which patients benefit most from self.management plans, and which components are effective should be subject of further research. 
Samenvatting 
In dit proefschrift worden verschillende aspecten van astma controle in de huisartspraktijk beschreven. De nadruk ligt echter op zelfmanagement en allergeenvermijding. De hoofdvraag die we in dit proefschrift willen beantwoorden is of huisstofmijt allergeen vermijding door middel van matrashoezen een effectief onderdeel is van een zelfimanagement plan.

In hoofdstuk 1 worden enkele algemene aspecten van astma en het doel van dit proefschrift besproken. Het doel van astma behandeling is het bereiken van astma controle voor alle ernst graden van de ziekte. Astma controle wordt gekenmerkt door minimalisering van astma symptomen zowel overdag als 's nachts, preventie van astma aanvallen, handhaven van een zo normaal mogelijk activiteiten niveau, een optimale longfunctie, het terugdringen van het gebruik van luchtwegverwijdende medicatie en het minimaliseren van bijwerkingen van medicijnen.

Met het verschijnen van de astma controle vragenlijst (Asthma Control Questionnaire $(A C Q)$ is er een gevalideerd instrument gekomen om astma controle te meten. De $A C Q$ integreert verschillende aspecten van astma controle in één meetinstrument. In Appendix B op pagina 133 staat een voorbeeld van de $A C Q$. De astma controle score varieert van $O$ (volledige controle) tot 6 (extreem slechte controle).

Inhalatie corticosteroïden, oftewel ontstekingsremmende pufjes, vormen de hoeksteen van de behandeling van astma, omdat deze medicijnen het onderliggende ontstekingsproces van de luchtwegen behandelen. Vanwege mogelijke bijwerkingen is het van belang om de dosering zo laag mogelijk te houden.

Zelfmanagement wordt omschreven als effectief gedrag wat de ziekte astma gebaseerd op voldoende kennis over astma en factoren die de ziekte uitlokken, adequaat coping gedrag, naleving van voorschriften voor het gebrulk van inhallatie medicatie, aandacht voor veranderingen in de ernst van de zlekte, een adequate inhalatietechniek van medicatie en het juist gebruiken van een piekstroommeter. Vooral geindividualiseerde, geschreven actieplannen gebaseerd op persoonlijk beste piekstroomwaarde, verscheidende actiepunten, en aanbevelingen ten aanzien van het gebruik van inhalatie corticosteroiden en orale corticosteroilden voor de behandeling van astma aanvallen leiden tot verbetering van astma gerellateerde uitkomstmaten.

Allergie voor huisstofmijt speelt een belangrijke rol bij astma. Reductie van blootstelling aan allergenen bij patiënten die allergisch zijn voor die allergenen, zou kunnen leiden tot vermindering van symptomen en klachten. Hoezen om matrassen, kussens en dekbedden zijn de meest werkzame manier om in huis de blootstelling aan huisstofmijt allergenen te verminderen. De resultaten van studies naar de effecten van huisstofmijt ondoorlaatbare hoezen op verschillende klinische uitkomstmaten, laten tegenstrijdigie resultaten zien. 
De hoofdvraag van dit proefschrift luidt: leidt de combinatie van allergeenvermijding en zelfmanagement tot verminderd gebruik van inhalatie corticosteroîden en betere astma controle in vergelijking met zelfmanagement alleen?

In hoofdstuk 2 zijn de resultaten weergegeven van een onderzoek naar de prevalentie van allergie voor huisstofmijt in een eerstelijns populatie. Verder is de mate van het gebruik van huisstofmijt ondoorlaatbare hoezen bepaald.

In de literatuur variëren cijfers over het voorkomen van huisstofmijt allergie van 45 tot $85 \%$. Verschillende nationale en internationale richtlijnen adviseren het gebruik van huisstofmijt ondoorlaatbare hoezen. In Nederland worden de kosten van hoezen vergoed door de ziektekostenverzekering bij een aangetoonde allergie voor huisstofmijt. Hierdoor zijn de omstandighedlen ideaal voor wijdverbreid gebruik van hoezen door allergische astmapatiënten. Het is echter onbekend in hoeverre astmapatiënten met een allergie voor huisstofmijt allergenen in Nederland deze hoezen momenteel gebruiken.

Uit een aantal huisartspraktijken werd een steekproef van astmapatiënten tussen de 16 en 60 jaar genomen. Met behulp van een RAST (radio-allergo-sorbent test, bloedtest) werd allergie vastgesteld. Met behulp van een vragenlijst werden demografische kenmerken en het gebruik van huisstofmijt ondoorlaatbare hoezen voor matras, kussen en dekbed bepaald. 534 patiënten werden uitgenodigd om deel te nemen aan het onderzoek, van wie er 160 daadwerkelijk wilden deelnemen. 53 patiënten uit de groep die niet wilden deelnemen werden willekeurig geselecteerd om de generaliseerbaarheid van de bevindingen te onderzoeken. De steekproef was representatief voor de eerstelijns astma populatie. Bijna de helft van de patiënten ( $48.8 \%)$ was allergisch voor huisstofmijt allergenen. Slechts een minderheid van de astmapatiënten met een allergie voor huisstofmijt (25.6\%) gebruikte ten tijde van het onderzoek huisstofmijt ondoorlaatbare hoezen.

De resultaten van een studie naar de invloed van matraskenmerken op de concentratie huisstofmijt allergenen in matrassen worden beschreven in hoofdstuk 3. Matrassen zijn een van de belangrijkste bronnen van huisstofmijt allergenen in de leefomgeving van patiënten. In bed zijn de micro-omgeving en de voedselvoorziening ideaal voor de groei van mijten. Verder brengen mensen gemiddeld 8 uur per etmaal door in bed, en zijn daar in nauw contact met deze allergenen.

Van de bovenzijde van de matrassen werden stofmonsters genomen om de hoeveelheid Der p 1 allergenen, belangrijke subgroep van de huisstofmijt allergenen, te bepalen. 168 deelmemers vulden een vragenlijst in over het matrastype, de soort buitenlaag van het matras, karakteristieken valn de woning en schoonmaakgewoontes. Ten tijde van het nemen van een stofmonster werden 
tevens de luchtwochtigheid en de temperatuur van de slaapkamer gemeten. Twee factoren bleken geassocieerd te zijn met lagere hoeveelheden Der p 1 op het matras, namelijk een katoenen buitenlaag van het matras in vergelijking met een synthetische buitenkant $(0,8$ versus $2,6 \mu \mathrm{g} / \mathrm{g}$ Der $p 1$ per gram stof, $p<0.05)$ en een lagere relatieve luchtvochtigheid ten tijde van de stofmonster afname. Het verband tussen het type buitenkant van de matras en de concentratie Der $p 1$ dient verder onderzocht te worden, maar zou kunnen leiden tot de formulering van praktische adviezen ter vermindering van hwisstofmijt allergeen concentraties op matrassen.

In hoofdstuk 4 worden de resultaten beschreven van een studie naar welke factoren geassocieerd zijn met astma controle. Voor een dwarsdoorsnede onderzoek werden patiënten van 16 tot 60 jaar met mild tot matig ernstig astma geselecteerd. De invloed van de volgende factoren werd onderzocht in een multivariaat model: leeftijd, geslacht, sociaal-economische status (SES), roken (onderverdeeld in huidig roken, vroeger gerookt of nooit gerookt), ervaren hyperresponsiviteit (d.w.z. het reageren met astma symptomen op een of meer van de volgende uitlokkende prikkels: weersveranderingen, vocht in huis, open haard, sterke geuren en inspanning), allergie (gemeten met een phadiatop ${ }^{\circledR}$, dit is een allergietest voor meerdere inhalatie allergenen), langwerkende luchtwegverwijders en inhalatie corticosteroiden (ontstekingsremmende pufjes). Astma controle werd gemeten met de astma controle vragenlijst (Asthma Control Questionnaire ${ }^{\ominus}, \mathrm{ACQ}$, Appendix B pagina 133).

In deze studie met 311 patiënten, was de gemiddelde astma controle score 1.39 (spreiding 0-4.43 op een schaal van 0 (volledige controle) tot 6 (extreem slechte controle). Uit een stapsgewijze regressie-analyse werd duidelijk dat een lage sociaaleconomische status, huidig roken, een hoge dosering inhalatie corticosteroilden en ervaren hyperresponsiviteit voor oplopend aantal prikkels onafhankelijke voorspellers waren voor een slechtere astma controle.

De bevindingen van dit onderzoek duiden erop dat de behandeling van astma niet alleen gestoeld zou moeten zijn op het voorschrijven van medicatie. Stoppen met roken en vermijden van uitlokkende prikkels zijn ook factoren die een belangrijke impact zouden kunnen hebben bij de behandeling van astma. Onze bevindingen ondersteunen de huidige opvatting dat een gecombineerde aanpak van de behandeling met zowel medicamenteuze en als niet-medicamenteuze elementen, zoals stoppen met roken en het vermijden van prikkels, nodig is om astma controle te optimaliseren.

In hoofdstuk 5 hebben we de mate van astma controle bij verschillende categorieèn ernst van astma onderzocht in een eerstelijns astma populatie. Verder hebben we gekeken naar welke patiënten het meest baat lijken te hebben bij het gebruik van een zelfmanagement plan. In dit onderzoek werd de graad van astma 
vastgesteld aan de hand van de dosering inhalatie corticosteroilden, het gebruik van langwerkende luchtwegverwijders en de FEV (forced expiratory volume in one second, de hoeveetheid lucht die maximaal in éen seconde uitgeblazen kan worden na maximale inademing). Patiënten werden ingedeeld in de categorieën mild persisterend, matig persisterend en ernstig persisterend, overeenkomstig internationale richtlijnen.

Astma controle werd gemeten met de 5 items astma controle vragenlijst (Asthma Control Questionnaire, ACQ, Appendix B pagina 133). Patiënten kregen instructies ten aanzien van het gebruik van het zelfmanagement plan om de dosering inhalatie corticosteroïden aan te passen op basis van klachten en de piekstroomwaarde. In Appendix A op pagina 129 staat een Engelstalige samenvatting van het zelfmanagement plan.

Er werden 76 patiênten geïncludeerd. Bij aanvang van het onderzoek was de astma controle goed in alle ernstcategorieën. De gemiddelde astma controle score was, op een schaal van 0 (volledige controle) tot 6 (extreem slechte controle), in de mild persisterende groep 0.54, in de matig persisterende groep 0.96 en in de ernstig persisterende groep 1.61. De variantie-analyse (test verschil tussen de groepen) liet een statistisch significant verschil tussen de groepen zien, $p=0.001$. Nadat de patiënten een jaar lang de zelfmanagement uitgevoerd hadden, werd de mate van astma controle gehandhaafd in de mild persisterende groep (0.58) en nam de astma controle toe in de matige persisterende $(0.71)$ en de ernstig persisterende groep (1.27).

Op basis van deze resultaten kunnen we concluderen dat het mogelijk lijkt om met een zelfmanagement plan astma controle te handhaven of te verbeteren bij patiënten met persisterend astma, vooral in de groep met ernstig persisterend astma.

In hoofdstuk 6 worden de resultaten van een abservationeel onderzoek gepresenteerd. In dit onderzoek hebben we gekeken of blootstelling aan hoge concentraties huisstofmijt allergenen het afbouwen van inhalatie corticosteroïden belemmert. Huisstofmijt allergische astmapatiënten die inhalatie corticosteroïden gebruikten werden geselecteerd in een aantal huisartspraktijken. Van het matras werd een stofmonster genomen om de blootstelling aan huisstofmijt allergenen te bepalen. Met een semi-kwantitatieve test (Acarex ${ }^{(5)}$ ) werd de blootstelling vastgesteld en ingedeeld in de volgende categorieën: geen, laag, middel en hoog. Patiënten werd geleerd een zelfmanagement plan te gebruiken om de dosering inhalatie corticosteroïden aan te passen op basis van klachten en piekstroom waarden. In Appendix A op pagina 129 staat een Engelstalige samenvatting van het zelfmanagement plan. De observatie periode was drie maanden.

De gegevens van 123 patiënten werden geanalyseerd. In de groep met geen en een lage blootstelling aan huisstofmijt allergenen was het aantal patiënten dat de dosering inhalatie corticosteroïden moest ophogen in verhouding significant lager 
dan het aantal patienten dat de dosering kon afbouwen of op dezelfde dosering bleef. De groep met een hoge expositie aan huisstofmijt allergenen had in verhouding het grootste aantal patiënten dat de dosering inhalatie corticosteroïden moest ophogen.

Op basis van de gegevens van dit onderzoek kunnen we concluderen dat expositie aan een hoge concentratie huisstofmijt allergenen lijkt samen te gaan met het gebruik van hogere doseringen inhalatie corticosteroïden bij huisstofmijt allergische astmapatiënten.

De werkzaamheid van huisstofmijt ondoorlaatbare hoezen staat ter discussie. Het doel van het onderzoek dat gepresenteerd wordt in hoofdstuk 7, was om te onderzoeken of de combinatie van huisstofmijt ondoorlaatbare hoezen en een zelfmanagement plan leidde tot minder inhalatie corticosteroïd gebruik dan zelfmanagement alleen. Astmapatiënten tussen de 16 en 60 jaar oud, allergisch voor huisstofmijt allergenen en die volgens de NHG-standaard in aanmerking komen voor gebruik van inhalatie corticosteroiden, werden ingesloten in het onderzoek. Ze ontvingen instructies ten aanzien van het gebruik van een zelfmanagement plan gebaseerd op plekstroom en klachten. In Appendix A op pagina 129 is een samenvatting van het zelfmanagement plan in het Engels weergegeven. Na een oefenperiode van drie maanden begon de interventieperiode met huisstofmijt ondoorlaatbare en placebo hoezen. De follow-up periode was twee jaar.

De primaire uitkomstmaat was het gebruik van inhalatie corticosteroiden, secundaire uitkomstmaten waren astma controle, piekstroom parameters en symptomen.

126 patiënten begonnen aan de interventieperiode met hoezen. Na een en twee jaar follow-up werden sigmificante verschillen in allergeen expositie aangetoond tussen de interventie en de controle groep $(p<0.001)$. Allergeen concentraties waren bij aanvang van het onderzoek al erg laag. Mogelijk was dit een gevolg van saneringsmaatregelen die mensen reeds in huis genomen hadden, b.v. gladde vloeren en lamellen i.p.v. vloerbedekking en gordijnen. Het contrast tussen de interventie en de controle groep was daardoor erg klein.

Er konden geen significante verschillen aangetoond worden in de dosis inhalatie corticosteroïden, astma controle, ochtend piekstroom, piekstroomvariabiliteit., benauwdheid, piepende ademhaling en hoesten.

op basis van deze gegevens hebben we de conclusie getrokken dat huisstofmijt ondoorlaatbare hoezen in combinatie met zelfmanagement niet leiden tot minder gebruik van inhalatie corticosteroiden dan wanneer alleen zelfmanagement wordt toegepast.

Hoofdstuk 8 bevat de algemene discussie. 
De belangrijkste conclusies van dit proefschrift zijn:

- De prevalentie van allergie voor huisstofmijt bij patienten met astma in een eerstelijns populatie is ongeveer $50 \%$, dit is aan de lage kant. Een minderheid van deze patienten giebruikt momenteel huisstofmijt ondoorllaatbare hoezen.

- Een katoenen buitenlaag van het matras en een lage luchtvochtigheid in de Kamer zijn factoren die geassocieerd zijn met lagere hoeveelheden Der $p 1$ (huisstofmijtallergeen) op matrassen.

- Een laag sociaal economische status, huidig roken, een hoge dosering. inhalatie corticosteroïden en ervaren hyperresponsiviteit op meerdere prikkels zijn onafhankelijk geassocieerd met een slechtere astma controle. Stoppen met roken en vermijding van prikkels zijn factoren die een belangrijke invloed kunnen hebben op astma controle.

- Met behulp van een zelfmanagement plan kan bij patiēnten met persisterend astma, astma controle gehandhaafd blijven of zelfs verbeterd worden.

- Een hoge expositie aan lhuisstofmijt allergenen lijkt samen te gaan met gebruik van hogere doseringen inhalatie corticosteroïden bij astmapatiënten die allergisch zijn voor huisstofmijt allergeen.

- Zelfmanagement gecombineerd met huisstofmijt ondoorlaatbare hoezen leidt niet tot verminderd gebruik van inhalatie corticosteroïden of verbeterde astma controle in vergelijking met alleen zelfmanagement.

In dit proefschrift hebben we een positief effect van zelfmanagement op astma controle gevonden, vooral bij patiënten met ermstig persisterend astma. Deze groep had bij aanvang de minst goed gecontroleerde astma, zodat er meer ruimte voor verbetering aanwezig was.

Astma controlle was goed bij aanvang van het onderzoek. Indien er patienten met slechtere astma controle in het onderzoek ingesloten waren, hadden we misschien meer effect van zelfmanagement kunnen aantonen.

Huisstofmilt allergeenvermijding lijkt geen effectief onderdeel van een zelfmanagement plan te zijn. Matrashoezen hebben geen additioneel effect op reductie van de dosering inhalatie corticosteroïden in vergelijking met zelfmanagement alleen.

op basis van de resultaten van dit proefschrift, zouden wij het gebruik van matrashoezen niet aanbevelen voor alle astmapatiënten die allergisch zijn voor hulisstofmijt allergeen. Het zou echter kunnen zijn dat de hoezen wel effectief zijn in een subgroep van astmapatiënten, b.v. jongere patiënten of in een vroeger stadium van de ziekte. Dit zou verder onderzocht moeten worden.

De blootstelling aan hulisstofmijt allergenen was erg laag in dit onderzoek. Misschien dat in andere gebieden met hogere concentraties huisstofmijt allergenen, matrashoezen wel effectief zijn.

Zelfmanagement plannen zouden vaker gebruikt moeten worden in de dagelijkse praktijk bij de behandeling van astma patiënten. Ze leiden tot betere astma 
controle. Er zou verder onderzoek gedaan moeten worden naar welke patiënten het meeste baat hebben bij zelfmanagement en welke onderdelen van een zelfmanagement plan effectief zijn en welke niet. 
Appendix A 


\section{Appendix A}

\section{Summary of the self-management plan}

\section{Step-up instructions}

- Peak flow deteriorates $80 \%>$ PEFR $\geq 60 \%$ of Personal Best Value (PBV) for 2 out of 3 consecutive days:

Double budesonide dosage

In case of insufficient response within three weeks: again double budesonide dosage

- Peak flow deteriorates $60 \%>P E F R \geq 40 \%$ of PBV for 2 out of 3 consecutive days:

Increase budesonide dosage to 800 micrograms b.i.d.

In case of insufficient response within two days: contact your GP

- Peak flow deteriorates $\angle 40 \%$ of PBV:

Immediately contact your GP to start a course of oral prednisolone

\section{Step-down instructions}

- Peak flow improves to $40 \% \leq P E F R<60 \%$ of PBV:

Continue the current budesonide dosage until your PEFR is $>80 \%$ of PBV

- Peak flow improves to $260 \leq$ PEF $<80 \%$ PBV:

Continue the current budesonide dosage untill your PEFR is $>80 \%$ of PBV

- Peak flow improves to $\geq 80 \%$ of PBV:

Halve budesonide dosage when PEFR $\geq 80 \%$ for a period of six weeks 
Appendix B 


\section{Appendix B}

\section{ASTHMA CONTROL QUESTIONNAIREO}

Please answer questions 1-6.

Circle the number of the response that best describes how you have been during the past week

1. On average, during the past week, how often were you woken by your asthma during the night?
o Never
1 Hardly ever
2 A few minutes
3 Several times
4 Many times
5 A great many times
6 Unable to sleep because of asthma

2. On average, during the past week, how bad were your asthma symptoms when you woke up in the morning?

o No symptoms

1 Very mild symptoms

2 Milld symptoms

3 Moderate symptoms

4 Quite severe symptoms

5 Severe symptoms

6 Very severe symptoms

3. In general, during the past week , how limited were you in your activities because of your asthma?

O Not limited at all

1 Very slightly limited

2 Slightly limited

3 Moderately limited

4 Very limited

5 Extremely limited

6 Totally limited 
4. In general, during the past week, how much shortness of breath did you experience because of you asthma?

o None

1 A very ittlle

2 A little

3 A moderate amount

4 Quite a lot

5 A great deal

6 A very great deal

5. In general, during the past week, how much of the time did you wheeze?

o Not at all

1 Hardly any of the time

2 A little of the time

3 A moderate amount of the time

4 A lot of the time

5 Mast of the time

6 All the time

6. On average, during the past week, how many puffs of short-acting bronchodilator (e.g. Ventolin) have you used each day?

o None

1. 1-2 puffs most days

$23-4$ puffs most days

3. 5-8 puffs most days

4 - $9-12$ puffs most days

$513-16$ puffs most days

6 More than 16 puffs most days

To be completed by a member of the clinic staff

7. FEV 1 pre-bronchodilator: $0>95 \%$ predicted $195-90 \%$

FEV 1 predicted $289-80 \%$ $379-70 \%$

FEV $1 \%$ predicted 469-60\%

(Record actual values on the dotted lines $559-50 \%$ and score the $\mathrm{FEV}_{1} \%$ predicted in the next $6<50 \%$ predicted column) 
Publications 


\section{Publications}

de Vries MP, van Schayck CP. Bestaat er een verband tussen het optreden van luchtweginfecties op jonge leeftijd en het ontstaan van atopie? Longartsenvademecum, nummer 2-februari 2000

van den Bemt $L$, van Knapen $L$, de Vries MP, Jansen M, Cloosterman S, van Schayck CP. Clinical effectiveness of a mite-allergen impermeable bed covering system in asthmatic mite-sensitive patients. I Allergy Clin Immun, 2004, 114 (4): $858-62$

de Vries MP, van den Bemt $L$, van der Mooren FM, Muris JWM, van Schayck CP. The prevalence of house dust mite allergy and the use of HDM impermeable covers in a primary care population of patients with persistent asthma in the Netherlands. Prim Care Respir $\rfloor, 2005,14(4): 210-4$

de Vries MP, van den Bemt L, Lince S, Muris JWM, Thoonen BPA, van Schayck CP. Factors associated with asthma control. J Asthma, 2005;42:659-65

de Vries MP, van den Bemt L, Thoonen BPA, Muris JWM, van Schayck CP. Could high exposure to house dust mite allergen be an abstacle for tapering off inhaled corticosteroids in a self-management plan? Prim Care Respir $J$, in press

van den Bemt $L$, de Vries MP, van Knapen $L$, Jansen $M$, Goossens $M$, Muris JWM, van Schayck CP. Influence of mattress characteristics on house dust mite allergen concentration. Clin Exp Allergy, in press.

Manuscripts submitted for publication:

de Vries MP, Thoonen BPA, Muris JWM, van den Bemt $L$, van Schayck CP. Asthma control in patients with different severity of persistent asthma in primary care and the effect of a self-management plan on asthma control - an abservational study.

de Vries MP, van den Bemt $L$, Aretz $K$, Thoonen BPA, Muris JWM, Kester ADM, Cloosterman $S$, van Schayck $C P$. Does house dust mite allergen avoidance allow tapering off inhaled corticosteroids in allergic asthma patients using a selfmanagement plan? 
Dankwoord 


\section{Dankwoord}

Nu na ruim 7 jaar hard werken het proefschrift zo goed als klaar is, is het tij om iedereen te bedanken die op welke wijze dan ook een bijdrage heeft geleverd aan de totstandkoming ervan. Een aantal mensen will ik zeker met name noemen.

De onderzoeken beschreven in dit proefschrift zijn uitgevoerd in het kader van het ticara-onderzoek bij de Capaciteitsgroep Huisartsgeneeskunde aan de Universiteit Maastricht.

Onno van Schayck, jij bent degene geweest die samen met GeertJan Dinant me heeft "binnengehaald" bij huisartsgeneeskunde. Als promotor en projectleider ben je vanaf het begin bij het onderzoek betrokken geweest. De eerste jaren was je vaak wat meer op afstand, gezien je drukke agenda. Maar zeker in de laatste jaren was er altijd tijd voor overleg. Bedankt hiervoor.

Sonja Cloosterman, als bedenker van de vraagstelling was je als eerste begeleider bij het project betrokken. Bedankt voor je begeleiding tijdens mijn eerste schreden op het pad der promovendi. Als ervaringsdeskundige heb je me veel kunnen leren en waarschuwen voor vele valkuilen. Na jouw vertrek werd de begeleiding over genomen door Bart Thoonen en Jean Muris. Beste Bart en Jean, als co-promotoren hebben jullie een belangrijke ondersteunende rol gespeeld in dit onderzoek. Bart, doordat je wat meer op afstand zat bestonden onze contacten, zeker de laatste jaren, vooral uit telefonisch overleg. Menig woensdagochtend heeft in het teken gestaan van pittige inhoudelijke discussies, waarna ik de lijn van diverse artikelen weer een stuk duidelijker zag. Jean, bij jou was altijd tijd voor zowel inhoudelijk overleg, als voor spuien over de diverse problemen die er binnen en rond het onderzoek waren. Als ik het weer eens helemaal niet zag zitten, wist jij me altijd wel weer met een optimistisch gevoel te laten vertrekken na het overleg.

Lange tijd heb ik het project samen met Lisette van den Bemt gedaan. Lisette, we hebben altijd prettig samengewerkt en vele stormen binnen het project doorstaan. Jammer dat we, met de haven min of meer in zicht, het laatste stukje onderzoek niet meer samen hebben kunnen doen.

Daarnaast is er door de jaren heen op het project ondersteuning geweest door diverse onderzoeksassistenten en huisbezoeksters: Margreet Jansen, Willy Dubois, Manon Langhoor, Mayke Jilderda, Marion Gijbels en Anuska Weekers, bedankt allemaal voor juflie inzet voor het project op welke manier en in welke fase dan ook.

Van Willy hebben we helaas te vroeg afscheid moeten nemen, in de periode dat ze voor Ticara werkte, zou ze op vakantie gaan, om helaas niet meer terug te keren.

Een speciaal woord van dank gaat ook uit naar Karin Aretz. Karin, je hebt me geweldig geholpen met het opschonen en de analyses van de dagboekgegevens. 
Zonder jou was ik nu waarschijnlijk nog niet klaar geweest om de berg data te verwerken tot hapklare analysebrokken.

In de loop van het project hebben ook een aantal wetenschapsstudenten "rondgelopen' bij ticara en allemaal hun eigen deelproject gedaan. Een aantal van deze onderzoeken heeft ook geleid tot publicaties en zijn terug te vinden in dit proefschrift. Bedankt voor jullie enthousiasme en de leuke samenwerking: Sabrina Lince, Froukelien van der Mooren, Lieke van Knapen, Simone Terhaag, Koen Smolders, Laurelte Klinkers en Wouter Krikke.

Om te voorkomen dat ik vooral hier namen vergeet, wil ik alle medewerkers en oudmedewerkers van de Capaciteitsgroep huisartsgeneeskunde bedanken voor de prettige tijd en samenwerking door de jaren heen.

Dit proefschrift was er natuurlijk nooit gekomen zonder de inzet van de deelnemers en huisartsen. Langs deze weg will ik nogmaals alle deelnemers bedanken voor hun tijd en inzet tijdens de ruim twee jaar dat ze deelgenomen hebben aan het onderzoek. Bedankt voor het invullen van de dagboekjes, de jaarlijkse bezoeken aan de longfunctie afdeling en natuurlijk ook voor het feit dat onze huisbezoeksters steeds bij u langs mochten komen om 0.a. uw matrassen te stofzuigen. Huisartsen en assistentes bedankt voor het selecteren van mogelijke deelnemers voor het onderzoek. Een extra woord van dank gaat uit naar de huisartsen Otten, van de Ven, van Dijk, Sikkes, Wouters en Wijnhoven, die naast het selecteren van mogelijk geschikte patiënten, zelf ook de instructie en follow-up van het zelfmanagement plan hebben gedaan.

Medewerkers van de longfunctie afdeling in het Academisch ziekenhuis Maastricht en van het Diagnostisch Centrum Eindhoven bedankt voor de uitvoer van alle longfunctiemetingen en histamine provocatie testen. Ellen Arntz en Aimee Couteau van Stratumse apotheek te Eindhoven, dank ik voor de accurate levering van de onderzoeksmedicijnen. Wiet Koren, bedankt voor de analyses van alle stofmonsters. Jet Winkel van Cara C'air wil ik bedanken voor de levering van de actieve en placebo hoezen, en de flexibiliteit wanneer er weer eens iets mis ging met een bestelling.

Voor vragen en problemen op statistisch vlak kon ik altijd een beroep doen op Arnold Kester, bedankt voor je heldere uitleg.

De medewerkers van de data-entry afdeling van het MEMIC, bedankt voor de invoer van de vragenlijsten en de dagboekjes.

Tiny Wouters, heel erg bedankt voor je hulp bij de lay-out en het 'drukklaar' maken van dit proefschrift.

Naast het uitvoeren van het onderzoek en me bekwamen in verschillende facetten van de wetenschap, heb ik de afgelopen jaren ook het vak van huisarts geleerd. 
Yvonne van Leeuwen, Paul Ram en Geertan Dinant, bedankt voor jullie inzet en onvoorwaardelijke steun om het aiotho-traject mee te laten slagen.

Willem Nieuwdorp en Jan Nijhof, mijn opleiders in respectievelijk miln eerste en derde jaar van de huisartsopleiding, bedankt voor de prettige en leerzame tijd die ik bij Jullie in de praktijk gehad heb. Daarnaast wil ik ook de begeleiders van de drie haio-groepen, waarvan ik deel heb uitgemaakt, bedanken: Carla Stuurmans, Gerard van Mierlo, Gerrie Wagenaar, Maria Mulder, Bert ten Berge en Jos Sleijpen. Mijn 'partners in crime', mijn mede alotho's (artsen in opleiding tot huisartsonderzoeker), Loes van Bokhoven, Katinka Prince. Niels Chavannes, Patrick van Limpt, Roelf Norg, Rogiler Hopstaken, Annemiek Nijholt, Paul Houben en Wemke Veldhuijzen, het was niet altijd gemakkelijk om dit combinatle traject te volgen, maar aangezien gedeelde smart halve smart is en we gelukkig ook veel plezier en steun met en aan elkaar gehad hebben, ben ik de jaren goed doorgekomen.

Nu de huisartsdiners bijna allemaal achter de rug zijn, wordt het de hoogste tijd voor een ronde promotiefeestjes.

Naast werken was er gelukkig ook tijd voor ontspanning.

De overgang van werk naar ontspanning is snel gemaakt door te beginnen met de wine \& dine club, Niels en Paddy, bedankt voor al die avonden waarbij onder genot van lekker eten en wijn de grotere en minder grote problemen des levens werden besproken.

Vooral in de beginjaren van mijn onderzoek vervulden de vrijdagborrels bij Thembi een belangrijke rol. Hoewel ik de laatste jaren een minder trouwe bezoekster ben geweest, ben ik de borrels wel altijd bllijen waarderen. Het was een goede afsluiting van de werkweek en een prima begin van het weekend. Marjan, Tanja, ljmert, Marcus, Mark, 'frituurkoning van Randwyck' en alle anderen, bedankt.

ledere woensdag at ik samen met Pien, bedankt dat ik op onze 'goonsdag' en andere dagen altijd bij je terecht kon om mijn belevenissen en frustraties te spuien, daarna kon ik er weer prima tegen. Ook de nodige potjes Catan (natuurlijk met Steden en Riddersl) met jou en Patrick zorgden voor de onmisbare ontspanring. Ik moet jullie zeker nog een keer verslaan voordat ik naar jullie droomland vertrek, misschien kunnen we het daar ook nog eens spelen?!

Sabine en Loes, mijn paranimfen. Ik ben trots en dankbaar jullie als paranimfen en ook vriendinnen, te hebben. Sabine, al ruim 20 jaar zijn we vriendinnen, sinds de eerste dag op de middelbare school, toen we door onze mentor "Otter frotter etter" naast elkaar werden gezet. Dat die beslissing de rust in de klas niet echt ten goede kwam, wist hij toen nog niet. Bedankt voor je vriendschap en steun door de jaren heen. Loes, jou ken ik eigenlijk pas sinds we beiden aan ons aiotho traject begonnen in '98, maar in de afgelopen jaren heb jij je een zeer waardevolle collega en goede vriendin getoond. Jij ook heel erg bedankt voor je collegialiteit en vriendschap. 
Als laatste wil ik mijn familie bedanken.

Allereerst tante Nel, bedankt voor het ontwerp van de omslag van dit proefschrift. Ik vind het heel bijzonder om een "echte de Vries" op de voorkant te hebben.

Eelco en Jolanda (ja, Jolanda, je valt inmiddels toch wel in de categorie familiel), bedarikt voor jullie medeleven en interesse de afgelopen jaren. Ik hoop dat inmiddels duidelijk is wat ik de afgelopen jaren heb uitgespookt. En Eel, je kunt nu eindelijk vertellen dat je zus klaar is met haar boekje!

Mama, dank je wel dat papa en iij mij onvoorwaardelijk gesteund hebben in mijn keuzes. Jullie hebben de basis gelegd voor mijn ontwikkeling. Jammer dat papa dit moment niet meer mag beleven, wat zou hij trots geweest zijn. 
About the author 


\section{About the author}

Marjolein de Vries was born on March 18, 1972 in Eindhoven, the Netherlands. She grew up in Waalre. She completed secondary education at the Sint Joris College in Eindhoven in 1990. She studied medicine at Maastricht University. In 1998 she graduated from Medical School.

From 1998 to 2005 she participated in a combined vocational training and research programme at the Department of General Practice at Maastricht University. In this period the studies presented in this thesis were conducted. In December 2003 she finished vocational training. Since 2004 she has been working as a general practitioner in several practices.

In March 2006 she will be leaving for Queensland, Australia to work there as a general practitioner. 